CARLA ALMEDA CORREIA

OBTENÇÃO E CARACTERIZAÇÃO DE PLA REFORÇADO COM NANOCELULOSE

São Paulo 
CARLA ALMEDA CORREIA

\section{OBTENÇÃO E CARACTERIZAÇÃO DE PLA REFORÇADO COM NANOCELULOSE}

Dissertação apresentada à Escola

Politécnica da Universidade de São Paulo para a obtenção de título de mestre em engenharia.

São Paulo 
CARLA ALMEDA CORREIA

\section{OBTENÇÃO E CARACTERIZAÇÃO DE PLA REFORÇADO COM NANOCELULOSE}

Dissertação apresentada à Escola Politécnica da Universidade de São Paulo para a obtenção de título de mestre em engenharia.

Área de Concentração:

Engenharia Metalúrgica e de Materiais

Orientadora: Prof. a Dr. ${ }^{\text {a }}$ Ticiane Sanches Valera

\section{São Paulo}


Este exemplar foi revisado e corrigido em relação à versão original, sob responsabilidade única do autor e com a anuência de seu orientador.

São Paulo, de de

Assinatura do autor:

Assinatura do orientador:

Catalogação-na-publicação

Correia, Carla Almeda

OBTENÇÃO E CARACTERIZAÇÃO DE PLA REFORÇADO COM

NANOCELULOSE / C. A. Correia -- versão corr. -- São Paulo, 2015. $116 \mathrm{p}$.

Dissertação (Mestrado) - Escola Politécnica da Universidade de São Paulo. Departamento de Engenharia Metalúrgica e de Materiais.

1.Celulose 2.Nanopartículas 3.Biopolímeros (PLA) 4.Nanocompósitos 5.Reologia I.Universidade de São Paulo. Escola Politécnica. Departamento de Engenharia Metalúrgica e de Materiais II.t. 
Dedico este trabalho aos meus pais Lucia e Antônio, ao meu irmão Augusto e ao Bruno, por todo apoio, compreensão e, sobretudo, pelo amor de todos. 


\section{AGRADECIMENTOS}

Aos meus pais, simplesmente por tudo! Pelo amor incondicional, carinho, dedicação e por terem me apoiado em todas minhas decisões. Ao meu irmão Augusto e meu namorado Bruno pelo companheirismo, toda compreensão e força nos momentos difíceis. Sem vocês nada disso faria sentido! Amo muito vocês!

À Prof. ${ }^{a}$ Dra. Ticiane Sanches Valera pela orientação, atenção e apoio ao longo de todo este trabalho. Obrigada por ter me acolhido, por me apresentar este tema com o qual adorei trabalhar e, acima de tudo, obrigada pelo exemplo e pelos conhecimentos compartilhados!

Ao meu coorientador Prof. Dr. Marcio Yee, Universidade Federal de São Paulo (UNIFESP), pela disponibilidade, mesmo trabalhando em outra cidade! Obrigada por ter me apresentado à Prof. a Ticiane, pela paciência, compreensão e o enorme suporte que me proporcionou! Sem você tudo seria muito mais difícil!!

Aos meus queridos amigos e colegas do Laboratório de Polímeros! Obrigada a todos por me ajudarem a fazer tudo isso dar certo! Obrigada a Fernanda, Nati e Kleber pelas conversas, pelas risadas, pelos chocolates (Kleber, nem um caminhão da Lacta poderia pagar por eles...), enfim, obrigada pela amizade única!! Às alunas mais novas Anita e Suellen. Su, obrigada por toda a ajuda no trabalho, espero que continuemos firmes e fortes para prosseguir com os trabalhos futuros! Obrigada Camila pela enorme ajuda em tudo que parecia que não ia dar certo, sua experiência no Laboratório é única e fez (e ainda faz) a diferença, muito Obrigada Ca!! Ao Douglas por todas as análises de FTIR! Ao Eder pelo coleguismo, especialmente no início deste trabalho. Obrigada a todos, sem exceções, por fazerem meus dias muito melhores, vocês são demais!!

À todos os amigos que ficaram distantes devido à falta de tempo! Às amigas Cris e Camilla da FATEC-SP e ao Luan, minhas sinceras desculpas e meu agradecimento por toda compreensão. 
Ao Prof. Dr. Aparecido Júnior de Menezes, Universidade Federal de São Carlos (Campus Sorocaba), por toda ajuda prestada!

Ao técnico Danilo, Departamento de Engenharia de Materiais, pela dedicação e apoio em todos os momentos!

Ao técnico Veríssimo pelas imagens de MEV e por todas as tentativas anteriores, obrigada pela paciência!

Aos funcionários do Departamento de Engenharia Metalúrgica e de Materiais: Cristina, Vera, Ivo, Lívio, Patrícia, Rubens, Suellen, Rafael e Gilberto pela disposição, dedicação e apoio.

À Prof. a Dra. Vera R. Leopoldo Constantino, Instituto de Química da USP, obrigada pela utilização da centrífuga e liofilizador. Em especial, ao técnico Armando, por toda disponibilidade, compreensão e ajuda!

Ao técnico Adão, Faculdade de Medicina da USP, pelas imagens de MET.

À Capes pelo suporte financeiro. 
O fracasso é a oportunidade para começar de novo com mais inteligência, e redobrada vontade. (Henry Ford) 


\section{RESUMO}

A celulose é o polímero natural renovável disponível em maior abundância atualmente. Por possuir estrutura semicristalina, é possível extrair seus domínios cristalinos através de procedimentos que ataquem sua fase amorfa, como a hidrólise ácida, obtendo-se assim partículas cristalinas chamadas nanopartículas de celulose (NCs). Estas nanopartículas têm atraído enorme interesse científico, uma vez que possuem propriedades mecânicas, como módulo de elasticidade e resistência à tração, semelhantes a várias cargas inorgânicas utilizadas na fabricação de compósitos. Além disso, possuem dimensões nanométricas, o que contribui para menor adição de carga à matriz polimérica, já que possuem maior área de superfície, quando comparadas às cargas micrométricas. Nanocompósitos formados pela adição destas cargas em matrizes poliméricas podem apresentar propriedades comerciais atraentes, como barreira a gases, melhores propriedades térmicas e baixa densidade, quando comparados aos compósitos tradicionais. Como se trata de uma carga com dimensões nanométricas, obtida de fontes renováveis, uma das principais áreas de interesse para aplicação deste reforço é em biopolímeros biodegradáveis. O poli(ácido lático) (PLA), é um exemplo de biopolímero com propriedades mecânicas, térmicas e de processamento superiores a de outros biopolímeros comerciais. No presente trabalho foram obtidas nanopartículas de celulose (NCs), por meio de hidrólise ácida, utilizando-se três métodos distintos, com o objetivo de estudar o método mais eficiente para a obtenção de NCs adequadas à aplicação em compósitos de PLA. Os Métodos I e II empregam extração das NCs por meio do $\mathrm{H}_{2} \mathrm{SO}_{4}$, diferenciando-se apenas pela neutralização, a qual envolve diálise ou neutralização com $\mathrm{NaHCO}_{3}$, respectivamente. No Método III a extração das NCs foi realizada com $\mathrm{H}_{3} \mathrm{PO}_{4}$. As $\mathrm{NCs}$ foram caracterizadas por diferentes técnicas, como difração de raios $X(\mathrm{DRX})$, análise termogravimétrica (TG), espectroscopia vibracional de absorção no infravermelho (FTIR), microscopia eletrônica de transmissão (MET) e microscopia de força atômica (MFA). Os resultados de caracterização das NCs indicaram que, a partir de todos os métodos utilizados, há formação de nanocristais de celulose (NCCs), entretanto, apenas os NCCs obtidos pelos Métodos II e III apresentaram estabilidade térmica suficiente para serem empregados em compósitos preparados por adição da carga no polímero em estado fundido. A incorporação das NCs em matriz de PLA foi realizada em câmara de mistura, com posterior moldagem por prensagem a quente. Compósitos obtidos por adição de NCs obtidas pelo Método II foram caracterizados por calorimetria exploratória diferencial (DSC), análise termogravimétrica, microscopia óptica, análises reológicas e microscopia eletrônica de varredura (MEV). A adição de NCs, extraídas pelo Método II, em matriz de PLA afetou o processo de cristalização do polímero, o qual apresentou maior grau de cristalinidade. Além disso, a adição de $3 \%$ em massa de NCs no PLA foi suficiente para alterar seu comportamento reológico. Os resultados reológicos indicaram que a morfologia do compósito é, predominantemente, composta por uma dispersão homogênea e fina da carga na fase matriz. Micrografias obtidas por MEV corroboram os resultados reológicos, mostrando, predominantemente a presença de partículas de NC em escala nanométrica. Compósitos de PLA com NCs obtidas pelo Método III apresentaram aglomerados de partículas de NC em escala micro e milimétrica, ao longo da fase matriz, e não foram extensivamente caracterizados.

Palavras- chave: celulose, nanopartículas, biopolímeros, nanocompósitos, reologia. 


\begin{abstract}
Cellulose is the renewable natural polymer currently available in greatest abundance. Cellulose is a semicrystalline polymer, and it is possible to extract its crystalline domains through a procedure that destroys its amorphous phase, such as acid etching, so obtaining crystalline cellulose particles called cellulose nanoparticles (NC). These nanoparticles have attracted great scientific interest because they have mechanical properties similar to those of many inorganic types of filler used in polymer matrix composites, like elastic modulus and tensile strength. Moreover, they have nanometric dimensions, which contribute to lower filler contents in the polymer matrix, due to its increased surface area when compared to the one of micrometric fillers. Nanocomposites formed by adding these fillers into polymeric matrices can present attractive commercial properties such as gas barrier, improved thermal properties, and low density, when compared to traditional composites. As NC are nanometric scale fillers, obtained from renewable sources, there is a great interest in their application into biodegradable biopolymer matrixes. Poly (lactic acid), PLA, is an example of biopolymer that presents improved thermal, mechanical and processing properties, when compared to the ones of other commercial biopolymers. In this work, cellulose nanoparticles (NC) were obtained, via acid hydrolysis, using three different methods, in order to study the most efficient method to obtain NC suitable to be used in polymer matrix composites. NC obtention methods I and II employ extraction by $\mathrm{H}_{2} \mathrm{SO}_{4}$. Methods I and II differ only in the neutralization step, which involves dialysis, for Method I, and neutralization with $\mathrm{NaHCO}_{3}$, for Method II. In Method III, the extraction of the NC's was performed using $\mathrm{H}_{3} \mathrm{PO}_{4}$. The $\mathrm{NC}$ were characterized by different techniques such as X-ray diffraction (XRD), thermogravimetric analysis (TG), infrared absorption spectroscopy (FTIR), transmission electron microscopy (TEM) and atomic force microscopy (AFM). The characterization results indicated that all methods yielded cellulose nanocrystals. However, only NC obtained by methods II and III showed sufficient thermal stability to be used in composites prepared by melt mixing. The NC/PLA composites were prepared in a mixing chamber, followed by hot press molding. The composites with addition of NC obtained by Method II were characterized by differential scanning calorimetry (DSC), TG, optical microscopy, rheological analysis and scanning electron microscopy (SEM). The cellulose nanoparticles extracted by Method II affected the crystallization process of the PLA. The composite presented a higher degree of crystallinity than the pure matrix. Furthermore, the addition of $3 \mathrm{wt} \%$ of the NC in PLA was enough to change its rheological behavior. The rheological results indicated that the morphology is predominantly composed by a fine and homogeneous dispersion of the filler in the matrix. The SEM micrographs corroborate the rheological data, showing, predominantly, NC particles in nanometric scale. Composites with NC obtained by Method III presented micro and milimetric scale clusters of NC particles in the matrix phase and were not extensively characterized.
\end{abstract}

Keywords: Cellulose, nanoparticles, biopolymers, nanocomposites, rheology. 


\section{LISTA DE FIGURAS}

Figura 1 - Unidade de repetição da molécula de celulose.

Figura 2- Esquemas de (a) microfibrilas de celulose mostrando uma das configurações sugeridas das regiões cristalinas e vítreas e (b) nanocristais de celulose extraídas após destruição das regiões desordenadas.

Figura 3- Estruturas cristalinas da celulose Iß e II: a) projeção da célula unitária (CU) ao longo do plano a-b; b) projeção da CU paralela ao plano (100) (celulose I) e ao plano (010) (celulose II)

Figura 4- Curvas de difração de raios -X para a Celulose I, II, III e IV. .28

Figura 5- Diversos tipos partículas de celulose: a) Imagens de SEM de fibras de madeira ${ }^{[6]} \quad$ b) Imagens de SEM de MCCs ${ }^{[6]}$; c) Imagens de TEM de MFCs [9]; d) Imagens de TEM de NFCs [18]; e) Imagens de TEM de NCCs ${ }^{\text {[9]. }}$ 30 Figura 6- llustração esquemática da secção transversal da estrutura cristalina das

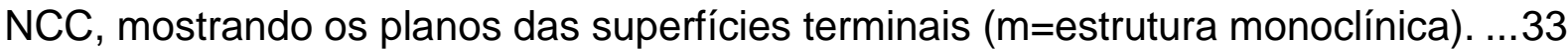
Figura 7- Representação esquemática dos grupos ligados às nanopartículas de celulose após a hidrólise ácida com ácido sulfúrico e com ácido clorídrico .36 Figura 8- Curva TG característica dos nanocristais (CNW) e microcristais (MCC) de celulose 39

Figura 9- Fotos de NCs preparadas por diferentes ácidos após serem submetidas $200^{\circ} \mathrm{C}$ por $30 \mathrm{~s}$ 39

Figura 10- (a) Birrefringência da solução aquosa a 0,63\% (m/m) de NCs observada através de duas lentes polarizadas cruzadas. (b) mesma solução após uma semana, havendo formação de duas fases: (c) fase isotrópica e (d) fase anisotrópica.

Figura 11- (a) Separação de fases de soluções aquosas de NCs a diferentes concentrações: 8,$78 ; 7,75 ; 6,85 ;$ e $5,78 \%(\mathrm{~m} / \mathrm{m})$ da esquerda para a direita, respectivamente. (b) Textura nemática quiral da fase anisotrópica da suspensão celulósica

Figura 12- Estrutura molecular do poli(ácido lático). .43

Figura 13- Isômeros ópticos da molécula de ácido lático. .44

Figura 14- Rota de obtenção do Poli (ácido lático) pelo processo da Cargill Dow ${ }^{\mathrm{TM}}$. 
Figura 15- Curva de DSC para o PLLA de peso molecular de $200 \mathrm{kDa}$, a taxa de $10^{\circ} \mathrm{C} / \mathrm{min}$.

Figura 16- Representação esquemática da resposta reológica esperada para o aumento do número de partículas por unidade de volume.

Figura 17- Fotografias de filmes de (a) PLA puro, e PLA reforçados com NCs b) a $2,5 \%$ (c) a $7,5 \%$ (d) a $15 \%(\mathrm{~m} / \mathrm{m})$; e de PLA com NCs modificadas com ICN (e) a $2,5 \%$ (f) a $7,5 \%(\mathrm{~g})$ a $15 \%(\mathrm{~m} / \mathrm{m})$. .58

Figura 18- Microscopia eletrônica de varredura (MEV) de (a) PLA puro, e PLA reforçado com NCs b) a $2,5 \%$ (c) a $7,5 \%$ (d) a $15 \%(\mathrm{~m} / \mathrm{m})$; e com NCs-ICN (e) a $2,5 \%(\mathrm{f})$ a $7,5 \%(\mathrm{~g})$ a $15 \%(\mathrm{~m} / \mathrm{m})$. 59

Figura 19- Imagens topográficas de MFA para PLA reforçado com 2,5\% $(\mathrm{m} / \mathrm{m})$ de: (a) NFCs (b) NFCs modificadas. 60

Figura 20- Curva de DSC para PLA puro e com 3\% $(\mathrm{m} / \mathrm{m})$ de NCs modificados com os grupos silanos: metracrilato; amino; acrilato; n-propil.

Figura 21- Curva TG (a) e sua derivada (b) de PLA puro e reforçado com 0,1 e 0,5\% $(\mathrm{m} / \mathrm{m})$ de NCs.

Figura 22- Viscosidade complexa do PLA puro e com 0,5 a 7\% em massa de NCs em função da frequência $(\omega)$.

Figura 23- Módulo de armazenamento (G') de PLA reforçado com NCs em função da frequência $(\omega)$. 65

Figura 24- Fotografia das NCs obtidas pelo Método I (NCSOD) .74

Figura 25- Fotografia das NCs obtidas pelo Método II (NCSOB). .75

Figura 26- Fotografias das NCs obtidas pelo Método III (NCPO): (a) após liofilização; (b) após moagem. .76

Figura 27- Curvas de DRX para as amostras de papel filtro e as NCs (NCSOD, NCSOB e NCPO). .76

Figura 28- Espectro vibracional de absorção no infravermelho (FTIR) obtido para as amostras de NCs preparadas pelos Métodos I (NCSOD), II (NCSOB) e III (NCPO).78 Figura 29- Curvas TG das amostras de papel e das NCs preparadas pelos Métodos I (NCSOD), II (NCSOB) e III (NCPO);

Figura 30- Curvas DTG das amostras de papel e das NCs preparadas pelos Métodos I (NCSOD), II (NCSOB) e III (NCPO); .80

Figura 31 - Suspensões aquosas de NCs produzidas pelo Método I (a), II (b) e III (c). As suspensões foram colocadas entre duas lentes polarizadas cruzadas. 
Figura 32- Micrografias obtidas por MET: (a) e (b) amostras de NCSOD; (c) e (d)

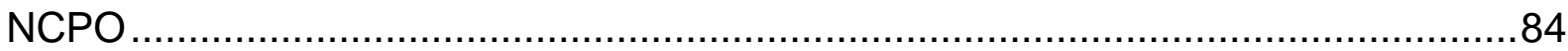

Figura 33- Imagem de MFA da amostra de NCSOD $(2,0 \times 2,0 \mu \mathrm{m})$; .85

Figura 34- Alturas transversais determinadas ao longo das linhas 1 e 2 apresentadas na Figura 33. 86

Figura 35- Imagem de MFA da amostra de NCPO $(2,5 \times 2,5 \mu \mathrm{m})$; 86

Figura 36- Alturas transversais determinadas ao longo das linhas 1 e 2 apresentadas na Figura 35.

Figura 37- Distribuição da razão de aspecto calculados para a amostras de (a) NCSOD e (b) NCPO.

Figura 38- Curvas de torque obtidas durante o processamento das amostras de PLA puro e com 1 e $3 \%$ de NCs. 89

Figura 39- Fotografias (a) do PLA puro; e dos compósitos obtidos: b) PLA com 1\% em massa de NCSOB; c) PLA com 3\% em massa de NCSOB. (Discos de 25 mm de diâmetro)

Figura 40- Fotografias dos compósitos obtidos: a) PLA com 1\% em massa de NCPO; b) PLA com 3\% em massa de NCPO. (Discos de 2,5 mm de diâmetro). .90 Figura 41 - (a) Curvas de TG para as amostras de PLA puro e com 1 e 3\% em massa de NCs e (b) detalhe da curva TG de 250 a $400^{\circ} \mathrm{C}$.

Figura 42- Curvas de DTG para as amostras de PLA puro e com 1 e $3 \%$ em massa de NCs, de 200 a $500{ }^{\circ} \mathrm{C}$.

Figura 43- Curvas DSC das amostras de PLA puro e com 1 e $3 \%$ em massa de NCs, de $0^{\circ} \mathrm{C}$ a $180^{\circ} \mathrm{C}$.

Figura 44- Micrografias ópticas de amostras submetidas às isotermas, nas suas temperaturas de cristalização (Tc): (a) PLA por 1 min na $T_{c 1}$; (b) PLA após 5 min na $\mathrm{T}_{\mathrm{c} 1}$; (c) PLA $+3 \%$ NCs na $\quad\left(\mathrm{T}_{\mathrm{c} 2}-10^{\circ} \mathrm{C}\right)$; (d) PLA $+3 \% \mathrm{NCs}$ em $\mathrm{T}_{\mathrm{c} 2}$ por 2 min...95 Figura 45- Curva de G' em função da deformação, de amostras de: (a) PLA puro, (b) PLA com 1\% em massa de NCs e (c) PLA com 3\% em massa de NCs.

Figura 46- Curvas de viscosidade complexa em função da frequência, para amostras de PLA puro e com 1 e $3 \%$ em massa de NCs.

Figura 47- Curva G' e G" em função da frequência, para PLA puro e com 1 e 3\% em massa de NCs.

Figura 48- Curva de G' e G” em função da frequência para o PLA com 3\% em massa de NCs. 
Figura 49- Micrografias obtida por MEV da amostra de PLA com 3\% em massa de NCs (a) com aumento de 35355 vezes (b) com aumento de 40000 vezes. 99 Figura 50- Correção de linha base da curva de DRX da amostra de papel filtro utilizada para cálculo da área da região cristalina. 113 Figura 51- Correção de linha base da curva de DRX da amostra NCSOD utilizada para cálculo da área da região cristalina 114 Figura 52- Correção de linha base da curva de DRX da amostra NCSOB utilizada para cálculo da área da região cristalina 115

Figura 53- - Correção de linha base da curva de DRX da amostra NCPO utilizada para cálculo da área da região cristalina 


\section{LISTA DE TABELAS}

Tabela 1 - Resumo dos tipos de partículas de celulose I.

Tabela 2- Propriedades mecânicas de diversos materiais utilizados como reforços em compósitos.

Tabela 3 - Propriedades mecânicas do PLLA com diferentes massas molares.

Tabela 4- Temperatura de transição vítrea $\left(T_{g}\right)$, temperatura de fusão $\left(T_{m}\right)$ e entalpia de fusão e cristalização $\left(\Delta \mathrm{H}_{\mathrm{m}}\right.$ e $\left.\Delta \mathrm{H}_{\mathrm{c}}\right)$ para o PLLA com diferentes pesos moleculares durante análise de DSC com ciclos de aquecimento/resfriamento entre 0 e $220^{\circ} \mathrm{C}$ à taxa de $10^{\circ} \mathrm{C} / \mathrm{min}$. 48

Tabela 5 - Propriedades do PLA Ingeo ${ }^{\mathrm{TM}}$ 3251D. .66

Tabela 6- Índices de cristalinidade (Ic) das amostras de NCs e papel filtro calculados através das curvas de DRX

Tabela 7 - Composição química semi-quantitativa das amostras de NCs obtidas pelo Método II.

Tabela 8- Dimensões das NCs preparadas pelo Método I (NCSOD) e III (NCPO) determinadas por MET e AFM.

Tabela 9- Temperaturas de início de degradação $\left(T_{i d}\right)$, temperaturas que ocorre perda de $50 \%$ em massa e massa residual das amostras de PLA puro e com 1 e $3 \%$ em massa de NCs.

Tabela 10 - Valores de entalpia de fusão e cristalização $\left(\Delta \mathrm{H}_{\mathrm{m}}\right.$ e $\left.\Delta \mathrm{H}_{\mathrm{c}}\right)$ e Grau de Cristalinidade $(X)$, para as amostras de PLA puro e com 1 e $3 \%$ em massa de NCs.

Tabela 11- Área total da curva de DRX da amostra de papel filtro sem correção de linha base.

Tabela 12- Áreas dos picos da curva de DRX da amostra de papel filtro após correção de linha base.

Tabela 13- Área total da curva de DRX da amostra NCSOD sem correção de linha base.

Tabela 14- Áreas dos picos da curva de DRX da amostra NCSOD após correção de linha base.

Tabela 15- Área total da curva de DRX da amostra NCSOB sem correção de linha base. 
Tabela 16- Áreas dos picos da curva de DRX da amostra NCSOB após correção de linha base. 115

Tabela 17- Área total da curva de DRX da amostra NCPO sem correção de linha base. 116 Tabela 18- Áreas dos picos da curva de DRX da amostra NCPO após correção de linha base. 116 


\section{LISTA DE ABREVIATURAS E SIGLAS}

\begin{tabular}{|c|c|}
\hline COPA & Cisalhamento Oscilatório de Pequenas Amplitudes \\
\hline DRX & Difração de Raios-X \\
\hline DSC & Calorimetria Exploratória Diferencial \\
\hline DTG & Derivada da curva Termogravimétrica \\
\hline FTIR & $\begin{array}{l}\text { Espectroscopia vibracional de absorção no infravermelho com } \\
\text { transformada de Fourier }\end{array}$ \\
\hline ICN & Isocianato \\
\hline MCCs & Microcirstais de celulose \\
\hline MEV & Microscopia Eletrônica de Varredura \\
\hline MET & Microscopia Eletrônica de Transmissão \\
\hline MFA & Microscopia de Força Atômica \\
\hline MFCs & Microfibras de celulose \\
\hline NCCs & Nanocristais de celulose \\
\hline NCPO & Nanopartículas de celulose obtidas com $\mathrm{H}_{3} \mathrm{PO}_{4}$ \\
\hline NCs & Nanopartículas de celulose \\
\hline NCSOB & $\begin{array}{l}\text { Nanopartículas de celulose obtidas com } \mathrm{H} 2 \mathrm{SO} 4 \text { e bicarbonato de } \\
\text { sódio }\end{array}$ \\
\hline NCSOD & Nanopartículas de celulose obtidas com H2SO4 e diálise \\
\hline NFCs & Nanofibras de celulose \\
\hline NWCs & Nanowhiskers de celulose \\
\hline PDLA & Poli(ácido lático) dextrogiro (+) \\
\hline PDLLA & Mistura racêmica dos dois enantiômeros do Poli(ácido lático) \\
\hline PF & Perda ao Fogo \\
\hline PHA & Polihidroxialcanoato \\
\hline PLA & Poli(ácido lático) \\
\hline PLLA & Poli(ácido lático) levogiro (-) \\
\hline TG & Termogravimetria \\
\hline VEL & Viscoelasticidade Linear \\
\hline VENL & Viscoelasticidade Não Linear \\
\hline
\end{tabular}




\section{LISTA DE SÍMBOLOS}

$\begin{array}{ll}\mathrm{E}_{\mathrm{l}} & \text { Módulo de Elasticidade na direção longitudinal } \\ \mathrm{G}^{\prime} & \quad \text { Módulo de armazenamento } \\ \mathrm{G}^{\prime \prime} & \quad \text { Módulo de perda } \\ \mathrm{I}_{\mathrm{c}} & \text { Índice de Cristalinidade } \\ \mathrm{M}_{\mathrm{n}} & \text { Massa molar média numérica } \\ \mathrm{M}_{\mathrm{w}} & \text { Massa molar média ponderada } \\ \mathrm{T}_{\mathrm{c}} & \text { Temperatura de cristalização } \\ \mathrm{T}_{\mathrm{g}} & \text { Temperatura de transição vítrea } \\ \mathrm{T}_{\mathrm{id}} & \text { Temperatura de início de degradação térmica } \\ \mathrm{T}_{\mathrm{m}} & \text { Gemperatura de fusão } \\ \mathrm{X} & \text { Deformação de cristalinidade } \\ \mathrm{Y} & \text { Entalpia de cristalização } \\ \Delta \mathrm{H}_{\mathrm{c}} & \text { Entalpia de fusão } \\ \Delta \mathrm{H}_{\mathrm{m}} & \text { Viscosidade complexa } \\ \eta^{*} & \text { Tensão de cisalhamento } \\ \sigma & \text { Frequência de cisalhamento } \\ \omega & \end{array}$




\section{SUMÁRIO}

1. INTRODUÇÃO

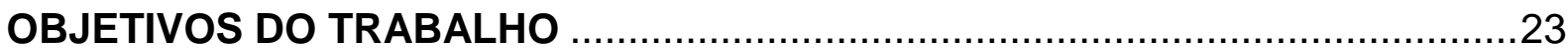

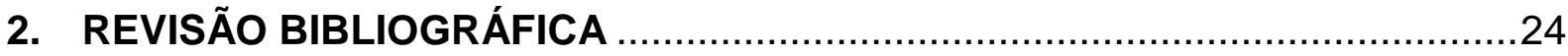

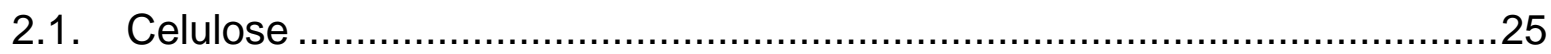

2.1.1. Estruturas cristalinas da celulose …...............................................26

2.2. Nanopartículas de celulose ...............................................................29

2.2.1. Fibras naturais ........................................................................

2.2.2. Microcristais de celulose (MCC) ………........................................

2.2.3. Microfibras de celulose (MFCs) …………....................................31

2.2.4. Nanofibras de celulose (NFCs) .......................................................

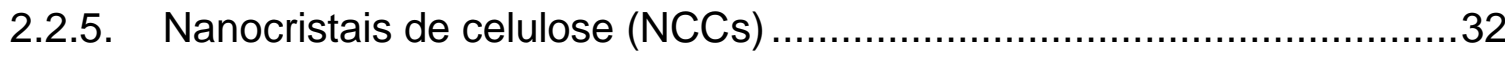

2.3. Obtenção das nanopartículas de celulose .................................................33

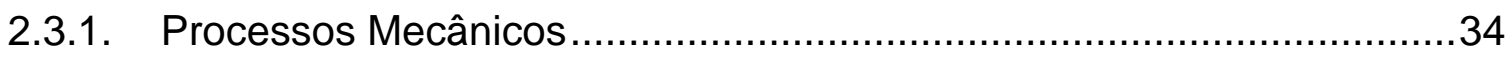

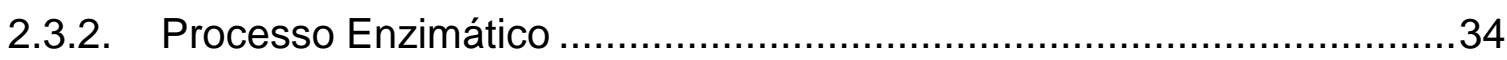

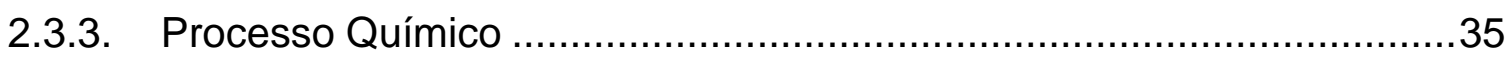

2.4. Propriedades das nanopartículas de celulose (NCs) …..............................37

2.4.1. Propriedades mecânicas ..................................................................

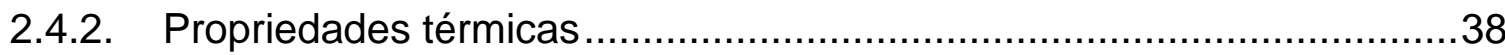

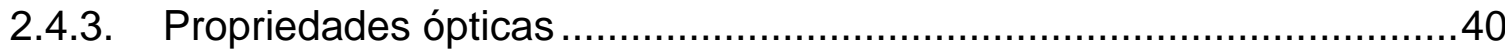

2.5. Biopolímeros e polímeros biodegradáveis ...............................................42

2.6. O poli(ácido lático)- PLA ........................................................................ 43

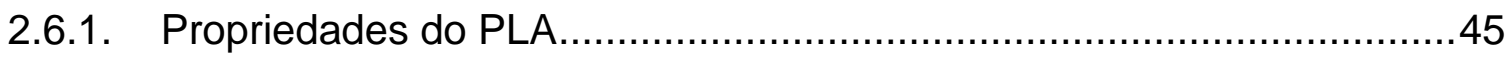

2.6.1.1. Propriedades mecânicas do PLLA ……….................................... 45

2.6.1.2. Propriedades térmicas e cristalização do PLLA ..............................46

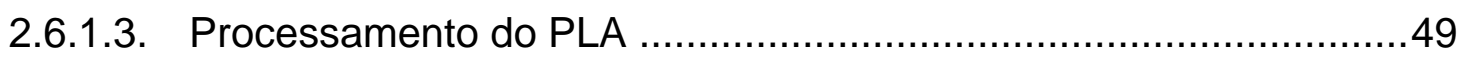

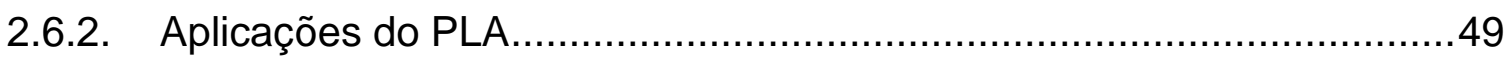


2.7. Nanocompósitos de matriz polimérica .50

2.7.1. Reologia de Nanocompósitos .52

2.7.2. Nanocompósitos de PLA reforçados com nanopartículas de celulose ..56

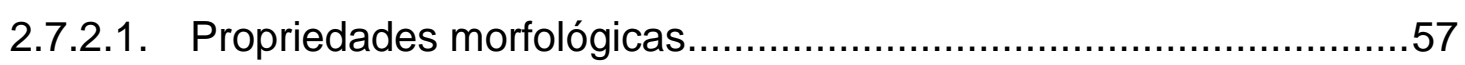

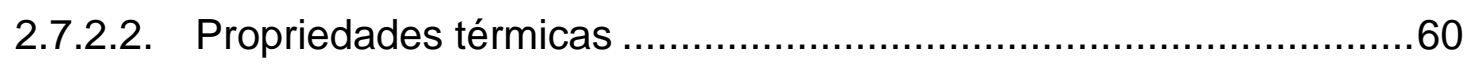

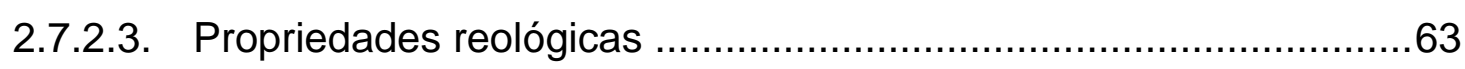

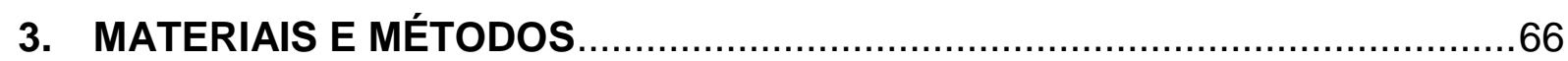

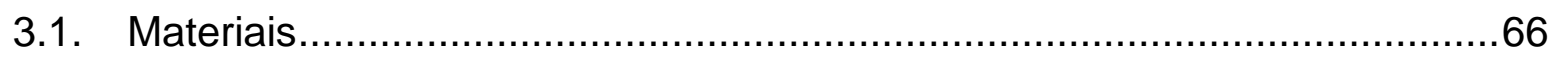

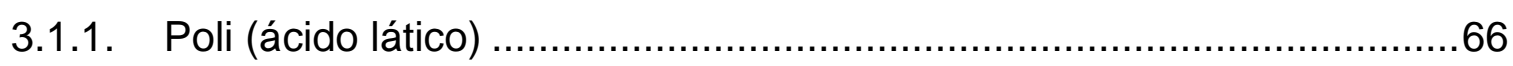

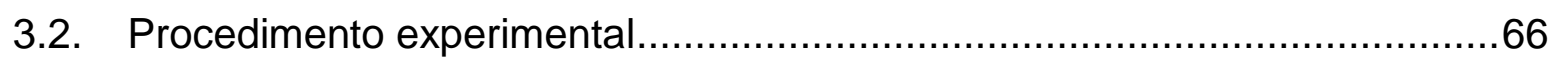

3.2.1. Obtenção das nanopartículas de celulose (NCs) ................................66

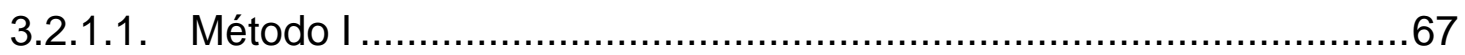

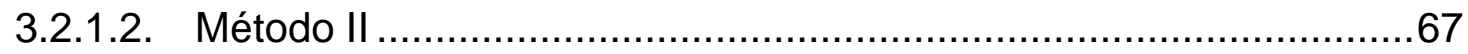

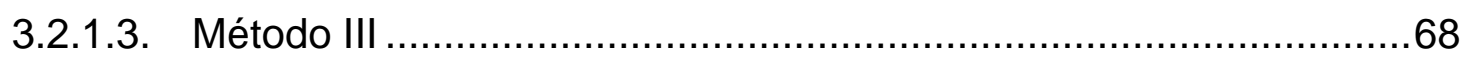

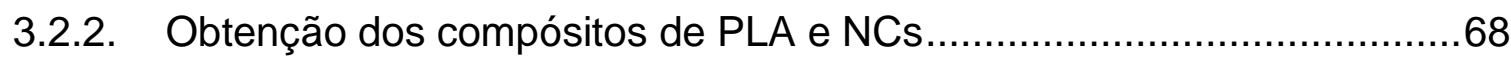

3.2.3. Caracterização das nanopartículas de celulose ...................................69

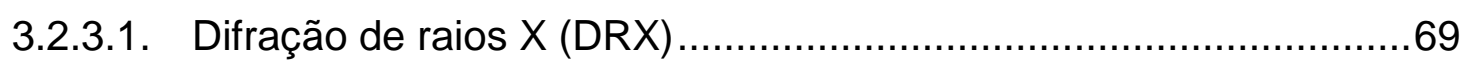

3.2.3.2. Espectroscopia vibracional de absorção no infravermelho com

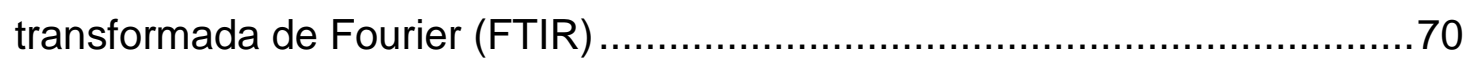

3.2.3.3. Análise Termogravimétrica (TG) ..............................................70

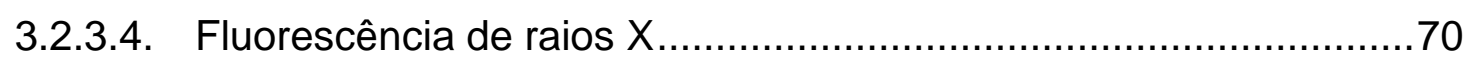

3.2.3.5. Birrefringência de fluxo ...........................................................

3.2.3.6. Microscopia Eletrônica de Transmissão (MET) ...............................71

3.2.3.7. Microscopia de Força Atômica (MFA) ……………………............

3.2.3.8. Análise quantitativa das imagens obtidas por MET .........................71

3.2.4. Caracterização dos compósitos de PLA e NCs ....................................72

3.2.4.1. Análise Termogravimétrica (TG) ………….............................72

3.2.4.2. Calorimetria Exploratória Diferencial (DSC) ..................................72 
3.2.4.3. Micrografia Óptica (MO) .72

3.2.4.4. Análises reológicas .73

3.2.4.5. Microscopia Eletrônica de Varredura com emissão de campo (MEV-FEG) .73

4. RESULTADOS E DISCUSSÕES .74

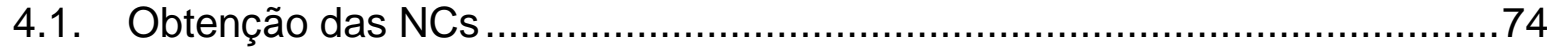

4.1.1. NCs preparadas pelo Método I (NCSOD) ………………...................74

4.1.2. NCs preparadas pelo Método II (NCSOB) …………………..............74

4.1.3. NCs preparadas pelo Método III (NCPO) ….........................................75

4.2. Caracterização das nanopartículas de celulose .........................................76

4.2.1. Difração de raios $X(D R X)$.............................................................

4.2.2. Espectroscopia vibracional de absorção no infravermelho com

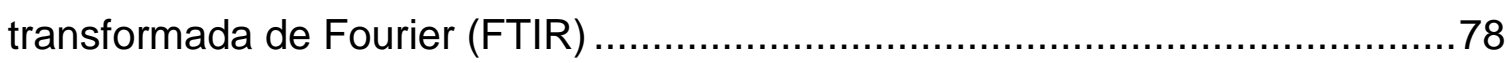

4.2.3. Análise Termogravimétrica (TG) ..................................................79

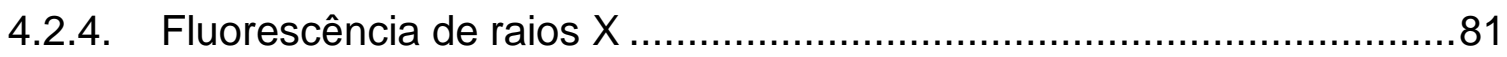

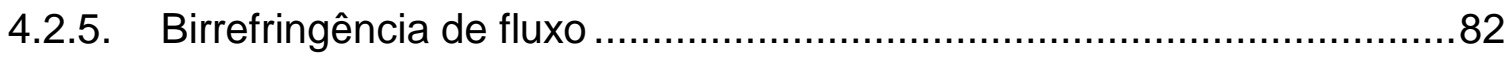

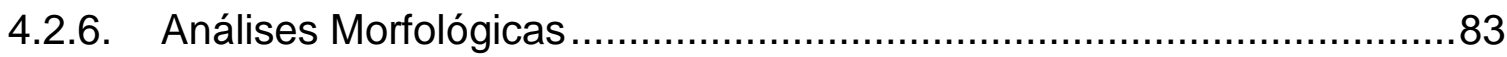

4.2.6.1. Microscopia Eletrônica de Transmissão (MET) ……………….......83

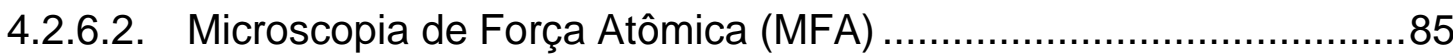

4.2.6.1. Determinação das dimensões das NCs através das análises

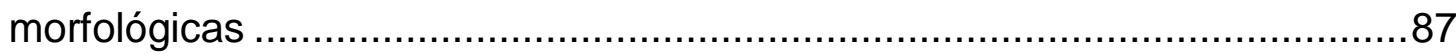

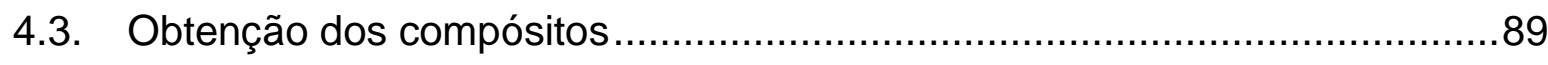

4.3.1. Utilização das NCs preparadas pelo Método II (NCSOB) .......................89

4.3.2. Utilização das NCs preparadas pelo Método III (NCPO) ……................90

4.4. Caracterização dos compósitos de PLA e NCs..........................................91

4.4.1. Análise Termogravimétrica (TG) ...................................................

4.4.2. Calorimetria Exploratória Diferencial (DSC) ……………...................93

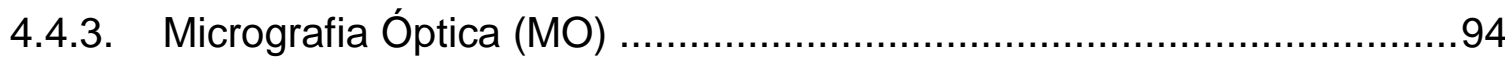




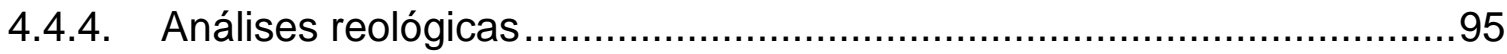

4.4.5. Microscopia Eletrônica de Varredura (MEV) ....................................99

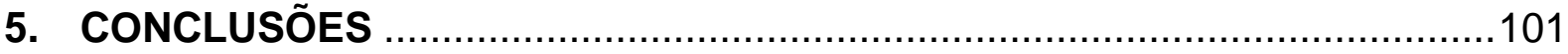

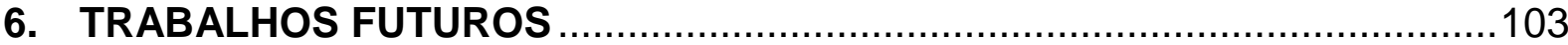

REFERÊNCIAS BIBLIOGRÁFICAS ..................................................... 104

APÊNDICE A- Dados para cálculo do Índice de Cristalinidade das nanopartículas através das curvas de DRX pelo método de subtração do alo amorfo...................113 


\section{INTRODUÇÃO}

Atualmente, a sociedade, a indústria e os órgãos governamentais têm manifestado grande preocupação na redução do volume de emissão de resíduos plásticos, que se acumulam nos aterros, levando mais de centenas de anos para se decompor. ${ }^{[1,2]}$

Além da redução do volume de detritos plásticos observa-se, também, o grande interesse pela busca por materiais alternativos que não só poupem matériaprima, como o petróleo, mas que também sejam de fácil processamento, e com baixo custo-benefício. Destacam-se, como alternativa, os crescentes estudos voltados para o desenvolvimento de biopolímeros, os quais podem ser fabricados a partir de inúmeras matérias-primas renováveis, como a cana-de-açúcar, tubérculos como batata e mandioca, entre outros. Além disso, podem ser biodegradáveis, ou seja, podem se decompor rapidamente pela ação de microorganismos, tais como bactérias e fungos, ao passo que os polímeros ditos não biodegradáveis levam centenas de anos para serem bioassimilados. ${ }^{[2]}$

Um dos biopolímeros biodegradáveis mais utilizados comercialmente é o Poli (ácido láctico) (PLA), o qual possui propriedades semelhantes a vários polímeros de fontes fósseis comuns, como elevado módulo de elasticidade, rigidez e boa capacidade de moldagem. ${ }^{[2,3]}$

Entretanto, algumas melhorias no desempenho tecnológico do PLA são desejadas, como em propriedades mecânicas, uma vez que sua resistência ao impacto, por exemplo, é relativamente baixa comparada a outros polímeros utilizados na indústria de embalagens, como o polietileno de alta densidade (PEAD). Para isto, é comum a adição de cargas sintéticas ou naturais no PLA, obtendo-se compósitos ou nanocompósitos, ou a obtenção de blendas poliméricas, por mistura com outro polímero, de fonte fóssil ou não. ${ }^{[4]}$

As nanopartículas de celulose (NCs) podem ser empregadas como reforço para matrizes poliméricas, como o PLA. Estes reforços são extraídos por diferentes métodos, sendo o método químico (por hidrólise ácida) o mais utilizado. ${ }^{[1]} \mathrm{A}$ utilização das NCs como reforço é extremamente vantajoso já que elas podem ser extraídas de fontes naturais e renováveis, tais como fibras naturais de juta, bambu, eucalipto e sisal. [5-7] Além disso, a literatura destaca que as NCs conferem melhorias à fase polimérica, tais como aumento em resistência ao impacto, sem 
perda significativa em rigidez, redução na permeabilidade a gazes e ganhos em propriedades térmicas, com adição de quantidades tão pequenas quanto $3 \% \mathrm{em}$ massa. As propriedades destes compósitos ganharam tanto destaque na literatura que estão impulsionando o aprimoramento do processo de obtenção, em grande escala, destas cargas. ${ }^{[8-11]}$

Neste contexto, o presente trabalho teve como objetivos a obtenção de nanopartículas de celulose e adicioná-las como reforço no PLA. Foi avaliada a influência da carga no comportamento térmico, morfológico e reológico do polímero.

\section{OBJETIVOS DO TRABALHO}

O presente trabalho teve como objetivos a obtenção de nanopartículas de celulose (NCs) e sua aplicação como reforço para a matriz polimérica de PLA.

Para atender a estes objetivos, o trabalho foi dividido em quatro partes experimentais:

- Obtenção das NCs por hidrólise ácida utilizando-se dois tipos de ácidos. Nos Métodos I e II foi utilizado ácido sulfúrico. A solução resultante foi neutralizada por duas rotas diferentes, e ambas foram secas por liofilização; No Método III foi utilizado o ácido fosfórico na reação de hidrólise.

- Caracterização das NCs. As NCs obtidas pelos três métodos foram caracterizadas, para posterior adição à matriz PLA;

- Preparo dos compósitos de PLA e NCs, via câmara de mistura e prensagem;

- Caracterização dos compósitos obtidos por análises térmicas, morfológicas e reológicas. Nesta etapa, comparou-se o efeito do método de preparo das NCs nas propriedades do compósito. 


\section{REVISÃO BIBLIOGRÁFICA}

Neste capítulo será apresentada uma breve revisão bibliográfica sobre os materiais utilizados neste trabalho. Inicialmente, as características e as propriedades da celulose serão apresentadas, uma vez que a obtenção de nanopartículas derivadas deste polímero natural é um dos principais objetivos deste trabalho.

A seguir, serão apresentadas as propriedades cristalinas da celulose e as nanopartículas. Os processos de obtenção das nanopartículas, suas propriedades e formas de caracterização serão descritos com o intuito de situar o leitor a cerca dos principais avanços encontrados na literatura sobre este tema.

Então, faz-se uma breve revisão sobre o tema "Biopolímeros e polímeros biodegradáveis". As propriedades e características do PLA também são apresentadas e utilizadas como base comparativa dos resultados alcançados neste trabalho.

Finalmente será apresentada uma revisão sobre os nanocompósitos de matriz polimérica, seguida de um tópico específico sobre nanocompósitos de matriz PLA reforçados com nanopartículas de celulose. Nesta seção serão relatados vários trabalhos encontrados na literatura, destacando-se os mais citados e os mais recentes segundo a base de dados Web of Science, os quais elucidam as propriedades morfológicas, térmicas e reológicas destes materiais. 


\subsection{Celulose}

A celulose pode ser considerada como o polímero renovável mais abundante na crosta terrestre. A estrutura deste material é naturalmente organizada em microfibrilas ligadas entre si, para formar fibras de celulose. É biossintetizado por diversos organismos vivos que variam a partir de pequenas a grandes plantas, algumas amebas e animais marinhos, bactérias e fungos. ${ }^{[1]}$

Independentemente de sua origem, a celulose pode ser caracterizada como um homopolissacarídeo linear de massa molar elevada, formada por unidades de Dglucose $\left(\mathrm{C}_{6} \mathrm{H}_{10} \mathrm{O}_{5}\right)$ ligadas entre si covalentemente através do átomo de oxigênio na posição $\beta-1,4$, conforme apresentado na Figura $1 .{ }^{[5,12,13]}$

Figura 1- Unidade de repetição da molécula de celulose.

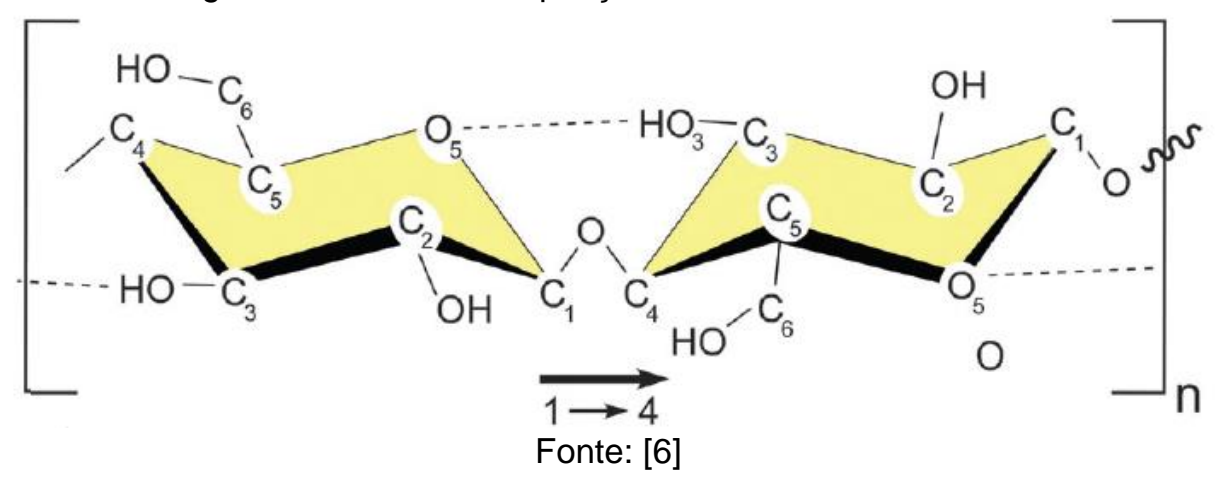

A partir da Figura 1, observa-se que cada monômero possui três grupos hidroxilas e as cadeias da celulose são lineares, há uma grande capacidade de formarem ligações de hidrogênio entre as mesmas. Tal característica desempenha um papel importante na orientação da estrutura cristalina e nas propriedades físicas da celulose. ${ }^{[1,5]}$

A celulose, devido a sua estrutura química, apresenta grande resistência a ácidos e à hidratação quando comparado a outros polissacarídeos, como o amido. ${ }^{[6]}$

Como o foco deste trabalho é a extração das regiões cristalinas da estrutura da celulose, o tópico a seguir abordará as estruturas cristalinas presentes na celulose. 


\subsubsection{Estruturas cristalinas da celulose}

A estrutura da celulose é constituída por regiões desordenadas, a fase vítrea, e por regiões de alta ordenação de cadeia, as fases cristalinas. Por esta razão a celulose é considerada um polímero natural semicristalino. ${ }^{[1]} \mathrm{Na}$ Figura 2 são apresentadas, esquematicamente, as fases que formam a estrutura da celulose.

Figura 2- Esquemas de (a) microfibrilas de celulose mostrando uma das configurações sugeridas das regiões cristalinas e vítreas e (b) nanocristais de celulose extraídas após destruição das regiões desordenadas.

a)

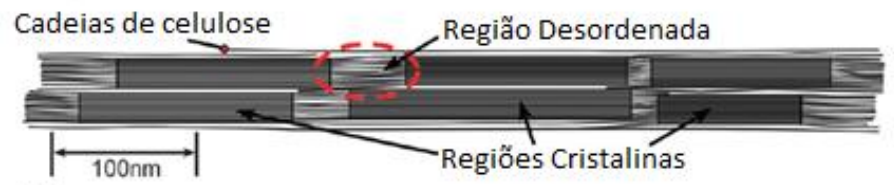

b)

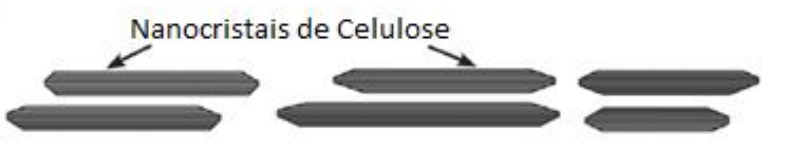

Fonte: [6]

Os grupos de hidroxila livres presentes na macromolécula de celulose são susceptíveis a serem envolvidas numa série de ligações de hidrogênio intra e intermoleculares, que podem originar vários arranjos cristalinos ordenados. ${ }^{[14]}$

Deste modo, existem vários polimorfos da celulose cristalina (I, II, III, IV), os quais têm sido amplamente estudados com o passar dos anos. A celulose I é a celulose cristalina que é produzida naturalmente por uma variedade de organismos (árvores, plantas, tunicados, algas, e bactérias). A sua estrutura é termodinamicamente metaestável, podendo ser convertida para as celuloses II ou III. [6]

A celulose I possui dois polimorfos, um com estrutura triclínica $\left(I_{\alpha}\right)$ e outro com estrutura monoclínica $\left(I_{\beta}\right)$, que coexistem em várias proporções dependendo da fonte da celulose. A estrutura $I_{\alpha}$ é encontrada predominantemente na maioria das algas e bactérias, enquanto que a estrutura $I_{\beta}$ é o polimorfo dominante para a maioria das plantas, contido na celulose da parede celular e nos tunicados. O polimorfo $I_{\alpha}$ é metaestável podendo ser convertido para $I_{\beta}$ através de tratamentos hidrotérmicos em solução alcalina e de alta temperatura, tratamentos em solventes orgânicos e gás hélio. No entanto, a conversão completa não é obtida. ${ }^{[6,7,14-16]}$ 
A celulose II possui uma estrutura monoclínica, sendo utilizada na obtenção do celofane (filmes transparentes), Rayon $^{\circledR}$ e Tencelt $^{\circledR}$ (fibras têxteis sintéticas). A celulose III pode ser formada a partir de celulose I ou II, através de tratamentos com amônia líquida e tratamentos térmicos subsequentes, podendo, então, ser utilizada para formar a celulose IV. ${ }^{[6,7,14]}$

Entretanto, até a atualidade, a celulose II é a estrutura mais estável e de maior relevância técnica, podendo ser produzida por dois processos: regeneração (solubilização e recristalização) e mercerização (tratamentos com hidróxido de sódio em solução aquosa). ${ }^{[1,6,7]}$ A seguir são representadas, na Figura 3, as estruturas cristalinas das celuloses $I_{\beta}$ e II.

Figura 3- Estruturas cristalinas da celulose $\mathrm{I}$ e e II: a) projeção da célula unitária (CU) ao longo do plano a-b; b) projeção da CU paralela ao plano (100) (celulose I) e ao plano (010) (celulose II).

a)
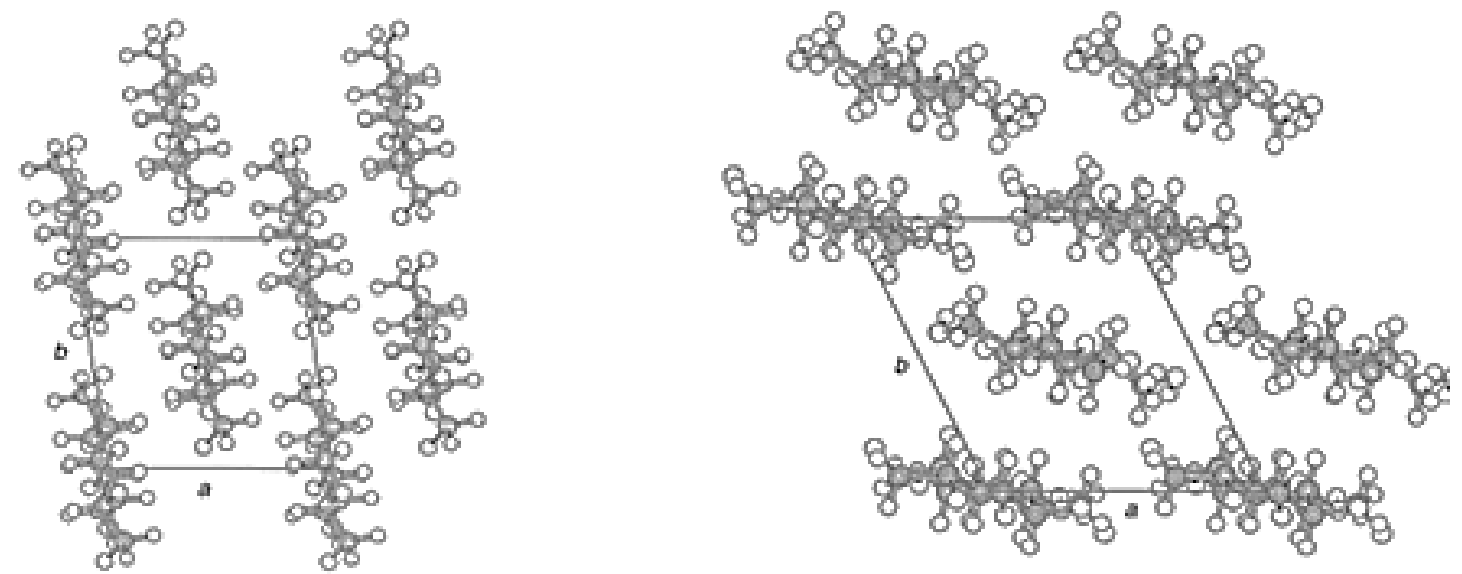

b)

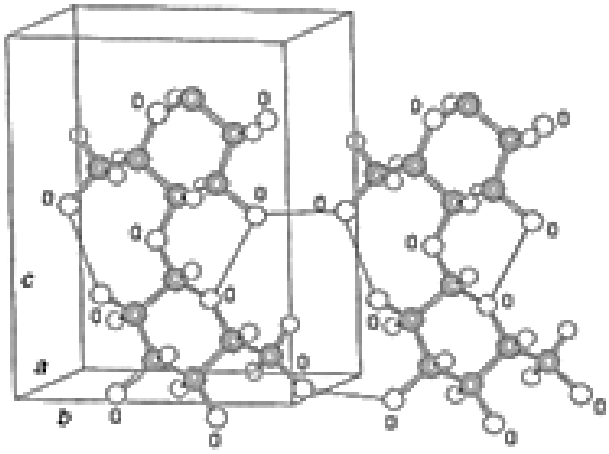

celulose $\mathrm{I}_{\mathrm{\beta}}$

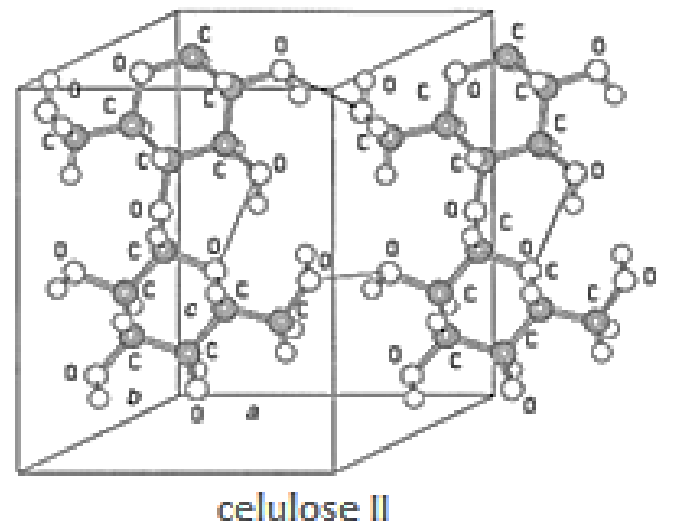

Fonte: [7]

A Figura 3b apresenta a vista lateral das cadeias centrais de uma célula unitária, evidenciando duas ligações intermoleculares (ligações de hidrogênio) em I $\beta$ 
e uma ligação na celulose II. Esta diferença na estrutura pode ser relacionada com a maior rigidez da celulose $I_{\beta} .{ }^{[6,7]}$

Estudos morfológicos realizados ${ }^{[6,7,12]}$ apresentam esta diferença na estrutura das diferentes celuloses cristalinas, conforme as curvas de difração de raios $X$ (DRX), na Figura 4, para as celuloses I, II, III, e IV.

Figura 4- Curvas de difração de raios X para a Celulose I, II, III e IV.

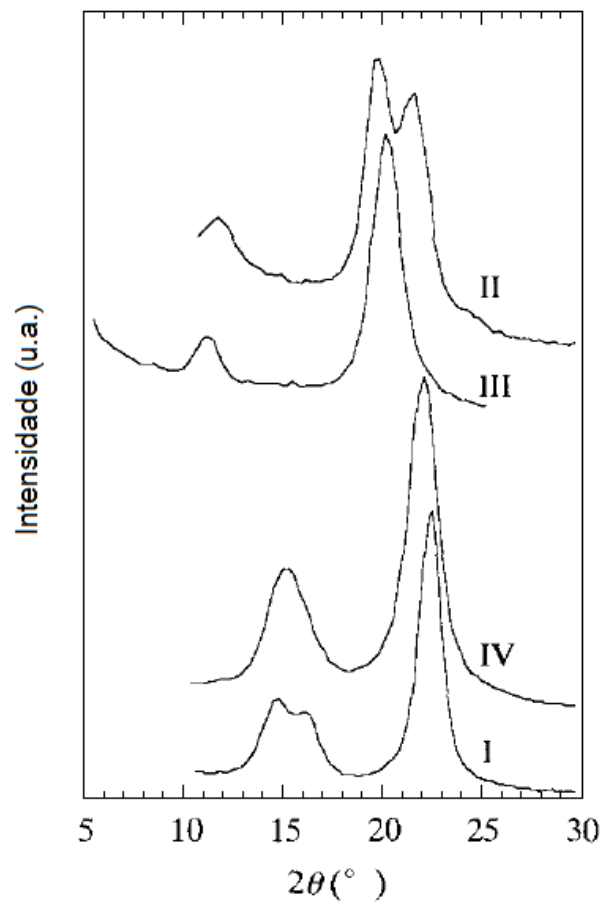

Fonte: [12]

De acordo com as curvas de DRX características para as celuloses I, II, III, e IV, os picos de maior intensidade evidenciam mudanças de estrutura cristalina entre as mesmas. Nota-se que para todas as amostras há três reflexões características em $1 \overline{1} 0,110$ e 002 , sendo $10^{\circ}<2 \theta<30^{\circ}$ para as celuloses I, II e IV e $5^{\circ}<2 \theta<25^{\circ}$ para a celulose III. Além disso, destaca-se que a celulose I apresenta maior porcentagem de cristalinidade (64\%), se comparada às demais. ${ }^{[12]}$

Como apresentado anteriormente, inúmeros estudos foram realizados com o intuito de caracterizar, e até mesmo modificar os diversos polimorfos da celulose cristalina para as mais variadas aplicações tecnológicas. ${ }^{[5,7]}$ Entretanto, o grande número de pesquisas relacionadas à celulose revelam que há um maior interesse no procedimento da extração da região cristalina da celulose, muitas vezes retirada de fontes naturais e renováveis, formando, predominantemente, partículas 
manométricas. Estas partículas são utilizadas, na maioria das vezes, em polímeros para o desenvolvimento de nanocompósitos.

Deste modo, sendo o foco deste trabalho a extração desses cristais de celulose para a aplicação em materiais poliméricos, visando à obtenção de nanocompósitos, a seguir serão abordados os temas nanopartículas de celulose, os procedimentos de obtenção e a caracterização dessas partículas.

\subsection{Nanopartículas de celulose}

As nanopartículas de celulose são partículas cristalinas constituídas de pelo menos uma dimensão nanométrica extraídas da celulose. Essas nanopartículas, quando isoladas, têm sido utilizadas como reforço para matrizes poliméricas, devido ao seu potencial em melhorar as propriedades mecânicas, dielétricas, ópticas, térmicas, dentre outras, dessas matrizes. Geralmente, essas nanopartículas são formadas pela estrutura da celulose I. ${ }^{[1,8]}$

A respeito da nomenclatura das nanopartículas de celulose não há uma padronização e, por isso, há um uso inconsistente de termos na literatura para descrever um dado conjunto de partículas de celulose. Existem apenas tendências atuais em terminologia, utilizadas de acordo com o tamanho das partículas, porcentagem de cristalinidade, morfologia e propriedades das mesmas. ${ }^{[6]}$

As nanopartículas de celulose (NCs) é utilizado como termo geral para vários dos tipos de partículas que têm pelo menos uma dimensão em nanoescala. Mais especificamente, há três tipos principais de partículas à base de celulose, são elas as microfibras de celulose (MFCs), nanofibras de celulose (NFCs) e nanocristais de celulose (NCCs) ou nanowhiskers de celulose (NWCs). Este último termo é utilizado em muitos estudos, devido ao formato de "whiskers" que os NCCs possuem, se tratando, do mesmo tipo de partículas. ${ }^{[6]} \mathrm{A}$ Tabela 1 apresenta os tipos de partículas de celulose e suas respectivas características. Para fins de comparação, as características das partículas com dimensões em escala micrométrica, chamadas de fibras de madeira (FM), fibras de plantas (FP) e microcristais de celulose (MCC), são também apresentadas. 
Tabela 1 - Resumo dos tipos de partículas de celulose I.

\begin{tabular}{|c|c|c|c|c|c|c|}
\hline \multirow[b]{2}{*}{$\begin{array}{l}\text { Tipo de } \\
\text { partícula }\end{array}$} & \multicolumn{3}{|c|}{ Dimensões das partículas } & \multirow{2}{*}{$\begin{array}{c}\text { Razão de } \\
\text { Aspecto } \\
\text { (RA) }\end{array}$} & \multirow[b]{2}{*}{$\begin{array}{c}\text { Cristalinidade }^{a} \\
(\%)\end{array}$} & \multirow[b]{2}{*}{$I_{\beta}(\%)$} \\
\hline & $\begin{array}{c}\text { Comprimento } \\
(\mu \mathrm{m})\end{array}$ & $\begin{array}{c}\text { Espessura } \\
(\mathrm{nm})\end{array}$ & $\begin{array}{c}\text { Altura } \\
(\mathrm{nm})\end{array}$ & & & \\
\hline MFC & $0,5-10$ & $10-100$ & $10-100$ & - & $51-69$ & $10-66$ \\
\hline NFC & $0,5-2$ & $4-30$ & $4-30$ & $>50$ & - & - \\
\hline NCC ou NWC & $0,05-0,5$ & $3-10$ & $3-10$ & $5-50$ & $54-88$ & $68-94$ \\
\hline FM e FP & $>2000$ & $20-50(\mu \mathrm{m})$ & $20-50(\mu \mathrm{m})$ & - & $43-65$ & - \\
\hline MCC & $10-50$ & $10-15(\mu \mathrm{m})$ & $10-15(\mu \mathrm{m})$ & $<2$ & $80-85$ & - \\
\hline
\end{tabular}

Fonte: [6] e [17]

Deve-se observar que para cada tipo de partícula existe uma distribuição de comprimentos, larguras, e percentagem de cristalinidade. Estes são, provavelmente, resultados de vários fatores, dentre eles: (i) a inerente variabilidade dos processos de extração, que resulta na variabilidade estatística na formação dos cristais; (ii) o tipo e parâmetros do processo de extração da partícula; e (iii) as diferenças nas técnicas de medição utilizadas, e a qualidade das análises dos dados. [6] Evidenciando ainda mais as diferenças entre os tipos de nanopartículas de celulose e as fibras, são apresentadas na Figura 5 as micrografias de cada tipo de partícula, sobre as quais serão discutidas nos itens a seguir.

Figura 5- Diversos tipos partículas de celulose: a) Imagens de SEM de fibras de madeira ${ }^{[6]}$ b) Imagens de SEM de MCCs ${ }^{[6]}$; ) Imagens de TEM de MFCs ${ }^{[9]}$; d) Imagens de TEM de NFCs [18]; e) Imagens de TEM de NCCs ${ }^{\left[{ }^{3]} \text {. }\right.}$

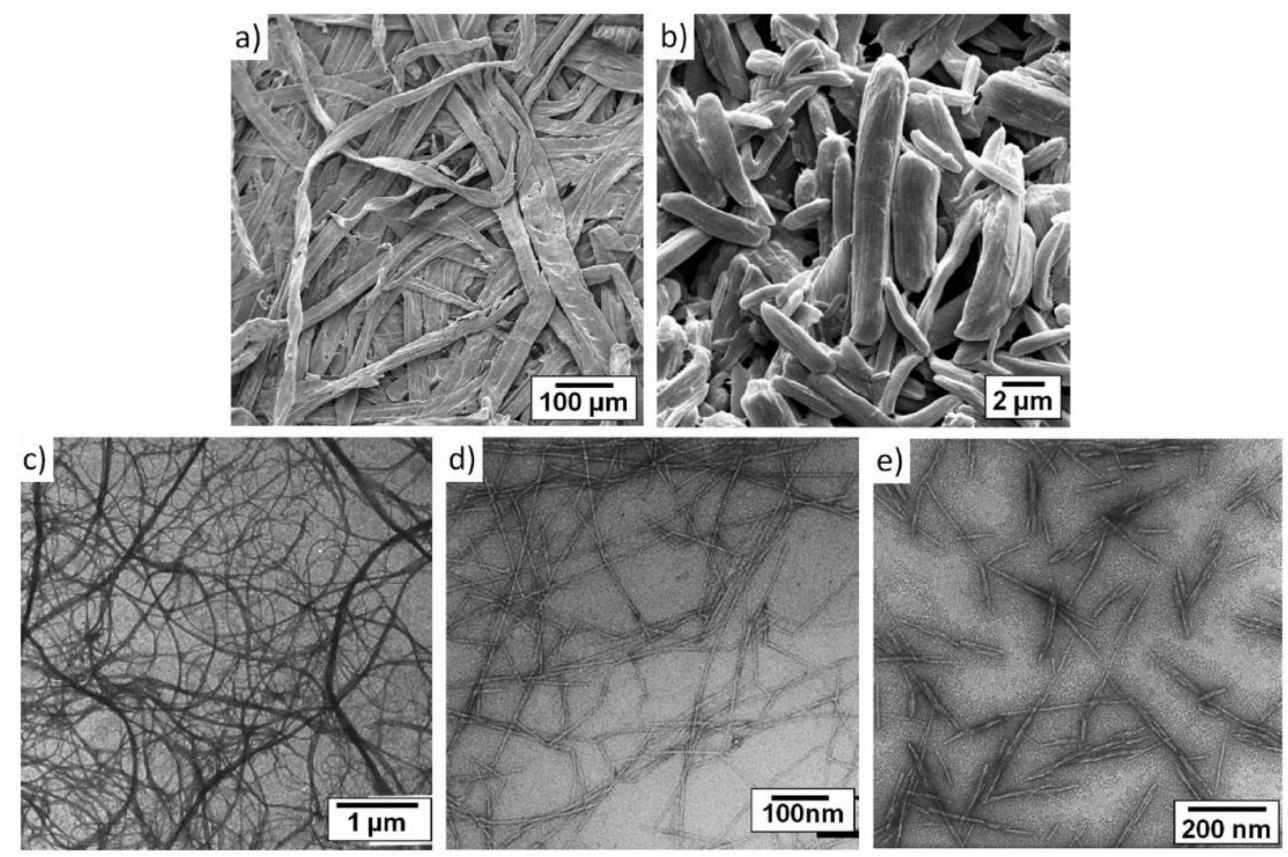




\subsubsection{Fibras naturais}

As fibras de madeira (FM) e de plantas (FP) são os maiores tipos de partículas apresentados na Figura 5 e descritos na Tabela 1, e dominam as indústrias de papel, têxtil e de biocompósitos há séculos. As partículas que passam pelo processo de purificação consistem em células de madeira ou de plantas individuais que medem $10 \mu \mathrm{m}$ de diâmetro, milímetros de comprimento, possuem elevada porcentagem de celulose, e uma cristalinidade relativamente baixa (43$65 \%$ ). Esses tipos de fibra podem possuir estrutura hierárquica. ${ }^{[6,19,20]}$

\subsubsection{Microcristais de celulose (MCC)}

Os MCC são materiais comerciais e são utilizados para aplicações nas indústrias farmacêuticas e de alimentos. A preparação dos MCC é realizada por hidrólise ácida de fibras naturais, neutralizados com álcalis, e secos por pulverização. As partículas resultantes são porosas, de 10-15 $\mu \mathrm{m}$ de largura. Elas possuem um elevado teor de celulose, uma cristalinidade elevada, e são compostas de pacotes agregados de microfibrilas de celulose de várias dimensões, que são fortemente ligadas entre si por ligações de hidrogênio. Normalmente, os MCC agregados são quebrados em partículas menores (1-10 mm de comprimento), antes da utilização em compósitos. ${ }^{[6,21]}$

\subsubsection{Microfibras de celulose (MFCs)}

As microfibras de celulose são produzidas via refino mecânico de polpas de fibra de madeira e plantas altamente purificadas. As MFCs têm sido utilizadas como agentes espessantes nas indústrias de alimentos e cosméticos. As partículas são consideradas como MFCs por conter várias fibrilas elementares, cada uma composta por 36 cadeias de celulose dispostas na estrutura cristalina da celulose $\mathrm{I}_{\beta}$. Elas possuem razão de aspecto elevada $(10-100 \mathrm{~nm}$ de largura e $0,5-10 \mathrm{~mm}$ de comprimento), são compostas basicamente por $100 \%$ de celulose, e contém tanto regiões amorfas quanto regiões cristalinas. ${ }^{[6,22]}$ 


\subsubsection{Nanofibras de celulose (NFCs)}

As nanofibras de celulose (NFCs) são partículas mais finas que as MFCs e são produzidas por refino mecânico e também por reação de oxidação utilizando-se, por exemplo, o reagente N-oxil-2,2,6,6-tetrametilpiperidina (TEMPO). Apresentam uma reminiscência de fibrilas elementares da madeira e da planta, cujo processo de biossíntese de celulose consiste em 36 cadeias de celulose dispostas na estrutura cristalina da celulose $I_{\beta}$, e tem uma secção transversal quadrada. As NFCs têm uma razão de aspecto elevada, geralmente maior que 50, possuindo 4-30 nm de largura, 500-2000 nm de comprimento. São compostas basicamente por $100 \%$ de celulose e contêm regiões tanto amorfas como cristalinas. A diferenciação entre NFC de MFC se baseia no processo de fibrilação, que produz os diâmetros das partículas mais finas. No entanto, na literatura as terminologias NFCs e MFCs são utilizadas indiscriminadamente, e por vezes podem ser confundidas. ${ }^{[6,18,23]}$

\subsubsection{Nanocristais de celulose (NCCs)}

Os nanocristais de celulose (NCCs) são partículas em forma de bastonetes ou whiskers, podendo assim ser chamados de nanowhiskers de celulose (NWCs). Eles podem ser obtidos principalmente após hidrólise ácida de diversas matérias-primas, incluindo as fibras naturais e até mesmo as MCC, MFCs e NFCs relatadas anteriormente. Os NCCs apresentam elevada razão de aspecto, geralmente na faixa de 5 a 50 e possuem 3-10 nm de largura e $50-500 \mathrm{~nm}$ de comprimento. OS NCCs são compostos basicamente por $100 \%$ de celulose, altamente cristalinos (54-88\%), e contém uma grande fração da celulose $I_{\beta}(68-94 \%)$. Os NCCs se assemelham a whiskers devido ao afinamento das extremidades dos cristais, provavelmente, um resultado originado do processo de hidrólise ácida, no qual é possível que os cristais se formem sob condições controladas, formando cristais de alta pureza. ${ }^{[1,6,14,24]}$

Os NCCs, assim como as NFCs, possuem uma reminiscência das regiões cristalinas dentro das fibrilas elementares do processo de biossíntese de madeira e de plantas, e consistem também em 36 cadeias de celulose dispostas em estrutura cristalina da celulose $I_{\beta}$ (monoclínica), possuindo uma secção transversal quadrada, com planos $(1 \overline{1} 0)$ e $(110)$ nas superfícies ${ }^{[6,25]}$, conforme apresentado na Figura 6. 
Figura 6- llustração esquemática da secção transversal da estrutura cristalina das NCC, mostrando os

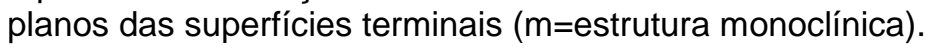

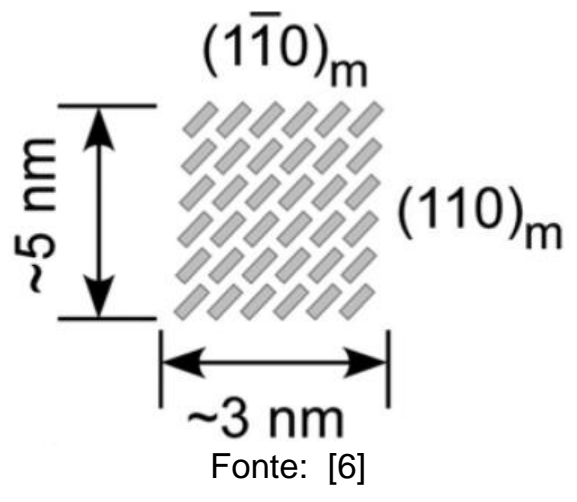

Apesar de estas estruturas serem consideradas ideais para os NCCs, existe uma considerável variabilidade na forma de partículas, comprimento e largura, que irá depender dos parâmetros utilizados no processo de obtenção. ${ }^{[1,6]}$

A seguir, será apresentado o processo de isolamento das nanopartículas de celulose, destacando-se o processo da hidrólise ácida, que foi utilizada na obtenção dos nanocristais deste trabalho.

\subsection{Obtenção das nanopartículas de celulose}

$O$ isolamento das nanopartículas de celulose a partir de fontes naturais ocorre em duas fases. A primeira fase é um pré-tratamento de purificação e homogeneização da matéria-prima. Em particular, este procedimento depende da fonte de celulose utilizada e, em menor grau, da morfologia desejada para as partículas de celulose a serem obtidas. Os pré-tratamentos para a madeira e plantas envolvem a remoção parcial ou completa de partes da matriz (hemicelulose, lignina, etc), e do isolamento total das fibras individuais. ${ }^{[6]}$

Geralmente, este processo consiste em tratamentos das fibras naturais com soluções orgânicas, hidróxido de sódio e ácidos, realizando o branqueamento das mesmas por meio da remoção da lignina. ${ }^{[10,26]}$ Entretanto, quando se utiliza como matéria-prima materiais já processados industrialmente, como o papel de celulose de alta pureza e os MCCs, esta etapa de pré-tratamento não é necessária, uma vez que os mesmos já passaram pelo branqueamento no processo de fabricação. ${ }^{[27,28]}$

A segunda etapa da obtenção das nanopartículas refere-se ao isolamento dos domínios cristalinos da estrutura celulósica. A realização desta etapa consiste no processo de ataque da parte amorfa, sem que a parte cristalina seja atacada, extraindo-se assim as nanopartículas de celulose. Tais partículas também podem 
variar de forma e nomenclatura conforme o tipo de processo de isolamento utilizado. Os processos mais comumente encontrados na literatura são o mecânico, enzimático e por hidrólise ácida ${ }^{[1,6]}$, os quais serão discutidos a seguir.

\subsubsection{Processos Mecânicos}

Os processos mecânicos para obtenção das nanopartículas de celulose podem ser realizados através de homogeneizadores de alta pressão, moedores, refinadores ou mesmo tratamentos de ultrassom de alta intensidade. ${ }^{[6,29-31]}$

Em geral, estes processos de produção de alto cisalhamento provocam clivagem transversal ao longo do eixo longitudinal da estrutura microfibrilar da celulose, resultando na extração de microfibras de celulose, as chamadas MFC. ${ }^{[1,6]}$

Entretanto, como o tratamento mecânico geralmente é repetido algumas vezes, com intuito de se obter partículas menores e de tamanhos mais homogêneos, é comum a ocorrência de maiores danos mecânicos na celulose cristalina, em comparação a outros processos de obtenção. ${ }^{[6,30]}$ Além disso, como ligações de hidrogênio são formadas entre as fibras de celulose no processo de secagem, é comum a formação de aglomerados difíceis de serem separados mecanicamente. Por este motivo, a reidratação das fibras a serem utilizadas na extração é necessária, promovendo alguns deslocamentos das ligações de hidrogênio entre as fibras e facilitando a remoção de fibras únicas. ${ }^{[6]}$

\subsubsection{Processo Enzimático}

O processo enzimático é realizado através de enzimas da classe celulase, compostas por endoglicanases, exoglucanases e celobiohidrolases. Estas enzimas atuam sinergisticamente na hidrólise da celulose. A endoglucanase ataca aleatoriamente e hidrolisa as regiões amorfas enquanto que a exoglucanase ataca a cadeia celulósica a partir de terminais redutores ou não redutores. A celobiohidrolase hidrolisa a celulose a partir dos carbonos $C_{1}$ ou $C_{4}$. A hidrólise enzimática, é mais específica que a hidrólise ácida e apresenta a vantagem de ser menos corrosivo do que tratamentos químicos, não danificando as fases cristalinas da celulose e originando nanopartículas de celulose relativamente dispersas e de 
tamanhos razoavelmente uniformes. Além disso, este tratamento possui a vantagem de não gerar resíduos químicos de alta periculosidade. ${ }^{[11,14,32]}$

Através do tratamento enzimático, pode-se obter tanto nanofibras quanto nanocristais de celulose, dependendo da fonte utilizada para a extração das nanopartículas. ${ }^{[11]}$

Entretanto, trata-se de um processo de alto custo de produção, o que inviabiliza sua utilização em casos que necessitem de uma significativa quantidade de massa. ${ }^{[11,32]}$

\subsubsection{Processo Químico}

Sendo a parte amorfa susceptível ao ataque ácido, o processo mais comum e que, na maioria das vezes, resulta na obtenção de nanocristais ou nanowhiskers de celulose (NCCs e NWCs), é a hidrólise ácida. ${ }^{[33,34]}$

Por este processo, é possível que os íons de hidrogênio $\left(\mathrm{H}^{+}\right)$, provindos do ácido, penetrem nas cadeias de celulose, nos domínios amorfos, e promovam a segmentação hidrolítica das ligações glicosídicas, liberando cristais individuais. Estes cristais podem mudar de tamanho por causa da grande liberdade de movimento após a segmentação hidrolítica. ${ }^{[34]}$

O preparo de suspensões coloidais aquosas de NCCs que consiste da segmentação hidrolítica com ácido é dependente do tipo de ácido, concentração de ácido, do tempo e a temperatura da reação da hidrólise. ${ }^{[33,34]}$ Além disso, diferentes tratamentos destes cristalitos carregados, tais como a dispersão mecânica ou ultrassons, permitem a dispersão dos agregados e, finalmente, são capazes de produzir as suspensões coloidais.

Os ácidos mais utilizados na reação de hidrólise são o ácido sulfúrico $\left(\mathrm{H}_{2} \mathrm{SO}_{4}\right)$ e o ácido clorídrico $(\mathrm{HCl})$. A utilização do ácido sulfúrico para o preparo de nanocristais de celulose proporciona uma suspensão mais estável do que o preparo com ácido clorídrico. Isto porque os $\mathrm{NCC}$ preparados com $\mathrm{HCl}$ apresentam grupos hidroxilas na superfície, os quais podem formar ligações de hidrogênio entre as partículas, causando a aglomeração entre elas. Já os preparados com $\mathrm{H}_{2} \mathrm{SO}_{4}$ apresentam uma superfície ligada a grupos sulfonados, que formam uma superfície com carga negativa, causando a repulsão das partículas. Na Figura 7 é 
apresentado, esquematicamente, como os grupos sulfonados e hidroxilas se ligam nos NCCs, após a hidrólise ácida. ${ }^{[6,33,35]}$

Figura 7- Representação esquemática dos grupos ligados às nanopartículas de celulose após a hidrólise ácida com ácido sulfúrico e com ácido clorídrico

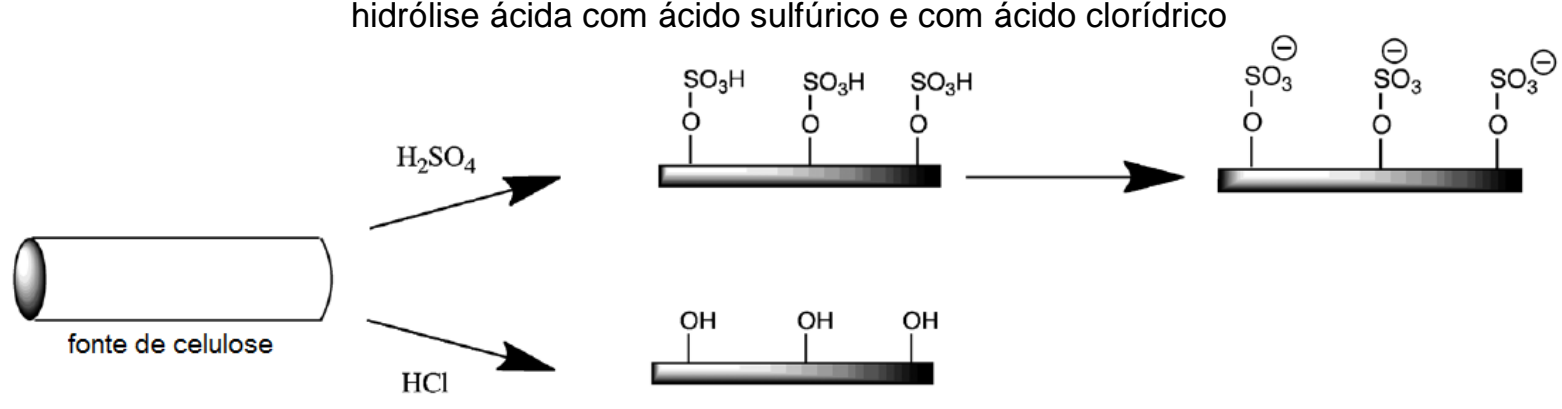

Fonte: [6] modificado.

A partir da Figura 7, observa-se que a camada com carga negativa é constituída pelos grupos sulfonados, o que causa repulsão eletrostática entre as partículas obtidas com $\mathrm{H}_{2} \mathrm{SO}_{4}$, fazendo com que as suspensões sejam mais homogêneas e evitando que as partículas finais se aglomerem. ${ }^{[6,33]}$

Após este procedimento de ataque aos domínios amorfos da celulose com ácido, é necessário que haja a neutralização da solução final. Muitos estudos ${ }^{[26-28]}$ realizam esta etapa de neutralização com centrifugações a altas rotações, seguida de diálise por meio de membrana de celulose com água deionizada, a fim de que se obtenha uma solução neutra de nanopartículas de celulose. Há estudos ${ }^{[36]}$, entretanto, que utilizam soluções alcalinas na reação de neutralização. Porém, procedimentos que não geram subprodutos na solução diminuem a probabilidade de ocorrer impurezas no produto final.

Por fim, a solução neutralizada deve passar pelo processo de secagem. A literatura ${ }^{[1,5,6]}$ apresenta que, na maioria das vezes, esta etapa pode ser realizada pelo processo de liofilização, pois através da secagem por sublimação é possível que a estrutura da celulose não seja destruída. ${ }^{[37]}$

Como este trabalho teve como foco a utilização das NCs como carga em matriz polimérica, formando nanocompósitos, os temas a seguir desta revisão bibliográfica apresentarão as propriedades e as caracterizações de nanopartículas de celulose, visando a aplicabilidade das mesmas. 


\subsection{Propriedades das nanopartículas de celulose (NCs)}

Serão apresentadas, a seguir, as diferentes propriedades e formas das NCs e as principais técnicas utilizadas para caracterizá-las.

\subsubsection{Propriedades mecânicas}

Há uma compreensão restrita das propriedades mecânicas das NCs. O pequeno tamanho da partícula combinado com as técnicas de metrologia limitadas disponíveis na caracterização destes materiais orgânicos, ao longo de vários eixos, faz com que a medição quantitativa das propriedades mecânicas seja extremamente desafiadora. Além disso, diversos fatores podem contribuir para uma larga distribuição de valores para as propriedades mecânicas na literatura, como estrutura cristalina das partículas, porcentagem de cristalinidade, defeitos e métodos utilizados na medição. Assim, é fundamental considerar esses fatores quando se comparam dados de um determinado tipo de partícula. ${ }^{[6,38]}$

As propriedades mecânicas dos vários tipos de partículas de celulose estão resumidas na Tabela 2, além de outros tipos de fibras e nanopartículas, utilizados em comparações futuras.

Tabela 2- Propriedades mecânicas de diversos materiais utilizados como reforços em compósitos.

\begin{tabular}{|c|c|c|c|c|}
\hline \multirow[b]{2}{*}{ Material } & \multirow{2}{*}{$\begin{array}{c}\text { Densidade } \\
\left(\mathrm{g} / \mathrm{cm}^{3}\right)\end{array}$} & \multicolumn{2}{|c|}{ Módulo de Elasticidade (GPa) } & \multirow{2}{*}{$\begin{array}{l}\text { Resistência à } \\
\text { Tração (GPa) }\end{array}$} \\
\hline & & $E_{1}$ & $E_{t}$ & \\
\hline \multicolumn{5}{|l|}{ Fibras } \\
\hline vidro & 2,5 & 72 & - & 3,5 \\
\hline carbono & 1,8 & $150-500$ & - & $1,5-5,5$ \\
\hline Kevlar-49 & 1,4 & $124-130$ & 2,5 & 3,5 \\
\hline \multicolumn{5}{|l|}{ Nanopartículas } \\
\hline argila & - & 170 & - & - \\
\hline grafite & - & 1000 & - & - \\
\hline \multicolumn{5}{|l|}{ Celulose } \\
\hline Microfibras (MFC) & - & $25-78$ & - & - \\
\hline Nanocristais (NCC) & 1,5 & $100-200$ & $11-57$ & - \\
\hline
\end{tabular}

Fontes: [6] e [38]

De acordo com os dados médios experimentais apresentados na Tabela 2, os nanocristais de celulose, de modo geral, podem apresentar maior rigidez do que 
fibras de Kevlar-49 e de vidro e valores equivalentes aos obtidos para fibras de carbono e nanopartículas de argila, quando se compara os valores médios do módulo elástico no sentido longitudinal $\left(E_{l}\right)$. Além disso, os nanocristais de celulose possuem a vantagem da baixa densidade, aliada a altos valores para $\mathrm{E}_{\mathrm{l}}$.

Os trabalhos sobre propriedades mecânicas das NCs tem se concentrado na determinação do módulo de elasticidade, e por causa da anisotropia dentro da celulose cristalina, isto é, a estrutura assimétrica da cadeia de celulose, haverá diferenças nas propriedades dos cristais em função da direção em relação à estrutura da celulose cristalina. ${ }^{[6,14,38,39]}$

Tais propriedades mecânicas têm sido medidas experimentalmente utilizando ensaios de tração in situ, combinados com difração de raios $X$ (DRX). Entretanto, como esta técnica presume perfeita transferência de carga e orientação dos cristais de celulose dentro das microfibrilas ao longo do eixo de carregamento, o que, necessariamente, não acontece, os valores de $E$ obtidos podem ser subestimados, quando comparados com os valores experimentais. ${ }^{[6,38]}$

Além deste método, outras técnicas como microscopia de força atômica e espectroscopia Raman têm sido utilizadas para cálculos de valores de $E_{l}$ e $E_{t}$, os quais apresentam menores desvios quando comparados aos valores encontrados através de modelos matemáticos. ${ }^{[6]}$

\subsubsection{Propriedades térmicas}

As propriedades térmicas das nanopartículas de celulose são descritas em termos de degradação térmica e do coeficiente de expansão térmica. $O$ início da degradação térmica das NCs é obtido pela análise termogravimétrica (TG), que apresenta a porcentagem de massa em função da temperatura, para uma dada taxa de aquecimento. Normalmente, o aparecimento de degradação térmica das NCs, ocorre entre $200-300{ }^{\circ} \mathrm{C}$, dependendo da velocidade de aquecimento, do tipo de partícula, e do tipo de modificação de superfície. ${ }^{[6,14,40,41]}$

Na Figura 8 é apresentada uma curva TG característica dos nanocristais de celulose (NCCs) obtidos por hidrólise ácida com ácido sulfúrico, e para os microcristais de celulose (MCCs). 
Figura 8- Curva TG característica dos nanocristais (CNW) e microcristais (MCC) de celulose.

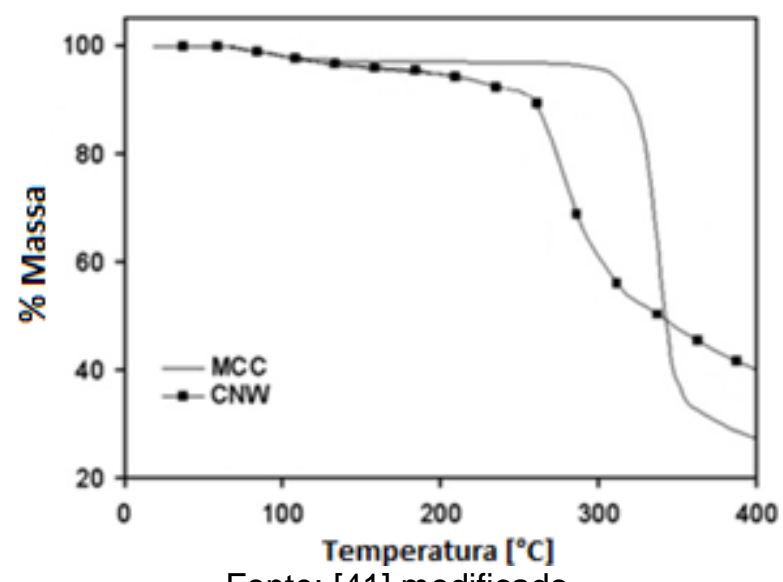

Fonte: [41] modificado

De acordo com a curva TG dos NCCs, pode-se observar que após a hidrólise dos MCCs com ácido sulfúrico, a estabilidade térmica do material diminui, uma vez que a temperatura de início de degradação térmica dos NCCs é de $\sim 260{ }^{\circ} \mathrm{C}$ e $\sim 300{ }^{\circ} \mathrm{C}$ para os MCCs. ${ }^{[6,41]}$ De fato, os nanocristais de celulose são termicamente mais frágeis que os microcristais, resultando num problema para a aplicação dos NCCs como carga, já que os mesmos, ao serem adicionados em equipamentos de processamento de polímeros fundidos, poderiam degradar, antes mesmo dos materiais serem completamente misturados. ${ }^{[1,6]}$

Por este motivo, estudos recentes ${ }^{[42]}$ apresentam que a utilização do ácido sulfúrico pode afetar a estabilidade térmica das NCs. Neste estudo, é sugerida a utilização do ácido fosfórico para a extração das partículas, uma vez que os grupos fosfatos são capazes de aumentar a estabilidade térmica das NCs após terem sido ligados à superfície das mesmas durante a reação de hidrólise. Deste modo, a Figura 9 apresenta um estudo simples, no qual NCs extraídas por três tipos de ácido foram submetidas à temperatura de $200^{\circ} \mathrm{C}$ por 30 segundos.

Figura 9- Fotos de NCs preparadas por diferentes ácidos após serem submetidas $200{ }^{\circ} \mathrm{C}$ por $30 \mathrm{~s}$.
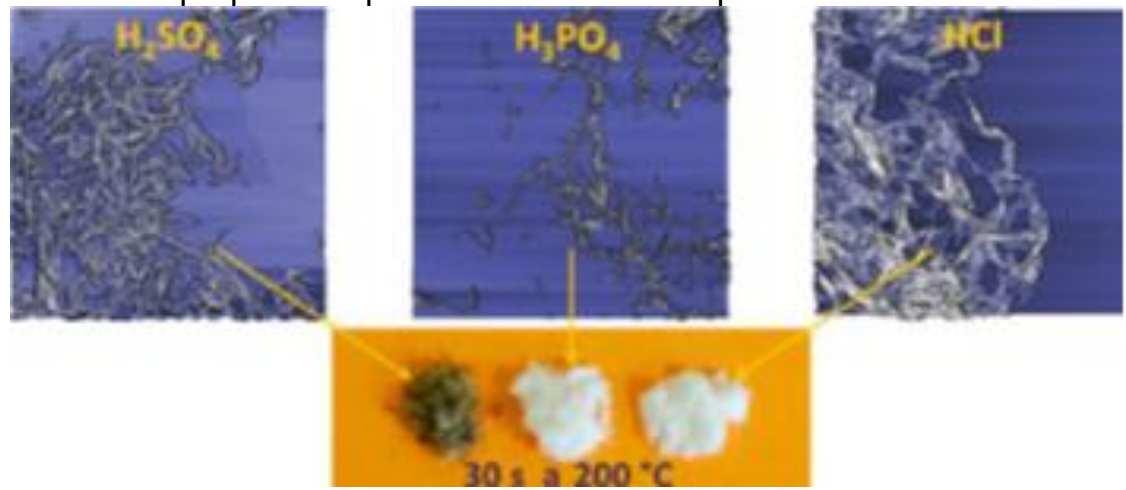

Fonte: [42] modificado 
A partir da Figura 9 é possível observar que o aquecimento à $200{ }^{\circ} \mathrm{C}$ por 30 segundos foi capaz de degradar as NCs obtidas através da hidrólise com $\mathrm{H}_{2} \mathrm{SO}_{4}$, $\mathrm{O}$ que não ocorreu com os outros dois ácidos utilizados. Isso mostra que a estabilidade térmica das NCs, neste caso, foi profundamente afetada com a utilização do ácido sulfúrico na extração dessas partículas. ${ }^{[42]}$

Outra propriedade térmica importante das NCs é o coeficiente de expansão térmica, que pode ser obtido por técnicas termomecânicas. De acordo com a literatura [40,43], o coeficiente de expansão térmica é estimado em aproximadamente 0,1 ppm $\mathrm{K}^{-1}$, o qual é mais do que uma ordem de magnitude mais baixa do que a maioria dos metais e cerâmicas, e semelhante a outras fibras anisotrópicas de alto módulo, tais como fibras de carbono. ${ }^{[6]}$

\subsubsection{Propriedades ópticas}

Apesar da sua composição, as NCs não possuem a mesma resposta óptica que outros materiais celulósicos. Com base na estrutura da celulose, que é constituída de éter, hidroxila e ligações carbono-carbono e carbono-hidrogênio, o material não deveria ter absorção na faixa de radiação eletromagnética visível, o que de fato, não acontece. Filmes obtidos via solução de NCs possuem excelente transparência. No entanto, as nanopartículas de celulose se diferem de outros materiais de celulose em três aspectos importantes: (1) elas estão em dimensões nanométricas; (2) certas estruturas são anisotrópicas e apresentam birrefringência;

(3) dependendo da escala de tamanho, da concentração e da razão de aspecto, são líquidos cristalinos. ${ }^{[6,7]}$

A birrefringência em partículas à base de celulose deve ser esperada em estruturas celulósicas que sejam anisotrópicas em quase todo o comprimento das cadeias de celulose da matéria-prima (seja de madeira ou planta), que apesar da fibrilação, são de certo modo preservadas. ${ }^{[6]} \mathrm{Na}$ Figura 10 é apresentada a birrefringência da solução aquosa de nanopartículas de celulose dispersas a 0,63\% $(\mathrm{m} / \mathrm{m})$ e após uma semana, mostrando a decantação das partículas e a formação de duas fases (isotrópica e anisotrópica). 
Figura 10- (a) Birrefringência da solução aquosa a 0,63\% $(\mathrm{m} / \mathrm{m})$ de NCs observada através de duas lentes polarizadas cruzadas. (b) mesma solução após uma semana, havendo formação de duas fases: (c) fase isotrópica e (d) fase anisotrópica.

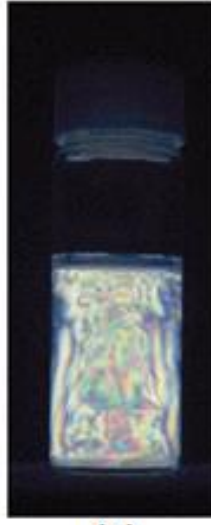

(a)

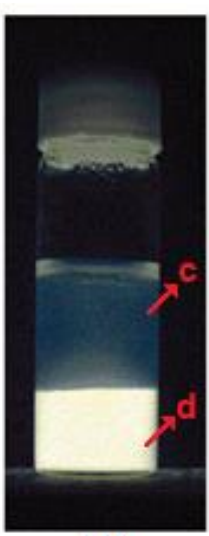

(b)

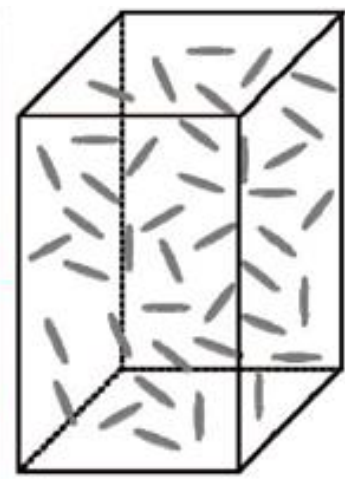

(c) fase isotrópica

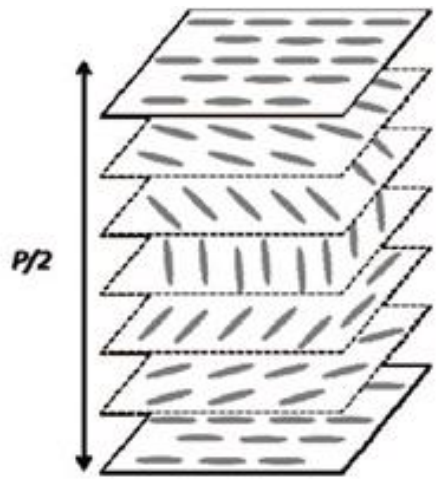

(d) fase anisotrópica

Fonte: [5]

Quando as suspensões estão abaixo de uma concentração crítica, o fenômeno da birrefringência é observado na solução. Entretanto, com o passar do tempo, a evaporação de solvente causa um aumento dessa concentração de NCs na solução, e as nanopartículas coalescem formando uma fase anisotrópica, isto é, ocorre uma auto-organização das NCs ao longo de um mesmo vetor direcional que resulta em um alinhamento líquido cristalino nemático quiral ou colestérico. ${ }^{[6,43,44]}$

O alinhamento nemático quiral é comprovado quando as suspensões com diferentes concentrações de NCs são analisadas em microscópio de luz polarizada, por meio do qual pode se observar padrões ou texturas semelhantes a "impressões digitais", ${ }^{[44,45]}$ conforme é observado na Figura 11.

Figura 11- (a) Separação de fases de soluções aquosas de NCs a diferentes concentrações: 8,78; 7,75; 6,85; e 5,78\% (m/m) da esquerda para a direita, respectivamente. (b) Textura nemática quiral da fase anisotrópica da suspensão celulósica.

(a)

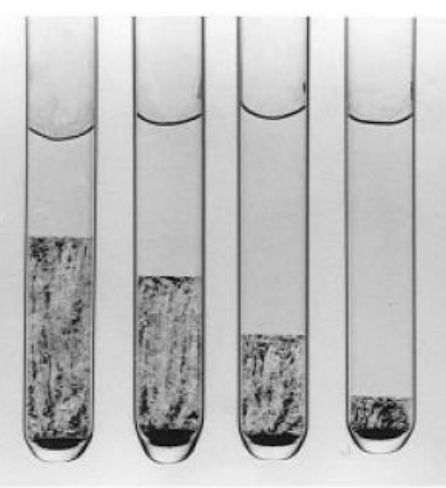

(b)

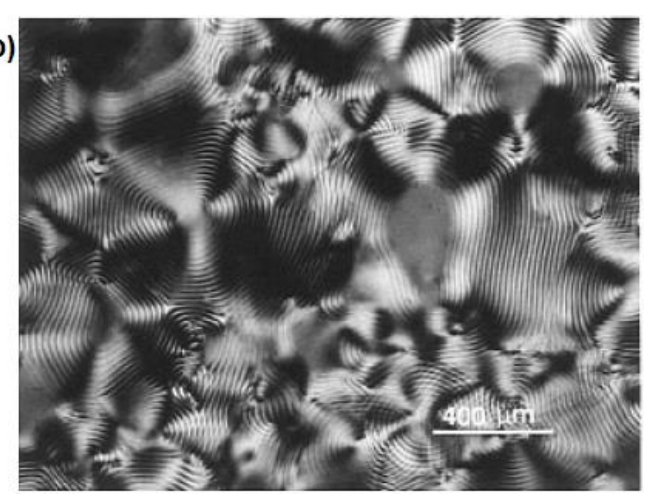

Fonte: [45] 
Vários fatores, como tamanho, forma, temperatura, dispersibilidade, carga, eletrólitos e estímulos externos afetam a formação da fase líquido-cristalina. A razão de aspecto das nanopartículas, entretanto, é a principal variável na determinação da concentração crítica, além de fatores como a força iônica, a natureza dos contra-íons, que também influenciam significativamente nesta formação ${ }^{[39]}$. De um modo geral, as propriedades líquido-cristalinas das NCs são mais facilmente observadas em baixas forças iônicas, em suspensões de nanopartículas relativamente curtas isoladas por hidrólise ácida. Suspensões de nanopartículas maiores tendem a gelificar antes de atingir o equilíbrio líquido-cristalino. ${ }^{[44,45]}$

Todas as propriedades citadas neste e nos itens anteriores correspondem ao conjunto de interesses que fazem com que as nanopartículas de celulose sejam exaustivamente estudadas para aplicação em nanocompósitos de matriz polimérica.

\subsection{Biopolímeros e polímeros biodegradáveis}

Polímeros biodegradáveis são polímeros nos quais a ação de microrganismos de ocorrência natural, como bactérias, fungos e algas, podem promover a degradação ${ }^{[46]}$, podendo ser consumidos em semanas ou meses sob condições favoráveis de biodegradação. [47]

A biodegradação pode ocorrer tanto na presença como na ausência de oxigênio (biodegradação aeróbica e anaeróbica, respectivamente). Estes processos são representados pelas reações abaixo:

$$
\begin{gathered}
\mathrm{C}_{\text {POLÍMERO }}+\mathrm{O}_{2} \stackrel{\text { Biodegradação Aeróbica: }}{\longrightarrow} \mathrm{CO}_{2}+\mathrm{H}_{2} \mathrm{O}+\mathrm{C}_{\mathrm{RESIIDUO}}+\mathrm{C}_{\mathrm{BIOMASSA}} \\
\text { Biodegradação Anaeróbica: } \\
\mathrm{C}_{\text {POLÍMERO }} \longrightarrow \mathrm{CO}_{2}+\mathrm{CH}_{4}+\mathrm{H}_{2} \mathrm{O}+\mathrm{C}_{\mathrm{RESIIDUO}}+\mathrm{C}_{\mathrm{BIOMASSA}} \\
\text { Fonte: (BASTIOLI, 2005) }
\end{gathered}
$$

Já os biopolímeros são denominados polímeros ou copolímeros produzidos a partir de matérias-primas de fontes renováveis, como: cana-de-açúcar, milho, quitina, celulose, e outras. ${ }^{[48]}$ Denominam-se fontes renováveis aquelas que possuem um ciclo de vida mais curto comparado com fontes fósseis, como o petróleo, o qual leva milhares de anos para se formar. ${ }^{[2]}$ 
Apesar de todas as vantagens, os biopolímeros possuem uma difícil processabilidade, devido às suas limitações térmicas e mecânicas. Assim, muitos estudos têm se dedicado à modificação dos biopolímeros na viabilização do processamento e utilização dos mesmos em diversas aplicações. ${ }^{[49]}$ Para isso, foram desenvolvidas blendas poliméricas ${ }^{[50]}$, compósitos poliméricos ${ }^{[51,52]}$ e nanocompósitos poliméricos ${ }^{[33,54]}$, que apresentam melhorias nas propriedades de processabilidade, resistência térmica, propriedades mecânicas, propriedades reológicas, permeabilidade a gases e taxa de degradação. ${ }^{[2]}$

\subsection{O poli(ácido lático)- PLA}

O poli(ácido lático) - PLA é um poliéster alifático, termoplástico, semicristalino ou amorfo, biocompatível e biodegradável, sintetizado a partir do ácido lático, que pode ser obtido de fontes renováveis. Entretanto o PLA pode ser também obtido pelo monômero de lactídeo, que então poderá ser chamado de poli lactídeo. ${ }^{[2,55,56]} \mathrm{A}$ estrutura molecular do PLA é apresentada na Figura 12.

Figura 12- Estrutura molecular do poli(ácido lático).

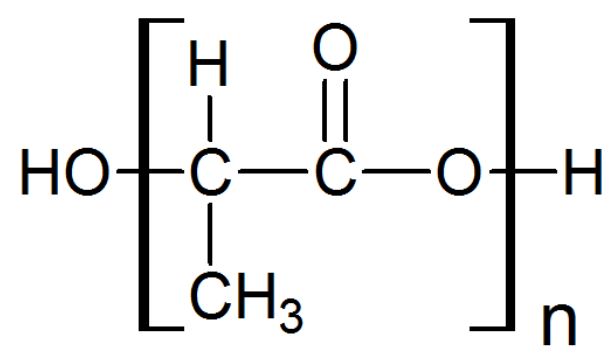

Fonte: [56]

A estrutura do mero do PLA contém variações quanto à isomeria óptica. Deste modo, tanto o poli(ácido lático) como o polilactídeo podem ser obtidos pelos dois enantiômeros do ácido lático e lactídeo, o $L(+)$ e $D(-)$, denominados PLLA e PDLA, respectivamente. Haverá a possibilidade também de uma mistura racêmica entre os dois enantiômeros para cada monômero, formando o PDLLA. ${ }^{[55]}$ Os enantiômeros do ácido lático são apresentados na Figura 13. 
Figura 13- Isômeros ópticos da molécula de ácido lático.<smiles>C[C@@H](O)C(=O)O</smiles>

L(+) Ácido Lático<smiles>C[C@H](O)C(=O)O</smiles>

D(-) Ácido Lático

Fonte: [3] modificado

O poli-L ácido lático e o poli-D ácido lático, respectivamente, levogiro (+) e dextrogiro (-), referente ao sentido de rotação da luz plano-polarizada, são polímeros de alta cristalinidade, devido à alta estereorregularidade, ou taticidade, da cadeia polimérica, enquanto que o PDLLA é completamente amorfo. ${ }^{[2,55,56]}$

Os polímeros à base de ácido lático são preparados por policondensação, polimerização de abertura de anel e outros métodos como extensão da cadeia e grafting. O PLA de alta massa molar geralmente é produzido pela polimerização por abertura de anel do monômero de lactídeo. A conversão de lactídeo em PLA de elevada massa molar é obtido comercialmente através de um processo desenvolvido pela Cargill Dow ${ }^{\mathrm{TM}}$, que consiste em três etapas separadas e distintas, que conduzem à produção de ácido lático e lactídeo em PLA. ${ }^{[2,55,56]}$ O processo pode ser representado esquematicamente pela Figura 14.

Figura 14- Rota de obtenção do Poli (ácido lático) pelo processo da Cargill Dow ${ }^{\mathrm{TM}}$.<smiles>C[C@@H](O)C(=O)O</smiles>

Ácido Lático

$\mid \begin{aligned} & \text { Condensação } \\ & -\mathrm{H}_{2} \mathrm{O}\end{aligned}$<smiles>CC(C)O[C@@H](C)C(=O)C(C)(C)C</smiles>

PLA (Mn 5000)

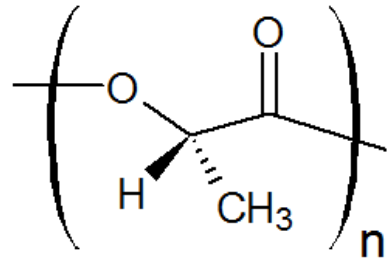

PLA de alto peso molecular $\begin{aligned} & \text { Polimerização por } \\ & \text { abertura de anel }\end{aligned} \| \begin{aligned} & \text { Livre de } \\ & \text { Solventes }\end{aligned}$<smiles>C[C@@H]1OC(=O)[C@H](C)OC1=O</smiles>

Fonte: [56] 
Conforme descritas na Figura 14, tanto a polimerização do PLA de baixa massa molar como a polimerização do PLA de alta massa molar, parte da molécula de ácido lático. Entretanto, obtenção do PLA de alta massa molecular é realizada a partir da despolimerização controlada do PLA de baixa massa molar na obtenção da molécula de lactídeo, que possui estrutura cíclica. Assim, a polimerização catalítica por abertura de anel da molécula intermediária de lactídeo resulta na produção do PLA com massa molar controlada. O processo é contínuo, não havendo necessidade de uma etapa de separação da molécula intermediária. ${ }^{[56]}$

\subsubsection{Propriedades do PLA}

O PLA, se comparado aos plásticos commodities, é um polímero de alta resistência à tração, um termoplástico biodegradável, compatível com a biosfera e obtido a partir de fontes renováveis. Dependendo do tipo de isômeros utilizados na sua polimerização, podem ocorrer diferenças nos valores das propriedades mecânicas, térmicas e mesmo ópticas dos diferentes tipos de PLA (PDLA, PLLA e PDLLA) discutidos anteriormente. Comercialmente, é possível encontrar os três tipos de PLA, sendo que o PLLA e PDLA são mais utilizados para aplicações tecnológicas, nas quais maiores propriedades mecânicas e termomecânicas são requeridas, ao passo que o PDLLA (mistura racêmica) é tipicamente utilizado para aplicações biomédicas. ${ }^{[3,57]}$ No Brasil, a empresa Nature Works ${ }^{\mathrm{TM}}$ que fornece o chamado INGEO ${ }^{\circledR}$ biopolymer, que é o PLA indicado nas aplicações de engenharia. Este produto, que foi utilizado neste trabalho, é produzido na maior parte com isômeros ácido lático $\mathrm{L}(+)$, e uma pequena porcentagem (menor que 5\%) de isômeros ácido lático $\mathrm{D}(-)$. Logo, este tipo comercial de PLA pode ser considerado como PLLA, cujas propriedades e características gerais serão discutidas a seguir.

\subsubsection{Propriedades mecânicas do PLLA}

Os principais valores das propriedades mecânicas do PLLA com diferentes massas molares são apresentados na Tabela 3. 
Tabela 3 - Propriedades mecânicas do PLLA com diferentes massas molares.

\begin{tabular}{lcccccc}
\hline \multicolumn{1}{c}{ Propriedade } & \multicolumn{2}{c}{ PLLA I } & \multicolumn{2}{c}{ PLLA II } & \multicolumn{2}{c}{ PLLA III } \\
\hline Tratamento térmico a 105 ${ }^{\circ} \mathrm{C}$ & Não & Sim & Não & Sim & Não & Sim \\
Massa Molar (M $\left(\mathrm{M}_{\mathrm{v}}\right.$ g/mol) & 23000 & 20000 & 58000 & 47000 & 67000 & 71000 \\
Temperatura de fusão $\left({ }^{\circ} \mathrm{C}\right)$ & 178 & 178 & 179 & 180 & 181 & 178 \\
Cristalinidade (\%) & 9 & 70 & 9 & 52 & 3 & 45 \\
Propriedades mecânicas: & & & & & & \\
$\quad$ Resistência ao escoamento (MPa) & - & - & 68 & 68 & 70 & 70 \\
$\quad$ Resistência à tração (MPa) & 59 & 47 & 58 & 59 & 59 & 66 \\
$\quad$ Elongação na ruptura (\%) & 1,5 & 1,3 & 5,0 & 3,5 & 7,0 & 4,0 \\
$\quad$ Módulo de Elasticidade (MPa) & 3550 & 4100 & 3750 & 4050 & 3750 & 4150 \\
\hline
\end{tabular}

Fonte: [3]

As amostras para os ensaios mecânicos são obtidas, geralmente, pelo método de injeção. Devido ao fato de o PLLA apresentar baixa cinética de cristalização, o tratamento térmico feito com os corpos de prova no molde de injeção próximo a sua temperatura de cristalização (em torno de $105^{\circ} \mathrm{C}$ ) causa um aumento do grau de cristalinidade, resultando em um material mais rígido, ou seja, com maiores valores do módulo de elasticidade $(E)$ e menores valores de elongação na ruptura $^{[3,57]}$, como é observado na Tabela 3.

A massa molar do PLA, por sua vez, é uma das principais propriedades que influenciam na resistência mecânica deste biopolímero, e foi vastamente estudada na literatura. De acordo com diversos estudos ${ }^{[3,58-60]}$, o aumento da massa molar de 107.000 a $550.000 \mathrm{~g} / \mathrm{mol}$ resulta em um aumento de $20 \%$ na resistência à tração. No entanto, em materiais de elevadas massas moleculares, a variação de propriedades mecânicas torna-se menos evidente.

De modo geral, os diferentes métodos utilizados na preparação das amostras para as análises podem contribuir para diferentes propriedades mecânicas. Entretanto, os dados apresentados na literatura são consistentes em mencionar que - PLA possui um alto módulo de elasticidade, elevada resistência à tração e baixa deformabilidade, se comparado a termoplásticos comuns. ${ }^{[3]}$

\subsubsection{Propriedades térmicas e cristalização do PLLA}

O PLLA puro, assim como o PDLA, possui temperatura de transição vítrea $\left(T_{g}\right)$ entre 50 e $70{ }^{\circ} \mathrm{C}$, temperatura de fusão $\left(T_{m}\right)$ entre 170 e $190 \stackrel{\circ}{ } \mathrm{C}$, e grau de cristalinidade de até 35\%. ${ }^{[57,61-63]}$ 
A Figura 15 apresenta uma curva de DSC obtida por calorimetria exploratória diferencial (DSC) de um PLLA comercial com um peso molecular de $200 \mathrm{kDa}$, submetido a três ciclos: (i) aquecimento de 0 a $220^{\circ} \mathrm{C}$, (ii) resfriamento de 220 a $0 \stackrel{\circ}{ } \mathrm{C}$, e finalmente (iii) aquecimento de 0 a $220^{\circ} \mathrm{C} .{ }^{[57]}$

Figura 15- Curva de DSC para o PLLA de peso molecular de $200 \mathrm{kDa}$, a taxa de $10^{\circ} \mathrm{C} / \mathrm{min}$.

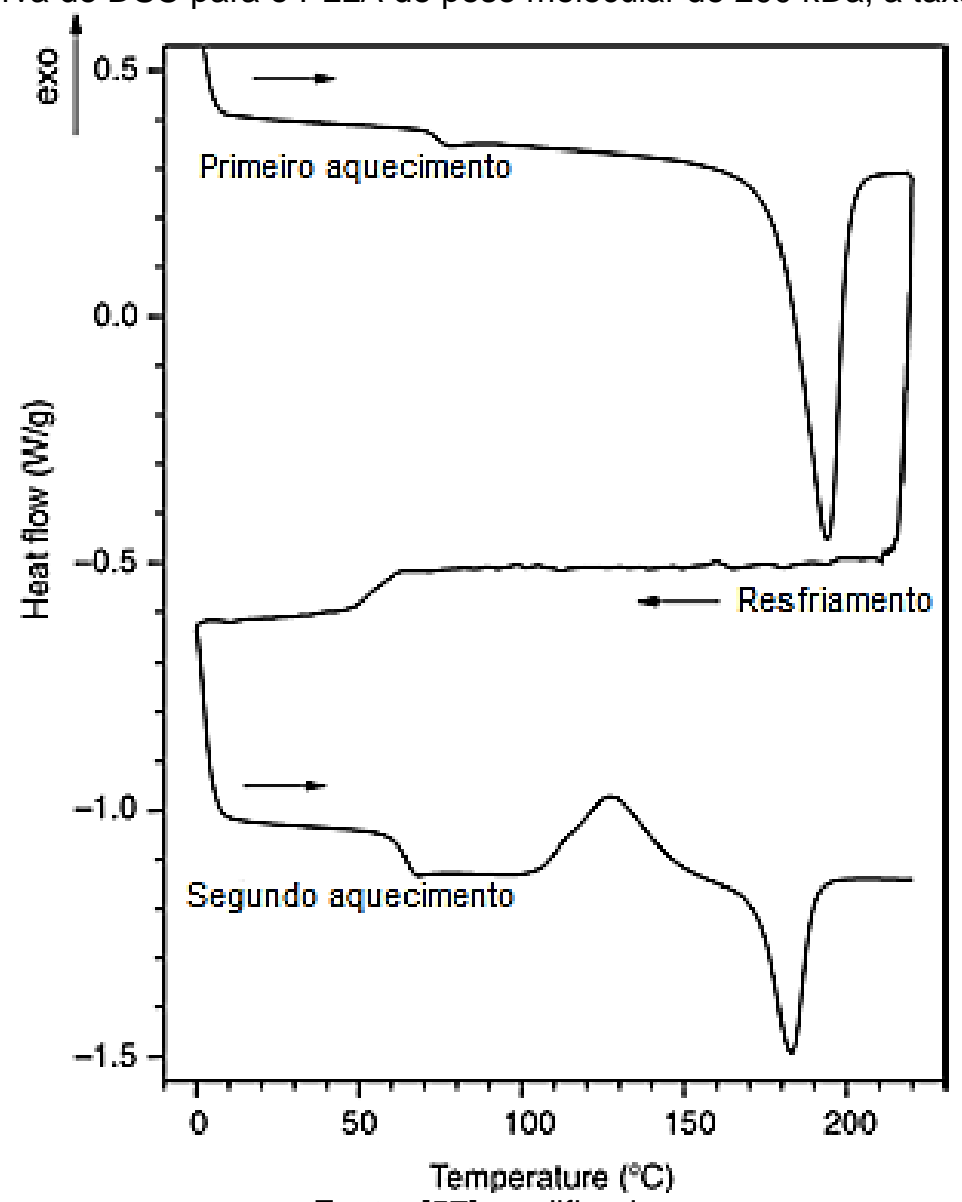

Fonte: [57] modificado.

O polímero inicialmente cristalino apresentava uma $T_{g}$ de $73^{\circ} \mathrm{C}$ e $T_{m}$ de $192{ }^{\circ} \mathrm{C}$. Durante o resfriamento, aparentemente sem pico de cristalização, o comportamento térmico do PLLA, agora inicialmente amorfo, mostra uma $T_{g}$ de $64{ }^{\circ} \mathrm{C}$, temperatura de cristalização $\left(T_{c}\right)$ de $127{ }^{\circ} \mathrm{C}$ e $T_{m}$ de $181{ }^{\circ} \mathrm{C}$. ${ }^{[57]}$

Entretanto, uma das características do PLA que mais influenciam em suas propriedades térmicas é o valor do peso molecular. A Tabela 4 apresenta os valores de $T_{g}, T_{m}, T_{c}$, entalpia de fusão $\left(\Delta H_{m}\right)$ e de cristalização $\left(\Delta H_{c}\right)$ para amostras de PLLA de diversos pesos moleculares (2, 30, e $200 \mathrm{kDa}$ ), submetidas aos mesmos ciclos térmicos, obtidos por DSC, apresentados na Figura 15. ${ }^{[57]}$ 
Tabela 4- Temperatura de transição vítrea $\left(T_{g}\right)$, temperatura de fusão $\left(T_{m}\right)$ e entalpia de fusão e cristalização $\left(\Delta \mathrm{H}_{\mathrm{m}}\right.$ e $\left.\Delta \mathrm{H}_{\mathrm{c}}\right)$ para o PLLA com diferentes pesos moleculares durante análise de DSC com ciclos de aquecimento/resfriamento entre 0 e $220^{\circ} \mathrm{C}$ à taxa de $10^{\circ} \mathrm{C} / \mathrm{min}$.

\begin{tabular}{ccccc}
\hline \multicolumn{5}{c}{ (i) Primeiro Aquecimento } \\
\hline $\mathrm{M}_{\mathrm{w}}(\mathrm{kDa})$ & $\mathrm{T}_{\mathrm{g}}\left({ }^{\circ} \mathrm{C}\right)$ & $\mathrm{T}_{\mathrm{m}}\left({ }^{\circ} \mathrm{C}\right)$ & $\Delta \mathrm{H}_{\mathrm{m}}(\mathrm{J} / \mathrm{g})$ & $\mathrm{X}(\%)$ \\
\hline 2 & 58 & 147 & 48 & 51 \\
30 & 79 & 171 & 68 & 73 \\
200 & 73 & 192 & 67 & 72 \\
\hline \multicolumn{5}{c}{ (ii) Resfriamento } \\
\hline $\mathrm{M}_{\mathrm{w}}(\mathrm{kDa})$ & $\mathrm{T}_{\mathrm{c}}\left({ }^{\circ} \mathrm{C}\right)$ & $\Delta \mathrm{H}_{\mathrm{c}}(\mathrm{J} / \mathrm{g})$ & $\mathrm{T}_{\mathrm{g}}\left({ }^{\circ} \mathrm{C}\right)$ \\
\hline 2 & - & - & 39 \\
30 & & - & 21 & 50 \\
200 & & - & - & 55 \\
\hline
\end{tabular}

(iii) Segundo Aquecimento

\begin{tabular}{ccccccc}
\hline $\mathrm{M}_{\mathrm{w}}(\mathrm{kDa})$ & $\mathrm{T}_{\mathrm{g}}\left({ }^{\circ} \mathrm{C}\right)$ & $\mathrm{T}_{\mathrm{c}}\left({ }^{\circ} \mathrm{C}\right)$ & $\Delta \mathrm{H}_{\mathrm{c}}(\mathrm{J} / \mathrm{g})$ & $\mathrm{T}_{\mathrm{m}}\left({ }^{\circ} \mathrm{C}\right)$ & $\Delta \mathrm{H}_{\mathrm{m}}(\mathrm{J} / \mathrm{g})$ & $\mathrm{X}(\%)$ \\
\hline 2 & 43 & 107 & 9 & 142 & 9 & 0 \\
30 & 55 & 97 & 21 & 174 & 50 & 31 \\
200 & 64 & 127 & 25 & 181 & 26 & 1 \\
\hline
\end{tabular}

Fonte: [57]

O grau de cristalinidade $(X)$ foi avaliado a partir dos dados experimentais de DSC, de acordo com a seguinte equação ${ }^{[3]}$ :

$$
X \%=\frac{100\left(\Delta H_{m}-\Delta H_{c}\right)}{\Delta H_{m}^{0}}
$$

Onde: $\Delta \mathrm{H}_{\mathrm{m}}$ e $\Delta \mathrm{H}_{\mathrm{c}}$ são, respectivamente, as entalpias de fusão e cristalização; $\Delta \mathrm{H}_{\mathrm{m}}^{0}$ é a entalpia de fusão para o PLLA $100 \%$ cristalino $(93,6 \mathrm{~J} / \mathrm{g}) .{ }^{[57,64]}$

Durante o primeiro aquecimento, de acordo com a Tabela 4, os valores de $\mathrm{T}_{\mathrm{g}}$ para todas as amostras de PLLA são mais elevados do que o esperado devido ao elevado teor inicial de cristalinidade, uma vez que os domínios cristalinos dificultam a mobilidade das cadeias amorfas. Também é interessante notar que, durante o resfriamento do PLLA (30 kDa) foi observado um pico de cristalização, enquanto nos outros casos este foi inibido pelo alto teor de grupos terminais que atuaram como defeitos em PLLA (2 kDa), e pela baixa mobilidade das longas cadeias do PLLA (200 kDa). ${ }^{[57]}$

Durante o segundo aquecimento, todos os polímeros apresentaram grau de cristalização, $T_{g}$ e $T_{m}$ diretamente dependentes do peso molecular da amostra de PLLA. O menor valor de $T_{c}$ do PLLA (30 kDa) é atribuível à sua cristalinidade, antes 
do segundo ciclo de aquecimento. A estrutura cristalina do primeiro ciclo térmico atuou como agente nucleante, promovendo a cristalização precocemente, no segundo ciclo. ${ }^{[57]}$

Apesar da grande influência do peso molecular do PLLA em suas propriedades térmicas, estudos realizados [57,63,65] mostram que diferentes tratamentos térmicos podem produzir diferentes resultados.

\subsubsection{Processamento do PLA}

Para o processamento do PLA é importante o conhecimento das características de $T_{m}$ e $T_{g}$, já discutidas anteriormente. Na extrusão, a temperatura de processo deve ser superior à $T_{m}$ para formar um material homogêneo, mas baixa o suficiente para minimizar a degradação térmica do polímero. Devido à distribuição do tamanho dos cristalitos não ser completamente uniforme, a fusão do PLA, na verdade, ocorre ao longo de um intervalo de temperaturas. Como regra geral, a temperatura de processo ocorre entre as temperaturas de $40-50 \stackrel{\circ}{ } \mathrm{C}$ acima da $T_{m}$ para assegurar que a fase cristalina está completamente fundida. ${ }^{[66,67]}$

Quando o material é conformado, o tempo de resfriamento no molde deve ser suficiente para a estabilização das dimensões, em temperaturas abaixo da sua $T_{g}$. Entretanto, é possível melhorar as propriedades físicas, como por exemplo, na orientação biaxial de filme ou no estiramento de sopro para moldagem de garrafas, nas quais as temperaturas de operação são geralmente definidas acima da $T_{g}$, mas bem abaixo da $T_{m}$, para manter o PLA em um estado elástico e suficientemente flexível para conformação, induzindo sua orientação. ${ }^{[63]}$

\subsubsection{Aplicações do PLA}

Polímeros a base de PLA podem ser aplicados em muitas áreas, como a de embalagens, filmes, fibras têxteis, área ambiental e na biomedicina, que consiste na área de sua maior aplicação atualmente. ${ }^{[15,68]}$

O desenvolvimento de fibras de PLA ainda é recente e, em comparação com fibras convencionais, sua substituição por fibras sintéticas à base de petróleo não possuem grande viabilidade econômica. No entanto, as propriedades das fibras de PLA são promissoras para muitas aplicações na indústria têxtil. Melhorias 
tecnológicas tanto na redução de custos de produção/transformação quanto no seu desempenho já são objetos de estudos. ${ }^{[68-70]}$

Quanto às aplicações ambientais, uma das mais promissoras envolve a utilização de substratos sólidos de PLA e até outros biopolímeros biodegradáveis em processos redox microbianos, para tratamento de água e águas residuais, como os processos de desnitrificação. A eficiência na remoção de nitrogênio no processo de desnitrificação utilizando-se o PLA é tão elevada como o do sistema baseado no polihidroxialcanoato (PHA). ${ }^{[68,71,72]}$

O PLA tem sido aplicado com sucesso na medicina ao longo das últimas décadas, especialmente em aplicações ortopédicas. Em geral, é utilizado o PDLLA, pelo fato deste apresentar menor tempo de biodegradação. No entanto, alguns problemas ainda estão associados a estes implantes, tais como degradação lenta e elevada hidrofobicidade, o que faz com que sua aplicação seja limitada. Inúmeras pesquisas estão em andamento a fim de superar estes problemas, como por exemplo, produzindo-se copolímeros e blendas. ${ }^{\text {[68,73-75] }}$

Além disso, o PLA, de modo geral, é um material promissor e sustentável, podendo substituir alguns termoplásticos provindos do petróleo em aplicações tais como embalagens, peças automotivas e até mesmo em peças para componentes eletrônicos. No entanto, a expansão das aplicações do PLA, a melhoria da resistência térmica, resistência ao impacto e durabilidade ainda são necessários. ${ }^{\text {[68] }}$

Para isso, há cada vez mais estudos a respeito da utilização do PLA como matriz polimérica em nanocompósitos, o que será discutido brevemente, a seguir.

\subsection{Nanocompósitos de matriz polimérica}

Atualmente, a adição de uma segunda fase orgânica ou inorgânica em uma fase polimérica, produzindo um compósito, é uma prática comum na indústria de plásticos. Os nanocompósitos poliméricos, por sua vez, representam uma alternativa mais promissora do que os compósitos poliméricos convencionais. ${ }^{[76,77]}$

Os nanocompósitos são materiais compósitos que possuem um componente que tem ao menos uma dimensão na escala nanométrica, sendo esta compreendida até $100 \mathrm{~nm}$. Embora também possam ser de matriz cerâmica e metálica, os nanocompósitos de matriz polimérica são os mais comuns, sendo os polímeros 
reforçados com nanopartículas de argila os nanocompósitos mais encontrados comercialmente. ${ }^{[76,78]}$

Os trabalhos mais relevantes sobre nanocompósitos, publicados nos últimos 15 anos, apresentam uma duplicação nos valores de módulo de elasticidade da fase matriz, em função da adição de nanocargas, sem afetar a resistência ao impacto, quando comparados aos compósitos formados pelos mesmos materiais. Além disso, estudos relatam que estes reforços podem aumentar a temperatura de distorção térmica da matriz polimérica em mais de $100{ }^{\circ} \mathrm{C}$, estendendo o uso destes nanocompósitos a aplicações que exigem altas temperaturas, como por exemplo, peças automotivas. ${ }^{[76,77]}$

Além de melhorias nas propriedades dos materiais, geralmente os nanocompósitos são facilmente extrudados ou moldados à forma final, simplificando a produção industrial. Como alto grau de rigidez e resistência são obtidos com baixas concentrações de carga, até cerca de 10\% em massa, estes materiais são muito mais leves que os compósitos poliméricos convencionais, resultando num grande benefício para aplicações em que leveza se torna essencial, como por exemplo, na indústria aeronáutica, automobilística e de embalagens. ${ }^{[77,78]}$

Comercialmente, os nanocompósitos apresentam várias vantagens, quando comparados aos polímeros sem adição de carga, permitindo sua viabilidade comercial. ${ }^{[76,77]}$ Dentre elas, pode-se citar:

- Reforço eficiente com perdas mínimas em ductilidade e resistência ao impacto;

- Aumento em resistência térmica;

- Aumento em resistência à chama;

- Aumento nas propriedades de barreira;

- Aumento na resistência à abrasão;

- Aumento da estabilidade dimensional, e redução da tensão residual de peças moldadas;

- Alterações nas propriedades elétricas e ópticas.

Devido a todas estas melhorias nas propriedades das matrizes poliméricas, as nanocargas consistem em materiais promissores para o desenvolvimento de 
nanocompósitos que possuam propriedades únicas e essenciais para diversas aplicações. ${ }^{[77]}$

Por este motivo, além do desenvolvimento de melhores técnicas de processamento, métodos de caracterização também vêm sendo amplamente estudados na avaliação da influência das nanocargas na matriz polimérica. Desse modo, técnicas complementares às análises morfológicas, como é o caso das análises reológicas, podem ser utilizadas na compreensão da dispersão do reforço da matriz polimérica. Assim, será discutido a seguir, os estudos reológicos aplicados a nanocompósitos.

\subsubsection{Reologia de Nanocompósitos}

A reologia consiste no estudo do comportamento deformacional e do fluxo de matéria submetido a tensões, em determinadas condições termodinâmicas ao longo de um intervalo de tempo. Ela relaciona propriedades tais como elasticidade, viscosidade e plasticidade dos materiais. ${ }^{[79]}$

Para os materiais poliméricos, o estudo reológico é realizado no estado fundido e seu comportamento consiste de fluidos viscoelásticos. Neste estado, o polímero é submetido a vários tipos de deformações, assim como no seu processamento. Com isso, é possível se determinar a morfologia e outras propriedades através destas deformações. Tais deformações podem ser de diversos tipos, como de cisalhamento, quando as superfícies paralelas do polímero se deslocam uma em relação à outra; ou de extensão, quando o polímero fluido é submetido à elongação. De acordo com a magnitude e intensidade destas deformações, o polímero terá um comportamento no regime de viscoelasticidade linear (VEL) ou não linear (VENL). ${ }^{[79,80]}$

O comportamento VEL é considerado o mais simples. Isto porque o desenvolvimento da teoria matemática de viscoelasticidade linear baseia-se no "princípio da sobreposição", o que implica que a resposta (por exemplo, a deformação), a qualquer momento é diretamente proporcional ao valor de estímulo inicial (por exemplo, a tensão). Ela é aplicável apenas quando a solicitação mecânica inicial for, ao mesmo tempo, muito lenta e extremamente pequena, não sendo possível, que a configuração de equilíbrio das macromoléculas do polímero seja perturbada. Na teoria linear de viscoelasticidade, as equações diferenciais são 
lineares. A VEL é importante principalmente para o estudo da microestrutura dos materiais em seu estado de equilíbrio, sendo considerado um método de caracterização de morfologia. ${ }^{[79-81]}$

O comportamento de viscoelaticidade não linear (VENL) é mais complexo, pois as propriedades reológicas dos polímeros passam a depender da magnitude de deformação, da taxa de deformação e da cinemática da deformação. ${ }^{\left[{ }^{80,82]}\right.}$ Isto porque as deformações maiores fazem com que as macromoléculas saiam de seu estado de equilíbrio. Desta forma, além das propriedades estruturais, o estudo da VENL é utilizado no conhecimento das propriedades de processamento dos polímeros, uma vez que, durante o processamento, os materiais poliméricos estão sempre no regime de VENL. ${ }^{[80,81]}$ No entanto, como o foco deste trabalho é a obtenção de nanocompósitos e o estudo de sua morfologia, optou-se por utilizar apenas o estudo reológico no regime de VEL.

Um dos principais ensaios realizados para se avaliar um comportamento de polímeros dentro do regime de VEL é o cisalhamento oscilatório de pequenas amplitudes (COPA). Através deste ensaio, pode-se determinar propriedades dos polímeros tais como o módulo de armazenamento ( $\left.G^{\prime}\right)$, que se refere à resposta elástica do material, o módulo de perda (G"), referente à resposta viscosa do material, e o módulo da viscosidade complexa $\left(\left|\eta^{*}\right|\right)$ em função da frequência de oscilação $(\omega)$. No ensaio de COPA, o material é submetido a uma deformação oscilatória $(\gamma(t))$ constante e de amplitude constante. A deformação e a tensão são defasadas por um ângulo $\delta$ em virtude do comportamento viscoelástico do polímero, como apresentado na equação ${ }^{[79-81]}$ :

$$
\begin{gathered}
\gamma(t)=\gamma_{0} \operatorname{sen}(\omega t) \\
\sigma(t)=\sigma_{0} \operatorname{sen}(\omega t+\delta)
\end{gathered}
$$

Onde $Y_{0}$ é a amplitude de cisalhamento, $\omega$ é a frequência de cisalhamento, t é o tempo, $\sigma(\mathrm{t})$ é a tensão de cisalhamento em função do tempo e $\sigma_{0}$ é amplitude de tensão de cisalhamento.

Uma vez calculada a tensão, dois módulos podem ser deduzidos: 


$$
\begin{gathered}
G^{\prime}=\frac{\sigma_{0}}{\gamma_{0}} \cos \delta \\
G^{\prime \prime}=\frac{\sigma_{0}}{\gamma_{0}} \operatorname{sen} \delta \\
\left|\eta^{*}\right|=\frac{\sqrt{\left(G^{\prime}\right)^{2}+\left(G^{\prime \prime}\right)^{2}}}{\omega}
\end{gathered}
$$

Onde G' é o módulo de armazenamento, G" é o módulo de perda e $\eta^{*}$ é a viscosidade complexa.

Uma vez que as propriedades reológicas de nanocompósitos são sensíveis às características da estrutura, tamanho das partículas, forma e superfície da nanocarga, a análise reológica é intensivamente utilizada na avaliação do estado de dispersão de nanocompósitos no estado fundido. ${ }^{\text {[83] }}$

Devido às medições viscoelásticas serem altamente sensíveis às estruturas em nanoescala e mesoescala de materiais poliméricos, quando combinadas com análises de difração de raios $X$, microscopia eletrônica, análises térmicas e mecânicas, fornecem uma compreensão fundamental do estado e do mecanismo da dispersão da carga em uma matriz de polímero. Além disso, a compreensão das propriedades reológicas dos nanocompósitos políméricos é crucial para o desenvolvimento da aplicação e avaliação da capacidade de processamento dos polímeros. ${ }^{[84]}$

De um modo geral, foi realizado um estudo ${ }^{[84]}$ que apresenta de forma sistemática o modo no qual a dispersão da carga pode afetar o comportamento reológico da matriz polimérica durante o ensaio de COPA. Deste modo, de acordo com a inclinação das curvas G' e G" é possível se correlacionar tal comportamento com o grau de dispersão da carga em compósitos e nanocompósitos, como é representado pela Figura 16. 
Figura 16- Representação esquemática da resposta reológica esperada para o aumento do número de partículas por unidade de volume.

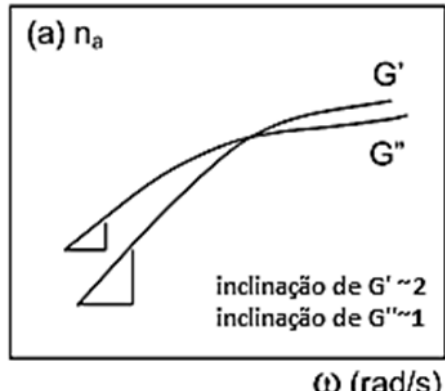

n= número de partículas por unidade de volume $n^{\rho}=$ Limite de percolação

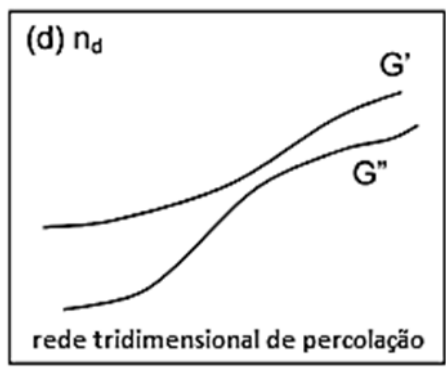

$\omega(\mathrm{rad} / \mathrm{s})$

$n_{b}>n_{a}$

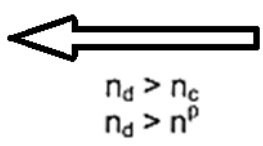

$n_{d}>n^{p}$
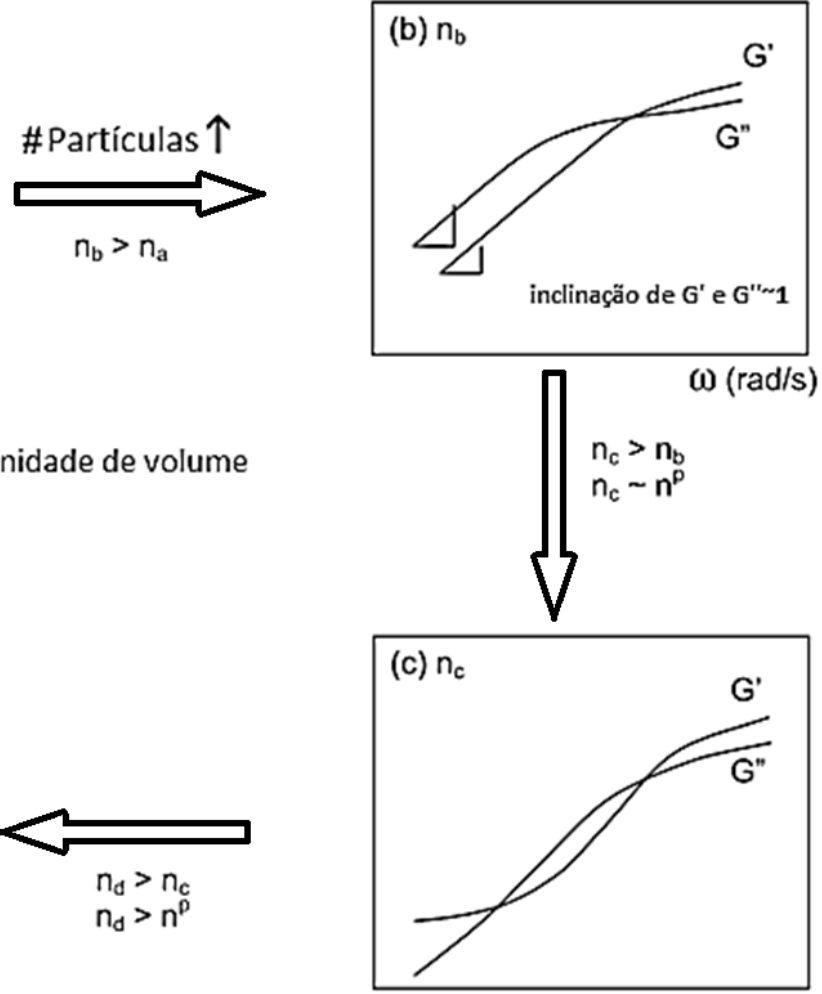

$\omega(\mathrm{rad} / \mathrm{s})$

Fonte: [84] modificado

A relação entre o comportamento reológico e a microestrutura do compósito pode ser estabelecida através de quatro tipos de respostas reológicas. A Figura 16(a) apresenta curvas típicas para homopolímeros. Neste caso, para alta taxas de cisalhamento o polímero possui uma resposta elástica, ou comportamento de sólido, visto que o módulo de G' é maior que o de G". O cruzamento das duas curvas é chamado de cross over, a partir do qual o comportamento se inverte e, neste caso, para baixas frequências o polímero se comporta como um liquido viscoso (G'>G'), sendo que, na região terminal, G' tem inclinação 1 e G' 2. Para o caso de um compósito apresentar tal resposta, pode-se afirmar que a carga não influencia no comportamento da fase matriz e a microestrutura predominante é de um microcompósito. ${ }^{[80,84]}$

Na Figura 16(b) é observado uma diminuição da inclinação da curva G' de 2 para 1 quando há um aumento da dispersão da carga na fase matriz. Isso indica que a carga está dificultando a movimentação molecular das cadeias poliméricas. Neste caso, a microestrutura predominante é de nanocompósito, que ainda apresenta grandes aglomerados de carga ao longo da fase matriz. 
Na Figura 16(c), observa-se que as inclinações das curvas do G' e G" tendem a 0 e ocorre o aparecimento do segundo cross over, indicando uma inversão do comportamento para baixas taxas onde G'>G", isto é, o número de partículas por unidade de volume atingiu o limite de percolação, e as partículas formam uma rede tridimensional, segurando as cadeias poliméricas e impedindo sua movimentação. ${ }^{[80,84]}$

A Figura 16(d) apresenta outro tipo de comportamento, no qual o módulo G' é maior do que o G" para todas as frequências. Isso indica que se ultrapassou o limite de percolação, e o nanocompósito tem uma resposta parecida com um sólido ao longo de todo o ensaio. ${ }^{[80,84]}$

Além das curvas G' e G", a viscosidade complexa $\left(\eta^{*}\right)$ também é outro parâmetro que se altera com o aumento de dispersão da carga na fase matriz. Com o aumento da dispersão, há o deslocamento do platô newtoniano (região linear da curva) observado para baixas taxas de cisalhamento, e o comportamento pseudoplástico existente para altas frequências passa a ser também observado em menores frequências. ${ }^{[84]}$

\subsubsection{Nanocompósitos de PLA reforçados com nanopartículas de celulose}

Desde o primeiro trabalho sobre a utilização de NCs em nanocompósitos de matriz de poli(estireno-co-butil-acrilato) por Favier et al. ${ }^{[85]}$, a nanocelulose atraiu e continua a atrair grande interesse na área de nanocompósitos, devido às suas propriedades intrínsecas como dimensões em nanoescala, grande área superficial, morfologia única, de baixa densidade e alta resistência mecânica, como já discutido anteriormente.

Além disso, como são facilmente disponíveis, de fonte renovável e biodegradáveis, as nanopartículas de celulose foram incorporadas numa grande variedade de matrizes de polímeros, incluindo o PLA. No entanto, o maior desafio da incorporação de NCs em matriz PLA tem sido a obtenção de uma elevada dispersão das nanopartículas no interior da matriz. De fato, a natureza hidrofílica das NCs dificulta sua dispersão em matriz relativamente hidrofóbica, tal como o PLA ou em solventes apolares comuns, e, consequentemente, as partículas de nanocelulose podem aglomerar. Isto faz com que resultados bem sucedidos sobre obtenção de compósitos à base de PLA e nanocelulose sejam raramente relatados. ${ }^{[86]}$ 
A literatura ${ }^{[4,86-89]}$ apresenta estudos sobre a utilização de surfactantes, com o objetivo de modificar a superfície dos NCs, e melhorar a interação entre carga e matriz, evitando aglomerados e aumentando a dispersão do reforço. A modificação é realizada, na maioria das vezes, por adição dos surfactantes, em dispersões contendo NCs e água ou solventes orgânicos, sob agitação constante. O aumento da temperatura muitas vezes é utilizado, e após um determinado tempo a reação é interrompida e a solução é centrifugada a altas rotações, para que o surfactante e solvente excedentes sejam retirados completamente. A intenção desta reação, é a formação de uma superfície melhor compatível com a matriz PLA, sendo necessária, uma boa seleção do surfactante a ser utilizado, levando em consideração a estrutura polar do PLA.

A utilização de surfactantes ou outros modificadores de superfície pode provocar uma significativa degradação da matriz PLA, devido ao excesso da substância fracamente adsorvida nas nanopartículas após o tratamento, podendo formar porosidades e reduzir o grau de cristalinidade do material em comparação ao nanocompósito com NCs não modificadas. ${ }^{[14]}$ Entretanto, alguns estudos relatam que, devido à maior dispersibilidade dos NCs no PLA após a modificação de superfície, é observado um grande aumento nas propriedades mecânicas do nanocompósito. ${ }^{[4,85-90]}$ A seguir serão discutidas as principais propriedades dos nanocompósitos de PLA com nanopartículas de celulose.

\subsubsection{Propriedades morfológicas}

A estrutura de nanocompósitos de PLA reforçados com NCs é largamente reportada. A literatura ${ }^{[4,87-89,91-93]}$ apresenta uma variedade de propriedades morfológicas, devido às características das nanopartículas de celulose e pelo tratamento utilizado para a modificação da superfície das mesmas.

A influência da modificação das NCs na dispersão em matriz PLA, em relação às não modificadas, pode ser observada em filmes dos nanocompósitos. A Figura 17 apresenta imagens de diferentes filmes, obtidos pelo método de solução, compostos por PLA reforçado com NCs não modificadas e modificadas com n-octadecil isocianato (ICN). A obtenção das NCs foi realizada através da hidrólise ácida de MCCs, utilizando-se ácido sulfúrico à $65 \%$ a $44^{\circ} \mathrm{C}$ por $130 \mathrm{~min}$. A modificação das $\mathrm{NCs}$ foi realizada utilizando-se o tolueno, à temperatura de $110{ }^{\circ} \mathrm{C}$, adicionando-se 
ICN em quantidade de 10 equivalentes, de acordo com o número de grupos hidroxilas presentes na superfície das NCs. O processamento dos nanocompósitos foi realizado através do método de solução em solvente, utilizando-se o clorofórmio. ${ }^{[4]}$

Figura 17- Fotografias de filmes de (a) PLA puro, e PLA reforçados com NCs b) a 2,5\% (c) a 7,5\% (d) a $15 \%(\mathrm{~m} / \mathrm{m})$; e de PLA com NCs modificadas com ICN (e) a $2,5 \%$ (f) a $7,5 \%$ (g) a $15 \%(\mathrm{~m} / \mathrm{m})$.

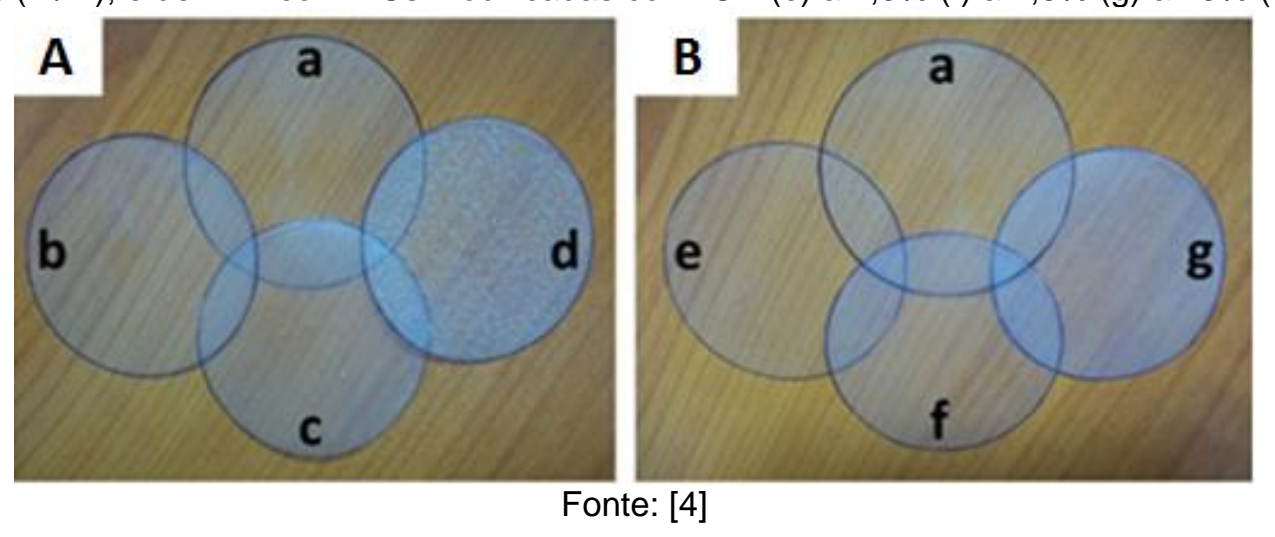

As imagens da Figura 17 apresentam uma ótima dispersão para ambas as amostras com a menor fração de NCs (2,5\%). Em todos os casos, os filmes reforçados com as NCs modificadas com ICN foram mais transparentes que os filmes com NCs não modificadas. Em porcentagens elevadas (7,5 e 15\%) de carga há aglomerados das nanopartículas não modificados na matriz. Já no caso das modificadas, os filmes com $15 \%$ de NCs tornaram-se opacos, mas não foram observados aglomerados (amostra g na Figura 17b). De acordo com o estudo, foi verificado que durante a reação de modificação química, grupos de isocianato se ligaram covalentemente às hidroxilas presentes na superfície das partículas, formando grupos uretanos. ${ }^{[4]}$

O mesmo comportamento pode ser observado quando os nanocompósitos são analisados por diferentes técnicas de microscopia. De modo geral, estudos sobre nanocompósitos de PLA com NCs modificadas com surfactantes ou outros agentes químicos apresentam uma melhora da dispersão, com a redução do número de aglomerados de partículas, quando comparados às NCs não modificadas. Esses resultados corroboram para os diferentes tipos de reagentes, como o próprio isocianato ${ }^{[4,89]}$, diversos organosilanos ${ }^{[87,88]}$ e anidrido acético (acetilação) ${ }^{[94]}$, sendo os dois primeiros os mais representativos. A Figura 18 apresenta a microestrutura da superfície de fratura das amostras apresentadas na Figura 17, ou seja, de PLA com NCs não modificados e modificados com isocianato (ICN). ${ }^{[4]}$ 
Figura 18- Microscopia eletrônica de varredura (MEV) de (a) PLA puro, e PLA reforçado com NCs b) a $2,5 \%$ (c) a $7,5 \%$ (d) a $15 \%(\mathrm{~m} / \mathrm{m})$; e com NCs-ICN (e) a $2,5 \%$ (f) a $7,5 \%(\mathrm{~g})$ a $15 \%(\mathrm{~m} / \mathrm{m})$.
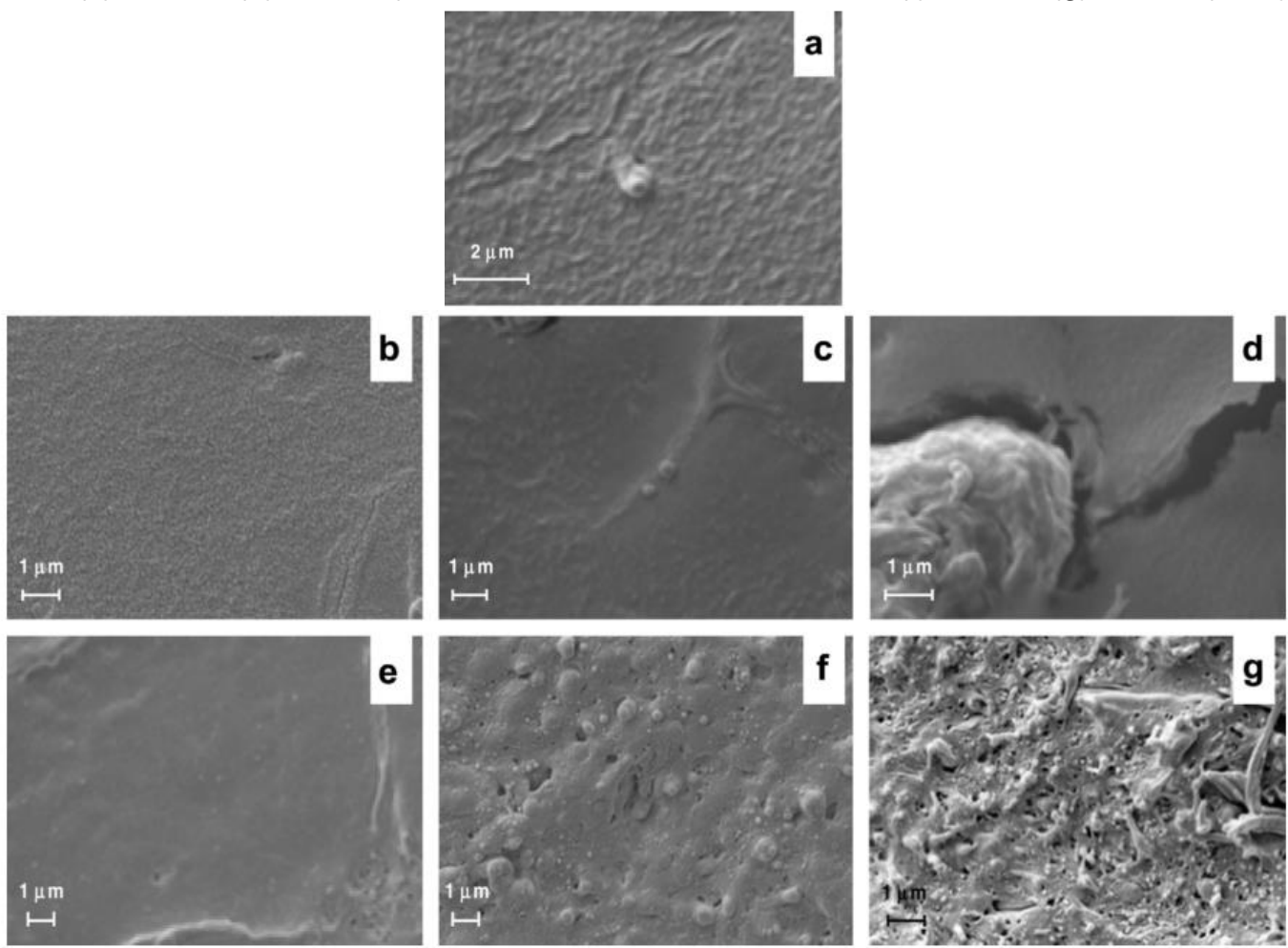

Fonte: [4]

Na Figura 18 observa-se que a adição de 2,5\% (m/m) de carga no PLA apresenta uma distribuição uniforme das cargas tanto para NCs (Fig. 18b) quanto para NCs-ICN (Fig. 18e).

A Figura 18d, apresenta uma fraca interação carga/matriz para NCs, devido à forte adesão interfacial entre aglomerados. A inserção de 15\% de NCs, neste caso, causou a formação de fissuras ao redor destes aglomerados. Já as NCs-ICN apresentam uma melhora na dispersão, já que estão melhor distribuídas da fase matriz quando comparadas com as NCs puras, e uma melhora adesão entre as NCs-ICN e o PLA pode também ser observada. O estudo mostra ainda que esta maior dispersão das cargas modificadas utilizando-se o ICN causou um ganho na resistência mecânica dos compósitos, o que não pôde ser observado no PLA com as NCs não modificadas. Enquanto que o PLA puro e com 2,5\% de NCs não modificadas apresentaram $40 \mathrm{MPa}$ de resistência à tração, o PLA com 2,5\% de NCs modificadas apresentou $51 \mathrm{MPa}{ }^{[4]}$

A técnica de microscopia de força atômica (MFA) também pode ser utilizada na avaliação da interação entre a carga de NCs e a matriz de PLA. Na Figura 19 são apresentadas imagens típicas de compósitos de PLA contendo nanofibras de 
celulose (NFCs) tratadas ou não com organossilano. Neste estudo, a extração das NFCs foi realizada através da hidrólise ácida de MCCs, utilizando-se ácido sulfúrico à $63 \%$, a $40^{\circ} \mathrm{C}$ por 10 horas. A modificação de superfície foi realizada utilizando-se etanol na dispersão de $10 \%$ de NFCs à temperatura ambiente, adicionando-se $10 \%$ de aminopropiltrietoxisilano, sob agitação contínua por 2 horas. O processamento dos nanocompósitos de PLA e as NFs puras e modificadas foram realizadas através de uma câmara de mistura à temperatura de $165^{\circ} \mathrm{C}$ por 10 minutos e velocidade de 60 rpm. ${ }^{[87]}$

Figura 19- Imagens topográficas de MFA para PLA reforçado com 2,5\% (m/m) de: (a) NFCs (b) NFCs modificadas.
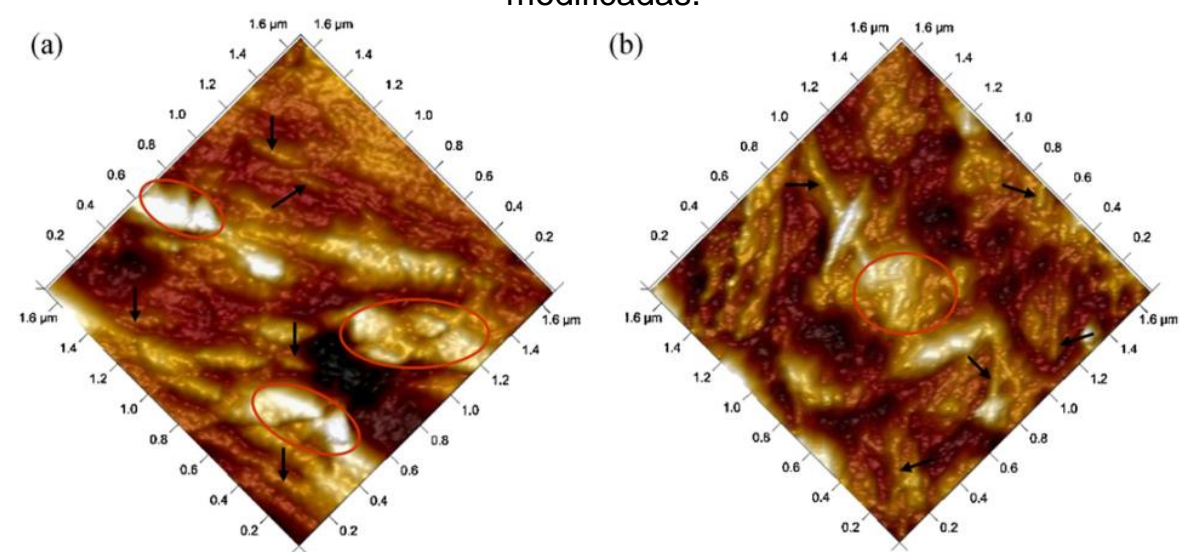

Fonte: [87]

A partir da comparação entre as micrografias, é possível observar uma melhora na dispersão dos compósitos de PLA reforçados em relação as NFCs tratadas. As aglomerações NFCs marcadas com círculos vermelhos e nanofibras individuais envolvidas pelo polímero (marcadas com setas pretas) podem ser observadas na Figura 19a. Uma nítida melhoria na dispersão é observada quando as nanofibras são silanizadas (Figura 19b). Os autores concluíram que a maioria dos aglomerados de NFCs (Figura 19a) está localizada na superfície do material, ao contrário das NFCs modificadas que estão localizadas em camadas mais profundas do polímero, o que sugere uma melhor interface fibra-matriz. ${ }^{[87]}$

\subsubsection{Propriedades térmicas}

O conhecimento das propriedades térmicas tanto do PLA puro quanto das NCs isoladas e de seus nanocompósitos são de suma importância na avaliação das condições de processamento e da aplicabilidade dos mesmos em condições que 
requerem resistência térmica. $\mathrm{O}$ comportamento térmico de nanocompósitos à base de PLA e NCs são semelhantes em diversos estudos reportados na literatura ${ }^{[4,87,88,92,94]}$, nos quais é apresentada a análise de DSC, apresentando que a cinética de cristalização do PLA é lenta. Além disso, os estudos apresentam que, com a adição da carga, a temperatura de cristalização no segundo ciclo de aquecimento tende a se antecipar, e o pico de cristalização tente a ser mais pronunciado em relação ao PLA puro. De modo geral, quanto maior a quantidade de NCs adicionados ao PLA, menor é a $T_{c}$.

Em relação ao tratamento de superfície das NCs, o comportamento também é semelhante. Os estudos ${ }^{[4,87,88,92,94]}$ apresentam que nanocompósitos à base de PLA e cargas modificadas, em comparação com as não tratadas, apresentam menor $T_{c} e$ também picos de cristalização mais pronunciados

$\mathrm{Na}$ Figura 20 é apresentado o resultado obtido por DSC, de amostras de PLA reforçado com NCs modificadas com diferentes grupos silanos. Neste trabalho, a extração das NCs foi realizada através da hidrólise ácida de fibras de rami, utilizando-se ácido sulfúrico a $65 \%$, a $55{ }^{\circ} \mathrm{C}$ por 30 minutos. O procedimento de modificação de superfície foi realizado utilizando-se ácido cítrico para estabilizar a solução de NCs $(0,5 \mathrm{~g}$ em $100 \mathrm{~mL})$ em pH de 5,4, à temperatura ambiente, adicionando-se $100 \mathrm{mM}$ de organossilanos e agitando-se por 2 horas. O processamento dos nanocompósitos de PLA e as NCs puras e modificadas foi realizado via extrusão a $165^{\circ} \mathrm{C}$ e $100 \mathrm{rmp}^{\text {[88] }}$.

Figura 20- Curva de DSC para PLA puro e com 3\% $(\mathrm{m} / \mathrm{m})$ de NCs modificados com os grupos silanos: metracrilato; amino; acrilato; n-propil.

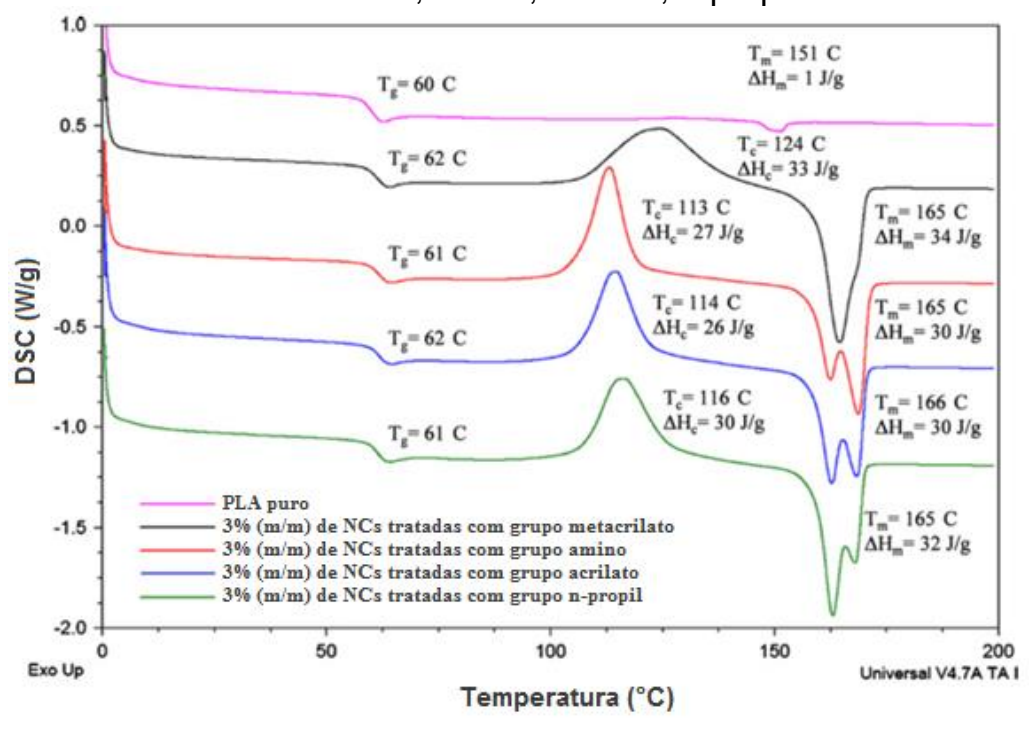

Fonte: [88] modificado. 
Conforme apresentado na Figura 20, a matriz de PLA puro utilizado para a análise apresenta apenas uma temperatura de transição vítrea perto de $60{ }^{\circ} \mathrm{C}$, e não apresenta uma clara $\mathrm{T}_{\mathrm{m}}$, atestando seu estado quase "amorfo". No entanto, os nanocompósitos de PLA com NCs organomodificadas apresentam dois picos de fusão em torno de 150 e $157^{\circ} \mathrm{C}$. A presença de um pico de fusão duplo é um fenômeno bem conhecido. No caso do PLA ele é gerado pela modificação do crescimento dos cristais. Muitas vezes, é atribuída à coexistência de duas estruturas cristalinas: cristais menos perfeitos (cristais de forma $\alpha^{\prime}$ ), que têm tempo suficiente para fundir e se reorganizarem em cristais com maior perfeição estrutural (cristais de forma $\alpha$ ), antes de fundir à temperatura mais elevada. ${ }^{[88,95]}$

Este comportamento pode ser explicado pela maior dispersão da carga na fase matriz, devido ao tratamento superficial. Uma vez que as partículas estão bem distribuídas e com menores aglomerados, a área superficial das NCs aumenta e, consequentemente, atuam como agentes nucleantes, resultando em um nanocompósito com maior capacidade de cristalização em comparação ao PLA puro. ${ }^{[88,96]}$ Entretanto, os valores de $\mathrm{T}_{\mathrm{g}}$ dos nanocompósitos resultantes não são afetados pela presença de NCs, indicando que nenhum efeito plastificante é causado pela adição das partículas.

Outra propriedade térmica de grande relevância para os nanocompósitos de PLA e NCs é a temperatura de degradação. Isso porque os valores de temperatura utilizados no processamento destes materiais via extrusão ou câmara de mistura podem estar próximos dos valores da temperatura de degradação dos materiais. Além disso, a baixa estabilidade térmica das NCs pode diminuir a temperatura de degradação do PLA. A Figura 21 apresenta uma análise termogravimétrica de filmes de PLA reforçados com NCs. ${ }^{[76,97]}$

Figura 21- Curva TG (a) e sua derivada (b) de PLA puro e reforçado com 0,1 e 0,5\% (m/m) de NCs.
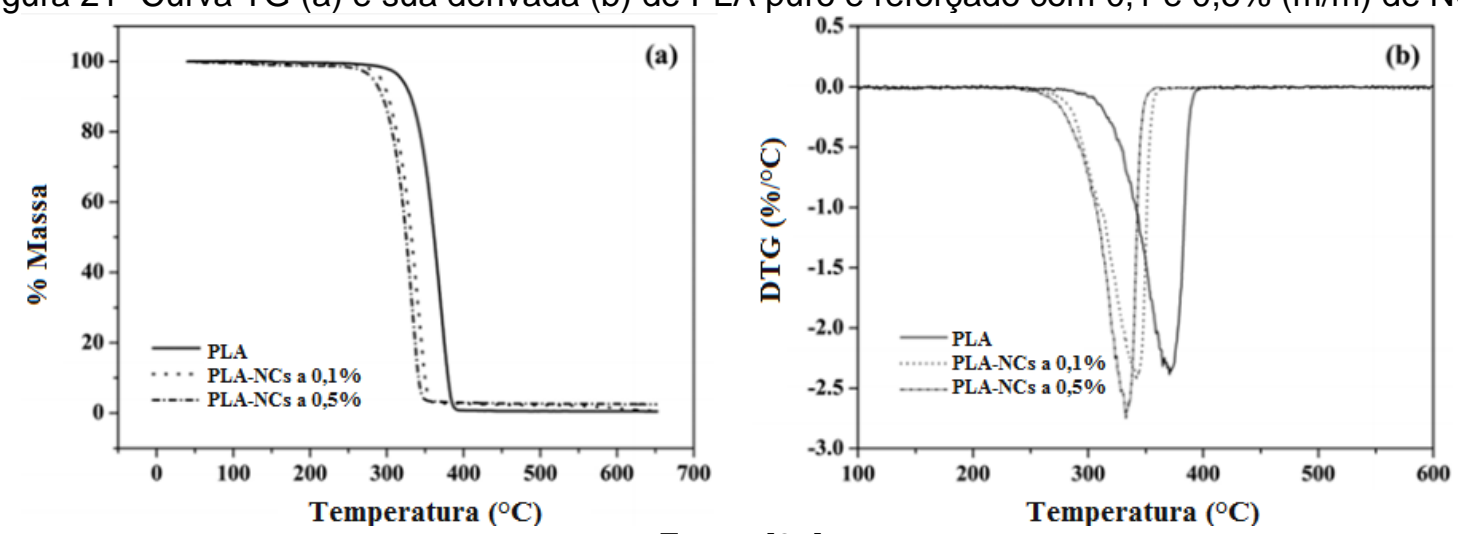

Fonte: [97] 
Neste estudo, a obtenção das NCs foi realizada através da hidrólise ácida de MCCs, utilizando-se ácido sulfúrico à concentração de $44 \%$, temperatura de $45^{\circ} \mathrm{C}$ por 120 min. O processamento dos nanocompósitos foi realizado pelo método de solução em solvente, utilizando-se o clorofórmio. A Figura 21 mostra que os compósitos de PLA contendo 0,1 e 0,5\% em massa de NCs começam a se decompor a temperatura de 277 e $259^{\circ} \mathrm{C}$, respectivamente, enquanto o PLA puro ficou estável em temperaturas muito mais elevadas. As temperaturas de decomposição, relativas à perda de $10 \%$ de massa, diminuíram significativamente de $331{ }^{\circ} \mathrm{C}$ para o PLA puro a $301{ }^{\circ} \mathrm{C}$ para o PLA com $0,1 \%$ de carga e $294^{\circ} \mathrm{C}$ para 0 PLA com $0,5 \%$ de NCs. A derivada da curva TG (DTG), apresentada na Figura 21b, indica que a máxima temperatura de degradação é de cerca de $370^{\circ} \mathrm{C}$ para o PLA puro, contra 340 e 330 para o PLA reforçado com 0,1 e $0,5 \%$ de NCs, respectivamente, o que resultou em uma diminuição de $8 \%$ e $10 \%$ da estabilidade térmica. ${ }^{[88]}$

\subsubsection{Propriedades reológicas}

No caso de nanocompósitos poliméricos, as análises das propriedades reológicas são importantes para o entendimento do processamento e na determinação da força das interações interfaciais do polímero e da carga, relacionando as estruturas e suas propriedades. Isso ocorre porque os comportamentos reológicos são fortemente influenciados pela estrutura em nanoescala e características interfaciais. ${ }^{\text {[98] }}$

No entanto, poucos estudos são encontrados a respeito das propriedades reológicas de nanocompósitos de PLA reforçados com NCs, dificultando a comparação dos resultados obtidos com a literatura. Felizmente, como se trata de uma técnica complementar às demais técnicas de caracterização, os resultados obtidos podem ser confrontados com outras caracterizações, como análises microscópicas, permitindo uma melhor interpretação dos mesmos.

$\mathrm{Na}$ Figura 22 são apresentadas as viscosidades complexas para amostras de PLA puro e com 1 a $7 \%$ em massa de NCs, obtidas por análise reológica. Nesse trabalho, as NCs foram fornecidas pela empresa canadense FPInnovations. A suspensão de NCs foram secas pelo método Spray Freeze Drying, no qual é realizada a pressurização da amostra para retirar o excesso de água, seguida de 
sua liofilização. Os compósitos de PLA com as NCs foram processados utilizando-se câmara de mistura, a $190^{\circ} \mathrm{C}$ e $60 \mathrm{rpm}$ por 10 minutos. O ensaio de Cisalhamento Oscilatório de Pequenas Amplitudes (COPA) foi realizado em um reômetro rotacional de placas paralelas, à temperatura de $190^{\circ} \mathrm{C}$ e $5 \%$ de deformação. [99]

Figura 22- Viscosidade complexa do PLA puro e com 0,5 a 7\% em massa de NCs em função da frequência $(\omega)$.

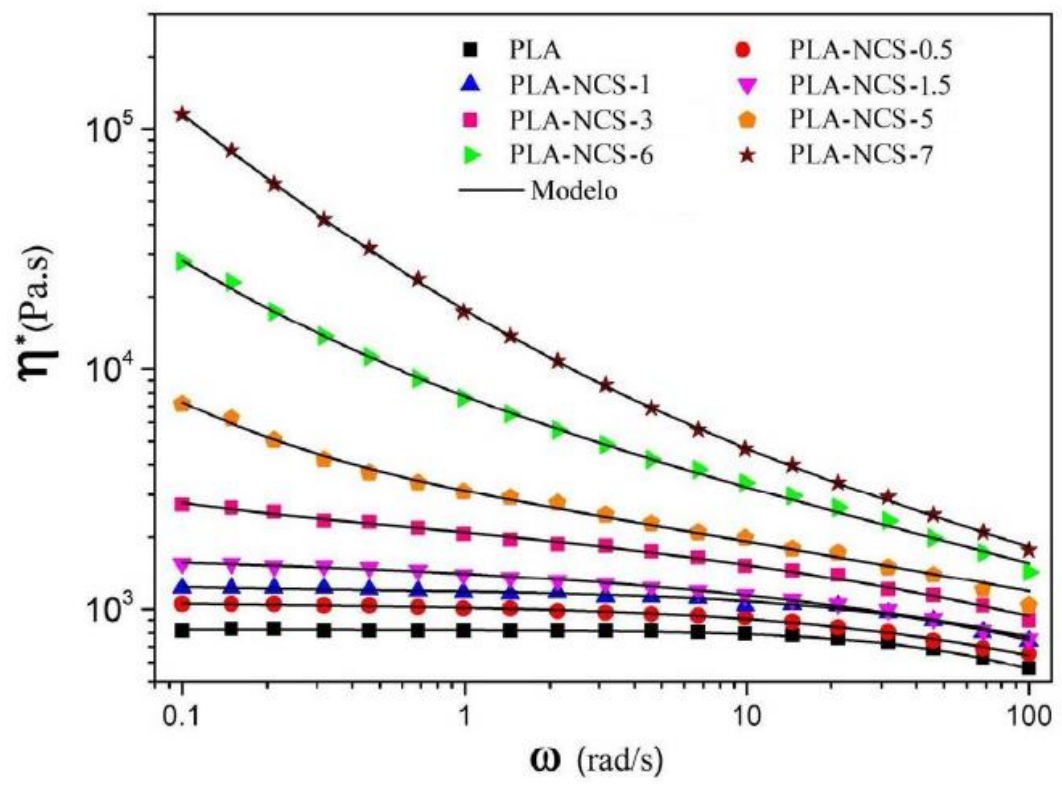

Fonte: [99] modificado.

A partir da Figura 22, pode-se observar que o PLA apresenta um comportamento newtoniano para baixas frequências, e comportamento pseudoplástico a partir de $7 \mathrm{rad} / \mathrm{s}$. A viscosidade complexa aumentou gradualmente com a adição das NCs no PLA. Para concentrações inferiores a 3\%, a viscosidade complexa aumentou para baixas frequências, mas não houve indício de comportamento pseudoplástico a estas concentrações. No entanto, para as amostras com mais de 3 \% de NCs, a viscosidade complexa não só aumentou, mas também exibiu um comportamento pseudoplástico a baixas frequências. De acordo com os autores, esta é uma indicação da ocorrência de formação de uma estrutura dentro do PLA fundido devido a interações entre as partículas. Concentrações acima de $3 \%$ de NCs resultaram em um rápido aumento da viscosidade do PLA à baixa frequência, e, finalmente, o sistema resiste a fluir em concentrações mais elevadas, tais como 5 e $7 \%$. ${ }^{[99]}$

Com base no mesmo estudo, a Figura 23 apresenta o módulo de armazenamento (G') em função da frequência do PLA puro e reforçado com NCs. 
Figura 23- Módulo de armazenamento (G') de PLA reforçado com NCs em função da frequência $(\omega)$.

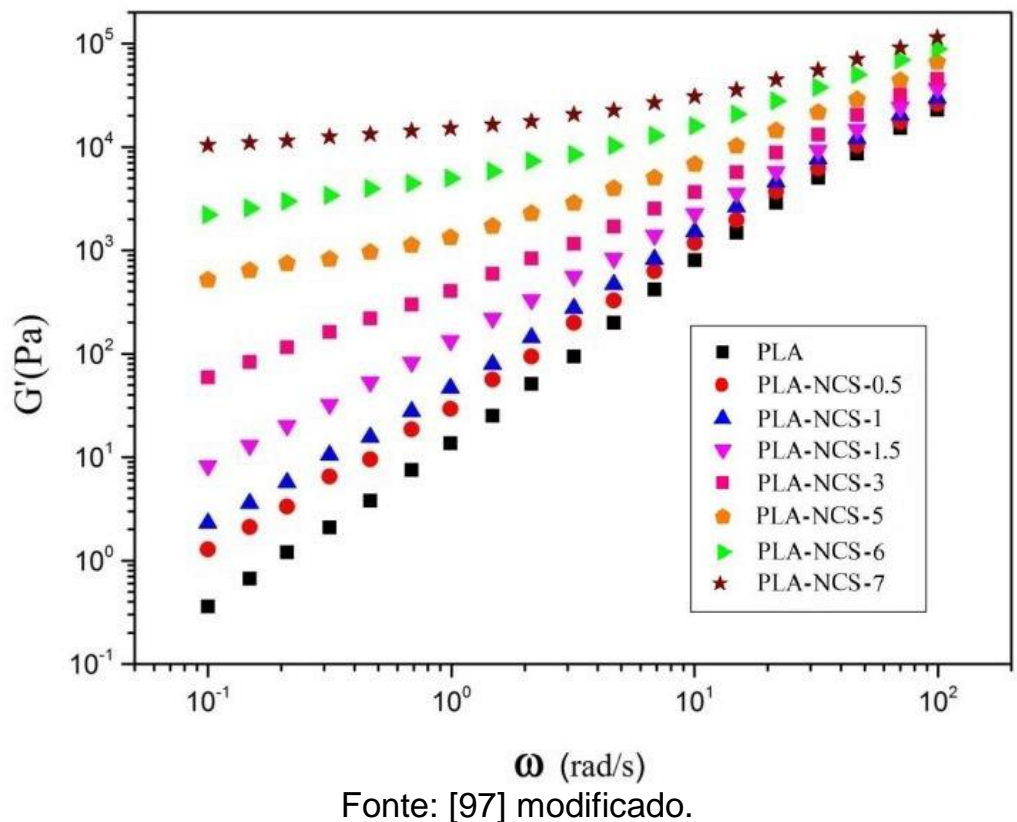

Do mesmo modo, um aumento significativo no módulo de armazenamento do PLA foi obtido depois da adição de $3 \%$ de NCs. A inclinação do módulo de armazenamento na região de baixa frequência foi reduzida de 1,5 do PLA para 0,15 do PLA contendo $7 \%$ de NCs.

Segundo o estudo, a presença do platô à baixa frequência para o PLA com altas concentrações de NCs é um indício de comportamento sólido do compósito. ${ }^{[99]}$ Este resultado pode ser explicado pelo fato da interação física entre os NCs levar à formação de uma estrutura de rede tridimensional interligada entre as nanopartículas e a matriz de PLA. ${ }^{[97,98,100-103]}$ 


\section{MATERIAIS E MÉTODOS}

Os materiais utilizados no presente trabalho, bem como suas propriedades são apresentados neste item.

\subsection{Materiais}

\subsubsection{Poli (ácido lático)}

O Poli(ácido lático) (PLA) utilizado neste trabalho possui denominação comercialmente Ingeo ${ }^{\mathrm{TM}}$ Biopolymer 3251D, fabricado pela Nature Works LLC, e fornecido pela empresa Cargil ${ }^{\mathrm{TM}}$. Suas especificações técnicas são descritas na Tabela 5.

Tabela 5 - Propriedades do PLA Ingeo ${ }^{\text {TM }}$ 3251D.

\begin{tabular}{cc}
\hline Propriedade & Valor \\
\hline Teor de isômero $\mathrm{D}$ & $4 \%$ em massa \\
Massa molar $\left(\mathrm{M}_{\mathrm{n}}\right)$ & $90.000-120.000 \mathrm{~g} / \mathrm{mol}$ \\
Densidade na temperatura de fusão & $1,12 \mathrm{~g} / \mathrm{cm}^{3}$ \\
Densidade relativa & 1,24 \\
Temperatura de transição vítrea $\left(\mathrm{T}_{\mathrm{g}}\right)$ & $55-60^{\circ} \mathrm{C}$ \\
Temperatura de fusão $\left(\mathrm{T}_{\mathrm{m}}\right)$ & $155-170^{\circ} \mathrm{C}$ \\
\hline
\end{tabular}

Fonte: Nature Works LLC.

\subsection{Procedimento experimental}

Os procedimentos realizados neste trabalho para obtenção das cargas e dos compósitos, bem como suas caracterizações são descritos nos subitens a seguir.

\subsubsection{Obtenção das nanopartículas de celulose (NCs)}

As NCs foram obtidas por três métodos alternativos, a fim de se selecionar o procedimento mais efetivo e viável, conforme posteriores resultados de caracterização. Os métodos foram chamados de I, II e III, e são descritos a seguir. 


\subsubsection{Método I}

A obtenção das nanopartículas de celulose (NCs) foi realizada por hidrólise ácida, utilizando o método descrito por Dong ${ }^{[28]}$ e Bondeson ${ }^{[27]}$, com algumas modificações. Para este procedimento, utilizou-se como fonte de celulose o papel filtro quantitativo faixa azul, e ácido sulfúrico $\left(\mathrm{H}_{2} \mathrm{SO}_{4}\right)$ a $63 \%(\mathrm{~m} / \mathrm{m})$, na proporção de 1:10 $(\mathrm{g} / \mathrm{ml})$, em relação à massa de papel e o volume de ácido. Cerca de $30 \mathrm{~g}$ de papel foram submetidos à agitação mecânica constante, em ácido, por 70 minutos à temperatura de $45{ }^{\circ} \mathrm{C}$, utilizando-se uma chapa aquecedora. Após o fim do procedimento, a solução resultante foi resfriada e diluída em 3 vezes, com água deionizada. A neutralização da solução foi realizada através de três centrifugações a $17000 \mathrm{rpm}$, a $4{ }^{\circ} \mathrm{C}$, por 10 minutos, desprezando-se o sobrenadante e adicionandose água deionizada. Logo após, a solução resultante foi submetida à diálise utilizando-se membrana de celulose semi-permeável para colocar a solução em contato com água corrente por 12 horas, sendo que as 2 últimas horas, com a solução em pH na faixa de 5-7, a troca iônica foi feita com água deionizada. Em seguida a solução enfim neutralizada foi submetida à ponteira de ultrassonificação de $450 \mathrm{~W}$ de potência por 10 minutos. Finalmente a solução obtida foi congelada e as NCs foram secas por liofilização durante 5 dias. As amostras obtidas foram chamadas de NCSOD.

\subsubsection{Método II}

A obtenção das NCs foi realizada conforme o Método I, entretanto para a neutralização utilizou-se o método descrito por Bajpai ${ }^{[36]}$, com algumas modificações. A neutralização da solução foi realizada através de duas centrifugações a $17000 \mathrm{rpm}$, a $4{ }^{\circ} \mathrm{C}$, por 10 minutos, desprezando-se $\mathrm{O}$ sobrenadante e adicionando-se água deionizada. Logo após, foi adicionada uma solução de bicarbonato de sódio $\left(\mathrm{NaHCO}_{3}\right)$ a $5 \%(\mathrm{~m} / \mathrm{m})$, até a solução final chegar a pH próximo de 7. Novamente a solução neutralizada foi submetida a duas centrifugações a $17000 \mathrm{rpm}$, por 10 minutos. Em seguida, a solução obtida foi submetida à ponteira de ultrassonificação, por 10 minutos. Finalmente a solução obtida foi congelada e as NCs foram secas por liofilização durante 5 dias. As amostras obtidas foram chamadas de NCSOB. 


\subsubsection{Método III}

A obtenção das nanopartículas de celulose (NCs) pelo Método III foi realizada por hidrólise ácida utilizando-se ácido ortofosfórico $\left(\mathrm{H}_{3} \mathrm{PO}_{4}\right)$, conforme procedimento descrito por Espinosa ${ }^{[42]}$, com algumas modificações. Para este procedimento, utilizou-se novamente como fonte de celulose o papel filtro quantitativo, e ácido ortofosfórico a 10,5 M na proporção de 1:20 ( $\mathrm{g} / \mathrm{ml})$, em relação à massa de papel e o volume de ácido. O papel e a quantidade de água necessária para diluição do ácido foram misturados com o auxílio de um misturador comum de cozinha, e em seguida a quantidade suficiente de $\mathrm{H}_{3} \mathrm{PO}_{4}$ a $85 \%$ foi lentamente adicionada, com a mistura em banho de gelo. Logo após, a mistura foi submetida à agitação mecânica constante, por 70 minutos à temperatura de $100{ }^{\circ} \mathrm{C}$, utilizando-se uma chapa aquecedora. Após o fim do procedimento, a solução resultante foi resfriada e diluída em 3 vezes, com água deionizada. A neutralização da solução foi realizada através de três centrifugações a $17000 \mathrm{rpm}$, a $4{ }^{\circ} \mathrm{C}$, por 10 minutos, desprezando-se 0 sobrenadante e adicionando-se água deionizada. Logo após, a solução resultante foi submetida à diálise utilizando-se membrana de celulose semi-permeável, colocando a solução em contato com água corrente por 12 horas, sendo que nas 2 últimas horas, com a solução em $\mathrm{pH}$ na faixa de 5-7, a troca iônica foi feita com água deionizada. Em seguida a solução enfim neutralizada foi submetida à ponteira de ultrassonificação por 10 minutos. Finalmente a solução obtida foi congelada e as NCs foram secas por liofilização durante 5 dias. As amostras obtidas foram chamadas de NCPO.

\subsubsection{Obtenção dos compósitos de PLA e NCs}

A incorporação dos nanopartículas de celulose no polímero poli(ácido lático) (PLA), no estado fundido, foi realizada em uma câmara de mistura acoplada a um reômetro de torque Thermo Haake (PolyLab900 / Rheomix 600p), com volume interno de $69 \mathrm{~cm}^{3}$. Todas as amostras foram processadas por 3 minutos a $170^{\circ} \mathrm{C}$, com velocidade de rotação de 100 rpm, utilizando-se massa suficiente para preenchimento de $70 \%$ do volume interno da câmara de mistura. Tanto o polímero quanto as NCs foram previamente secos em estufa a vácuo por $24 \mathrm{~h}$, a $58^{\circ} \mathrm{C}$. Foram preparados compósitos com 1 e 3\% em massa de NCs no PLA. Para a moldagem 
dos corpos de prova, as amostras obtidas na câmara de mistura foram moídas e prensadas em moldes com formato de discos de 1,5 $\mathrm{mm}$ de espessura e $25 \mathrm{~mm}$ de diâmetro. A prensagem foi realizada utilizando-se uma prensa hidráulica, com pressão de $18 \mathrm{MPa}$, a $180^{\circ} \mathrm{C}$, ocorrendo em três etapas: na primeira sem pressão por 4 min para fusão do material, na segunda com pressão total por $3 \mathrm{~min}$, na terceira um alívio de pressão e em seguida a amostra fica sob pressão total por mais 2 min.

\subsubsection{Caracterização das nanopartículas de celulose}

As técnicas de caracterização das NCs utilizadas neste trabalho são descritas nos itens a seguir.

\subsubsection{Difração de raios $X(D R X)$}

As análises de difração de raios $X(D R X)$ para as amostras de NCs foram realizadas através da metodologia do pó, em um difratômetro marca Philips modelo MPD 1880, utilizando-se radiação Ka de Cu (comprimento de onda 1,544 Å). O ângulo de varredura utilizado está compreendido entre $2 \theta$ de 5 a $40^{\circ}$, com passo de $0,02 \%$ min.

O cálculo do índice de cristalinidade $\left(I_{c}\right)$ das amostras de NCs foi realizado de acordo com o método de subtração do halo amorfo ${ }^{[104,105]}$. Através deste método, um ajuste da linha base foi aplicado ao espectro do material amorfo utilizando o software Origin Pro 8.0. Deste modo, após a subtração do espectro amorfo, ou vítreo, a partir do espectro original, nenhuma parte do espectro resultante contém um sinal negativo. Assim, o $\mathrm{I}_{\mathrm{c}}$ é calculado através da razão entre a área da região cristalina e a área total, conforme equação:

$$
I_{c} \%=\frac{A_{c}}{A_{t}} \times 100
$$

Onde $A_{t}$ é a área total da curva de $D R X$ e $A_{c}$ é a soma das áreas dos picos que correspondem à estrutura cristalina da celulose calculados após correção da 
linha base. Para o cálculo das áreas, os picos remanescentes das curvas DRX foram desconsiderados.

\subsubsection{Espectroscopia vibracional de absorção no infravermelho com transformada de Fourier (FTIR)}

As amostras de NCs foram analisadas por espectroscopia vibracional de absorção no infravermelho, utilizando um equipamento marca Nicolet, modelo 6700 , com resolução de $4 \mathrm{~cm}^{-1}$, localizada no Laboratório de Processos Cerâmicos do Departamento de Engenharia Metalúrgica e de Materiais. As amostras foram analisadas em modo de transmitância, preparando-se pastilhas prensadas com $\mathrm{KBr}$.

\subsubsection{Análise Termogravimétrica (TG)}

As análises termogravimétricas das NCs foram realizadas utilizando-se um equipamento marca Netzsch, modelo STA 449, pertencente ao Laboratório de Análises Térmicas do Departamento de Engenharia Metalúrgica e de Materiais. As amostras de NCs foram aquecidas da temperatura ambiente até $1000^{\circ} \mathrm{C}$, a uma taxa de $10^{\circ} \mathrm{C} / \mathrm{min}$, sob atmosfera de nitrogênio, a um fluxo de $20 \mathrm{ml} / \mathrm{min}$. Foi utilizado cerca de $10 \mathrm{mg}$ de amostra, utilizando-se um cadinho de alumina como referência.

\subsubsection{Fluorescência de raios-X}

A composição química e a perda ao fogo das amostras de NCs foram determinadas por espectrometria de fluorescência de raios- $X$ em um equipamento da marca PANalytical, modelo Axios Advanced, disponível no Laboratório de Caracterização Tecnológica do Departamento de Engenharia de Minas da EPUSP. A análise realizada foi semiquantitativa, sem padrões. A perda ao fogo (PF) foi efetuada a $1050^{\circ} \mathrm{C}$, por 1 hora.

\subsubsection{Birrefringência de fluxo}

Para a visualização das imagens iridescentes das suspensões de NCs, devido à birrefringência de fluxo, foi preparada uma suspensão contendo $0,63 \%$ em 
massa de NCs, assim como descrito por Habibi ${ }^{[5]}$. A solução foi colocada em recipiente de vidro e fotografada entre dois polarizadores cruzados, incidindo luz em um dos lados.

\subsubsection{Microscopia Eletrônica de Transmissão (MET)}

As amostras de NCs foram observadas no microscópio eletrônico de transmissão Jeol-1010, localizado no Laboratório de Microscopia Eletrônica da Faculdade de Medicina da USP. A tensão de aceleração utilizada foi de $80 \mathrm{kV}$, com aumentos de até 60000 vezes. As amostras de NCs foram preparadas através da dispersão por ultrassonificação das partículas em solução aquosa à concentração de $0,2 \mathrm{mg} / \mathrm{mL}$. Uma gota de cada solução foi colocada em tela (gride) de cobre recoberta com filme suporte de carbono, e seca em estufa a vácuo por 2 horas à $60^{\circ} \mathrm{C}$. As amostras foram tingidas com solução de acetato de uranila a $2 \%$ por 5 minutos.

\subsubsection{Microscopia de Força Atômica (MFA)}

A microscopia de força atômica foi realizada em equipamento da marca Bruker, modelo Nanoscope-IIla. As amostras de NCs foram preparadas através da dispersão por ultrassonificação das partículas em solução aquosa à concentração de $0,1 \mathrm{mg} / \mathrm{mL}$. Logo após, foi realizada uma dupla clivagem de uma folha de mica de 5 x $5 \mathrm{~mm}$, e uma gota da solução foi colocada nesta superfície, retirando-se o excesso de líquido por aproximação de papel filtro pelos cantos do substrato.

\subsubsection{Análise quantitativa das imagens obtidas por MET}

Os valores do diâmetro (d), comprimento (L) e razão de aspecto (RA) das NCs foram medidos e calculados com base nas medidas realizadas através das imagens de MFA e MET, por meio dos softwares Nanoscope e ImageJ, respectivamente. Foram utilizadas cerca de 4 micrografias obtidas por MET e duas obtidas por MFA, realizando-se até 40 medições, para cada amostra de NCs, calculando-se a média aritmética para cada parâmetro, juntamente com seu desvio padrão. 


\subsubsection{Caracterização dos compósitos de PLA e NCs}

As técnicas de caracterização dos compósitos de PLA reforçados com NCs utilizadas neste trabalho são descritas nos itens a seguir.

\subsubsection{Análise Termogravimétrica (TG)}

As análises termogravimétricas dos compósitos obtidos foram realizadas conforme descritas anteriormente para as amostras de NCs. As amostras também foram aquecidas da temperatura ambiente até $1000^{\circ} \mathrm{C}$, a uma taxa de $10^{\circ} \mathrm{C} / \mathrm{min}$, sob atmosfera de nitrogênio, a um fluxo de $20 \mathrm{ml} / \mathrm{min}$. Foi utilizado cerca de $10 \mathrm{mg}$ de amostra, utilizando-se um cadinho de alumina como referência.

\subsubsection{Calorimetria Exploratória Diferencial (DSC)}

As análises de DSC foram realizadas em um equipamento DSC Maia 200, da marca Netzsch, disponível no Laboratório de Análises Térmicas do Departamento de Engenharia Metalúrgica e de Materiais. As amostras de PLA puro e com carga foram seladas em cadinhos de alumínio. Em uma primeira etapa, a amostras foram aquecidas da temperatura ambiente até $180{ }^{\circ} \mathrm{C}$, à velocidade de $10{ }^{\circ} \mathrm{C} / \mathrm{min}$, sob atmosfera de nitrogênio, a um fluxo de $20 \mathrm{ml} / \mathrm{min}$. Na segunda etapa da análise, as amostras foram resfriadas até $0{ }^{\circ} \mathrm{C}$. Na última etapa da análise, as amostras foram aquecidas até $200^{\circ} \mathrm{C}$. A quantidade de amostra analisada foi de aproximadamente 10 mg e o equipamento foi previamente calibrado com Índio.

\subsubsection{Micrografia Óptica (MO)}

A microscopia óptica do PLA puro e com carga foi realizada utilizando-se um microscópio óptico marca Olympus, modelo BX-50. Utilizou-se para preparo e observação das amostras um equipamento de estágio a quente, no qual filmes são obtidos por prensagem do material entre duas placas de vidro aquecidas. As amostras de PLA foram observadas variando-se a temperatura de $120{ }^{\circ} \mathrm{C}$ a $180{ }^{\circ} \mathrm{C}$, e as amostras dos compósitos foram analisadas de $100{ }^{\circ} \mathrm{C}$ a $180{ }^{\circ} \mathrm{C}$, e as temperaturas finais foram mantidas por $15 \mathrm{~min}$. 


\subsubsection{Análises reológicas}

Os ensaios reológicos foram realizados utilizando-se um reômetro ARES LSII, da TA Instruments, disponível no Laboratório de Análises e Caracterização de Materiais Poliméricos do Departamento de Engenharia Metalúrgica e de Materiais. Os ensaios de Cisalhamento Oscilatório de Pequenas Amplitudes (COPA) foram realizados com geometria cone placa, com frequências de 500 a $0,1 \mathrm{rad} / \mathrm{s}$, à temperatura de $172^{\circ} \mathrm{C}$, sob atmosfera de nitrogênio, com gap de 0,056 mm e deformação de 8\%. A deformação utilizada para o ensaio de COPA foi determinada por ensaio de Varredura de Deformação, realizado a frequências de 1 e $100 \mathrm{rad} / \mathrm{s}$, a temperatura de $172^{\circ} \mathrm{C}$, para se definir a faixa de deformação contida no regime de viscoelasticidade linear.

\subsubsection{Microscopia Eletrônica de Varredura com emissão de campo (MEV-FEG)}

A amostra do compósito foi analisada morfologicamente em microscópio eletrônico de varredura (MEV), da marca Phillips, modelo XL-30 MEV-FEG, do Laboratório de Microscopia Eletrônica do Departamento de Engenharia Metalúrgica e de Materiais da EPUSP. As imagens foram coletadas com aumento de até 40000 vezes e voltagem de aceleração de $8 \mathrm{kV}$. O corpo de prova foi quebrado após permanecer 3 horas à temperatura criogênica, e a superfície de fratura foi recoberta com fina camada de material condutor (platina). 


\section{RESULTADOS E DISCUSSÕES}

\subsection{Obtenção das NCs}

Os detalhes de cada método utilizado na obtenção das nanopartículas de celulose serão relatados a seguir.

\subsubsection{NCs preparadas pelo Método I (NCSOD)}

Durante o procedimento descrito pelo Método I, o qual consistiu da hidrólise utilizando-se $\mathrm{H}_{2} \mathrm{SO}_{4}$, a solução de hidrólise, que inicialmente apresentava cor branca, foi aparentemente aumentando sua viscosidade. Ao término da reação, obteve-se uma solução viscosa e levemente amarelada.

Após a centrifugação e neutralização por diálise, obteve-se uma solução menos viscosa e branca. Em seguida, com a liofilização, partículas brancas foram obtidas, como é apresentado na Figura 24.

Figura 24- Fotografia das NCs obtidas pelo Método I (NCSOD).

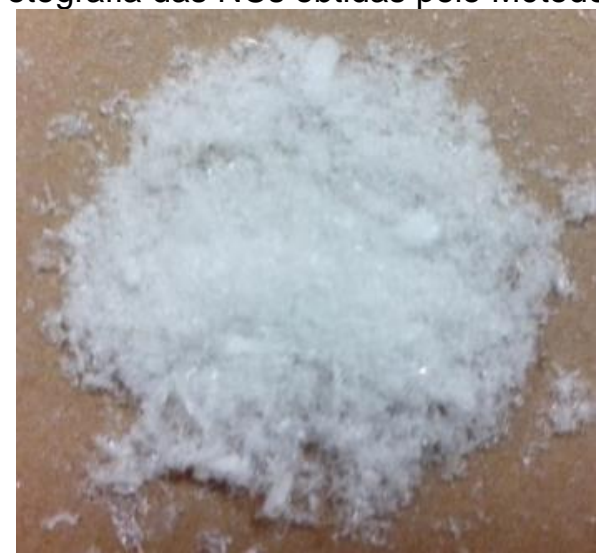

O cálculo do rendimento foi realizado através da razão entre a massa das partículas resultantes após liofilização e massa inicial de papel (30 g) utilizada na reação. Neste método, obteve-se um rendimento de $41 \%$.

\subsubsection{NCs preparadas pelo Método II (NCSOB)}

A partir do Método II, a solução obtida após neutralização com $\mathrm{NaHCO}_{3}$ também resultou em uma solução branca e menos viscosa em relação à solução 
posterior à reação de hidrólise. Após a liofilização, as NCs obtidas também apresentaram coloração branca e aspecto de pó, conforme é apresentado na Figura 25.

Figura 25- Fotografia das NCs obtidas pelo Método II (NCSOB).

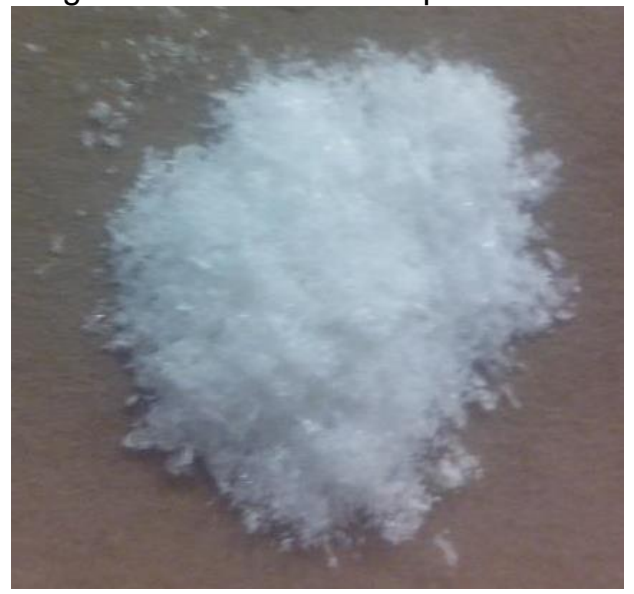

Para o Método II, no qual realizou-se neutralização através do $\mathrm{NaHCO}_{3}$, obteve-se um rendimento de $49 \%$.

\subsubsection{NCs preparadas pelo Método III (NCPO)}

Durante o procedimento descrito pelo Método III, o qual consistiu da hidrólise utilizando-se $\mathrm{H}_{3} \mathrm{PO}_{4}$, a solução de hidrólise, que inicialmente apresentava cor branca, foi aparentemente aumentando sua viscosidade. Em comparação com os métodos utilizando-se $\mathrm{H}_{2} \mathrm{SO}_{4}$, observou-se que a solução obtida pelo Método III aparentou ser menos viscosa que as dos Métodos I e II. No fim da reação também obteve-se uma solução levemente amarelada.

Após a centrifugação e a liofilização, foram obtidas partículas brancas, Observou-se que essas partículas apresentaram maior aglomeração, e grânulos mais rígidos do que as obtidas pelos outros dois métodos. Neste caso, foi necessário, após a liofilização, uma moagem manual utilizando-se almofariz e pistilo. Na Figura 26, são apresentadas as partículas após a liofilização (26a) e após a moagem (26b). 
Figura 26- Fotografias das NCs obtidas pelo Método III (NCPO): (a) após liofilização; (b) após

(a)

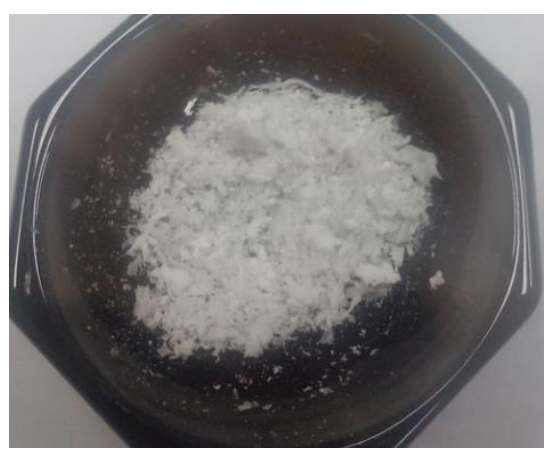
moagem.

(b)

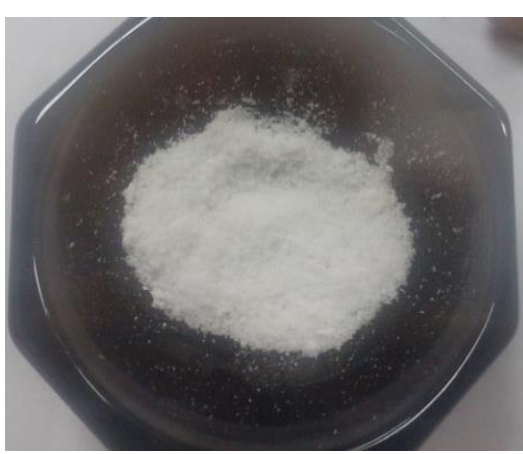

Para o Método III, no qual realizou-se hidrólise através do $\mathrm{H}_{3} \mathrm{PO}_{4}$, obteve-se um rendimento de $63 \%$.

\subsection{Caracterização das nanopartículas de celulose}

Os resultados das análises de caracterização para as nanopartículas de celulose obtidas pelos Métodos I, II e III são apresentados nos subitens seguintes.

\subsubsection{Difração de raios $X(D R X)$}

Na Figura 27 são apresentadas as curvas de difração de raios X obtidas para o papel e as NCs preparadas pelos Métodos I (NCSOD), II (NCSOB) e III (NCPO).

Figura 27- Curvas de DRX para as amostras de papel filtro e as NCs (NCSOD, NCSOB e NCPO).

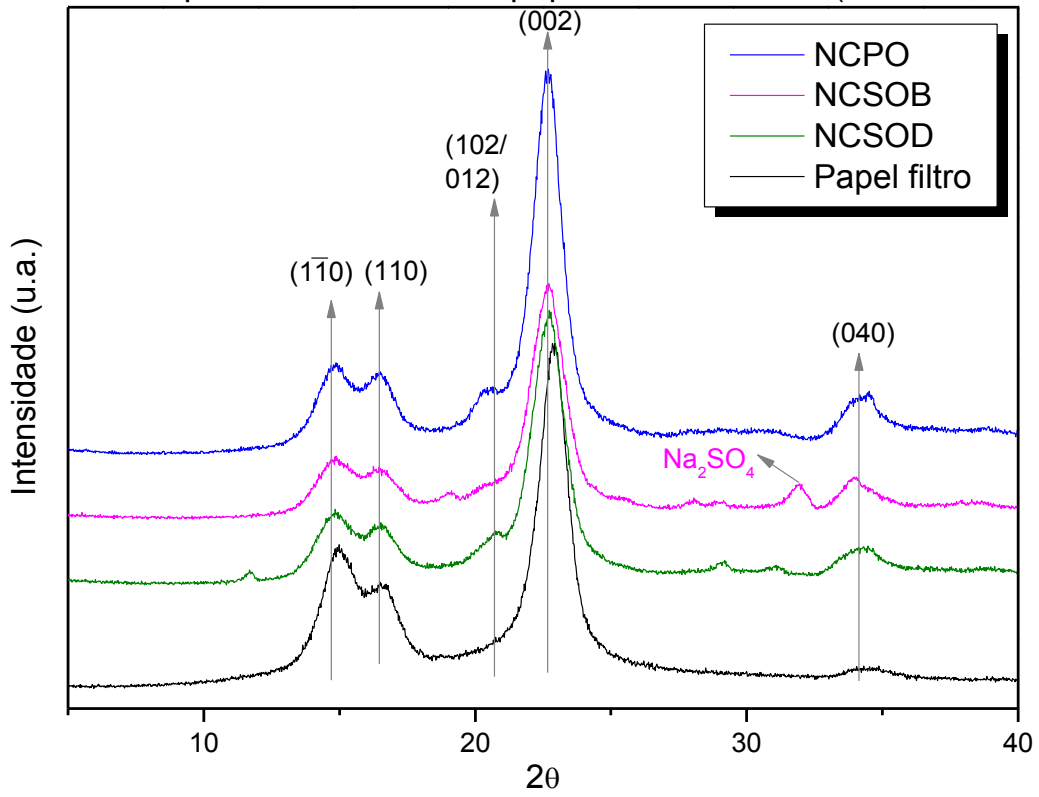


As curvas apresentadas na Figura 27 apresentam picos característicos da estrutura cristalina da celulose I. ${ }^{[8]}$ Pode-se observar que o pico de maior intensidade em $2 \theta=22,7^{\circ}$, referente ao plano (002), está presente em todas as curvas. Além disso, há a presença dos picos característicos da celulose $I_{\beta}$ em $2 \theta=14,8^{\circ}$ e $16,3^{\circ}$ referentes aos planos $(1 \overline{1} 0)$ e $(110) .{ }^{[23,38]}$ Ainda pode-se observar um ombro localizado ao redor de $2 \theta=21^{\circ}$ mais pronunciado nas amostras das NCs, que representa uma reflexão do plano $(102 / 012)$ e um pico bem definido a $2 \theta=34^{\circ}$ referente ao plano (040). ${ }^{[38]}$

Entretanto, observam-se picos adicionais na curva pertencente às NCs obtidas pelo Método II (NCSOD), devido à presença do sal $\mathrm{Na}_{2} \mathrm{SO}_{4}$, gerado na reação de neutralização entre o ácido $\mathrm{H}_{2} \mathrm{SO}_{4}$ e o bicarbonato de sódio. $\mathrm{O}$ pico observado em $2 \theta=31,8^{\circ}$ corresponde ao pico de maior intensidade da curva de DRX padrão do $\mathrm{Na}_{2} \mathrm{SO}_{4}$.

A Tabela 6 apresenta os índices de cristalinidade calculados através das curvas de DRX e da Equação 7. Os dados utilizados para realização do método de subtração do halo amorfo são apresentados no Apêndice A.

Tabela 6- Índices de cristalinidade (Ic) das amostras de NCs e papel filtro calculados através das curvas de DRX.

\begin{tabular}{cccc}
\hline Amostra & $\begin{array}{c}\text { Área total da curva de } \\
\text { DRX }\end{array}$ & $\begin{array}{c}\text { Área da região } \\
\text { cristalina }\end{array}$ & $\begin{array}{c}\text { Índice de } \\
\text { Cristalinidade }\left(\mathbf{I}_{\mathbf{c}}\right)\end{array}$ \\
\hline Papel filtro & 19045 & 12815 & $67 \%$ \\
NCSOD & 13420 & 10613 & $79 \%$ \\
NCSOB & 11177 & 8784 & $79 \%$ \\
NCPO & 17837 & 14858 & $83 \%$ \\
\hline
\end{tabular}

De acordo com os resultados obtidos na Tabela 6, pode-se observar um aumento dos índices de cristalinidade das nanopartículas em relação papel filtro utilizado para sua extração, uma vez que a hidrólise ácida é capaz de destruir parte da fase vítrea da celulose. Pode-se observar também um aumento do índice de cristalinidade das NCs obtidas através do ácido fosfórico em relação às obtidas com ácido sulfúrico. Isto deve-se ao fato do ataque com ácido sulfúrico também ser capaz de destruir parte da região cristalina, enquanto o ataque com $\mathrm{H}_{3} \mathrm{PO}_{4}$ tem um caráter mais brando. ${ }^{[42]}$ 


\subsubsection{Espectroscopia vibracional de absorção no infravermelho com transformada de Fourier (FTIR)}

Para se determinar os diferentes grupos funcionais presentes nas amostras, a análise de FTIR foi realizada. A Figura 28 apresenta os espectros obtidos das NCs preparadas pelos Métodos I, II e III.

Figura 28- Espectro vibracional de absorção no infravermelho (FTIR) obtido para as amostras de NCs preparadas pelos Métodos I (NCSOD), II (NCSOB) e III (NCPO).

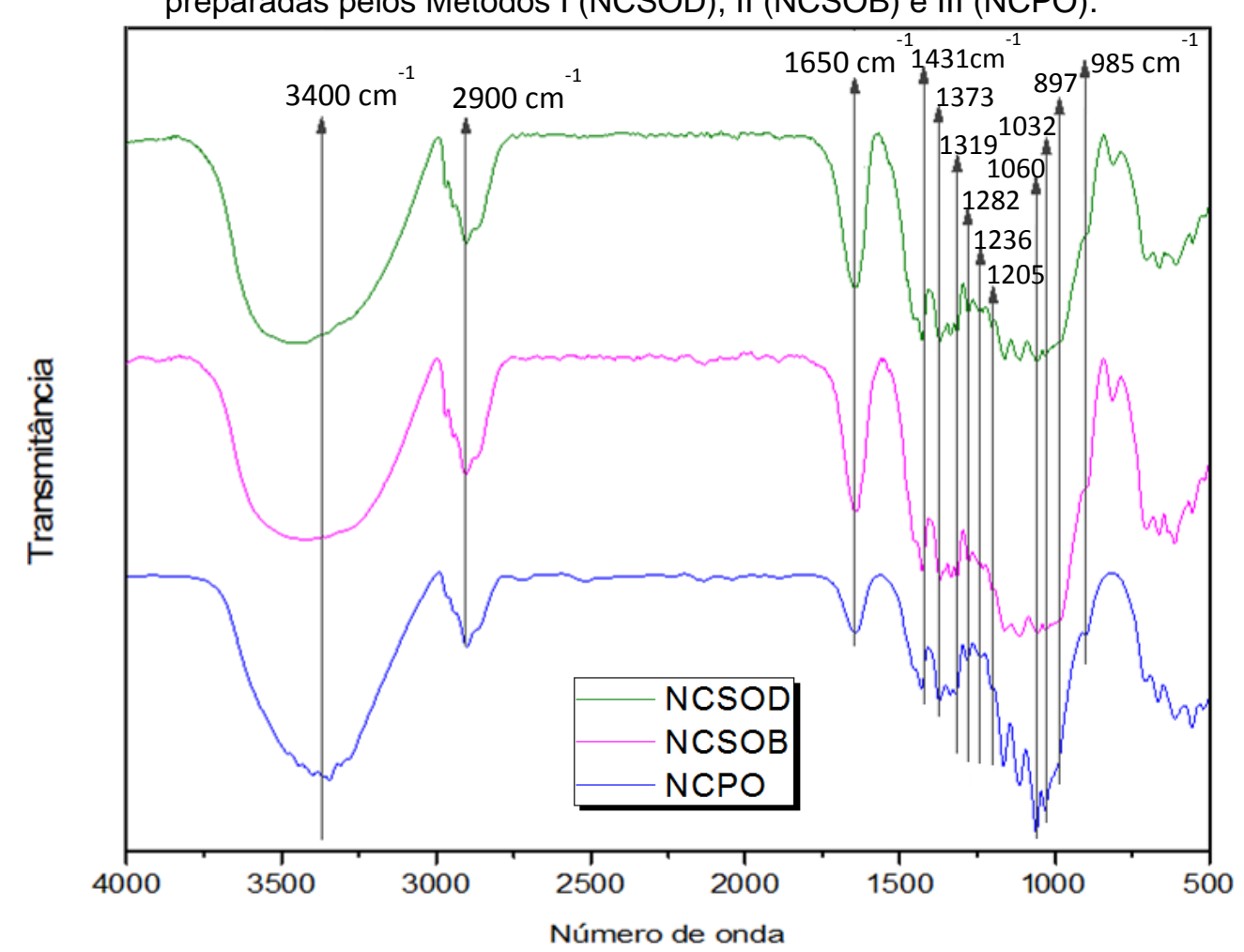

De acordo com os espectros acima, pode-se observar que todas as amostras possuem as mesmas bandas de absorção na região do infravermelho. Nestes espectros, a banda em $3400 \mathrm{~cm}^{-1}$ é atribuída à vibração do estiramento $\mathrm{O}-\mathrm{H}$. A absorção em $2900 \mathrm{~cm}^{-1}$ é característica do estiramento C-H, e a absorção em 1431 e $1319 \mathrm{~cm}^{-1}$ é atribuída à deformação de grupos $-\mathrm{CH}_{2}$. A banda em $1650 \mathrm{~cm}^{-1}$ é relacionada à absorção de água. As absorções em 1373 e 1282 cm$^{-1}$ são atribuídas à deformação da ligação C-H, enquanto que as bandas em 1236 e $1205 \mathrm{~cm}^{-1}$ são características da deformação da vibração de C-O-H. Já as absorções em 1032 e 985 são atribuídas ao estiramento da vibração C-O. Finalmente as bandas em 1060 e $897 \mathrm{~cm}^{-1}$ são atribuídas ao estiramento das vibrações C-O-C. ${ }^{[4,44,106]}$ 
Em conformidade com a literatura ${ }^{[4,94]}$, as bandas existentes em 3352, 2901, 1431, 1373, 1282, 1236, 1202, 1065, 1032, 983 e $897 \mathrm{~cm}^{-1}$ são características da estrutura cristalina da celulose I, confirmando os resultados obtidos por difração de raios $\mathrm{X}$, apresentados anteriormente.

\subsubsection{Análise Termogravimétrica (TG)}

A estabilidade térmica das NCs é uma característica muito importante a ser avaliada, uma vez que ao serem processadas, para obtenção de nanocompósitos, são submetidas a temperaturas ao redor de $200 \stackrel{\circ}{\circ}$. ${ }^{[76]}$ As Figuras 29 a e b apresentam as curvas TG obtidas para o papel filtro e as NCs obtidas pelos Métodos I, II e III.

Figura 29- Curvas TG das amostras de papel e das NCs preparadas pelos Métodos I (NCSOD), II (NCSOB) e III (NCPO);

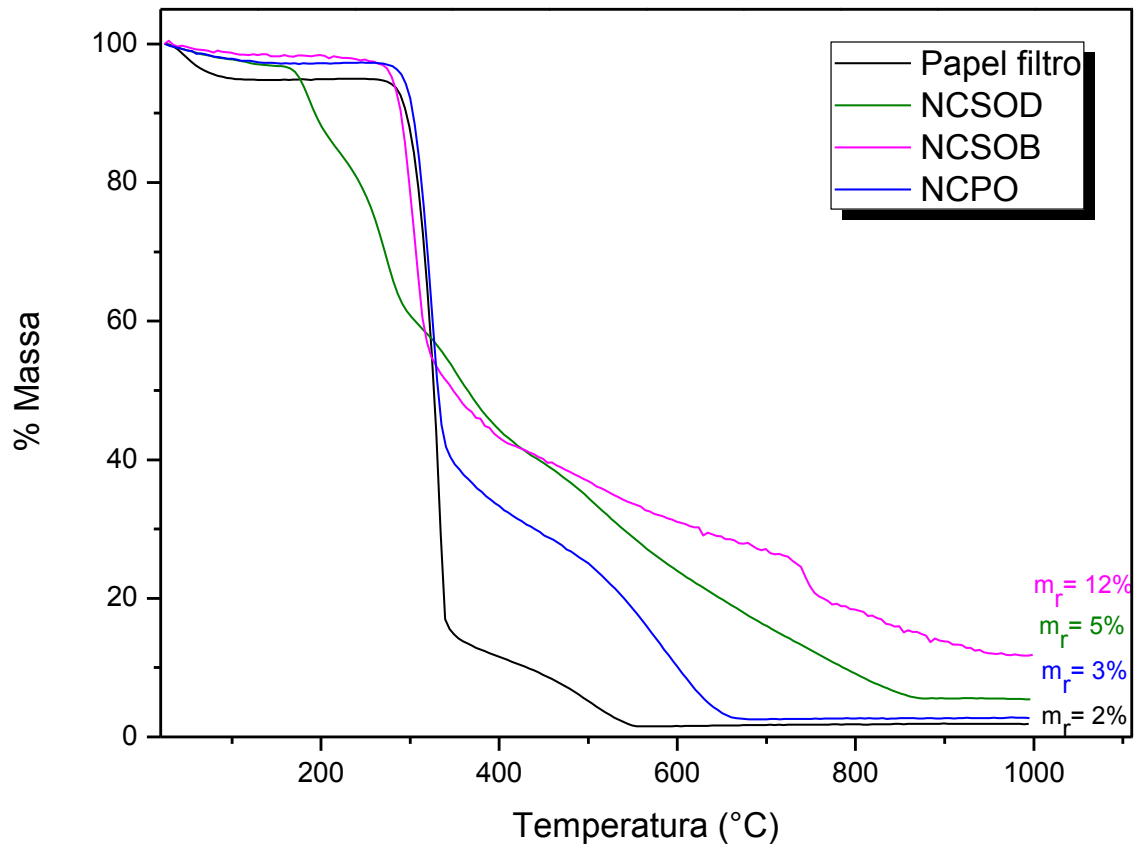

Conforme apresentado na Figura 29, pode-se notar que as amostras de NCSOD apresentaram o maior valor de massa residual $\left(m_{r}\right)$ de $12 \%$. Esta diferença de porcentagem deve-se ao sal originado pela reação de neutralização com bicarbonato de sódio. As amostras de NCPO, por sua vez, apresentaram o menor valor de massa residual, o que pode indicar baixa quantidade de subprodutos durante a reação de hidrólise e na neutralização. 
As temperaturas de início de degradação foram determinadas através da derivada da curva TG (DTG), apresentada na Figura 30.

Figura 30- Curvas DTG das amostras de papel e das NCs preparadas pelos Métodos I (NCSOD), II (NCSOB) e III (NCPO);

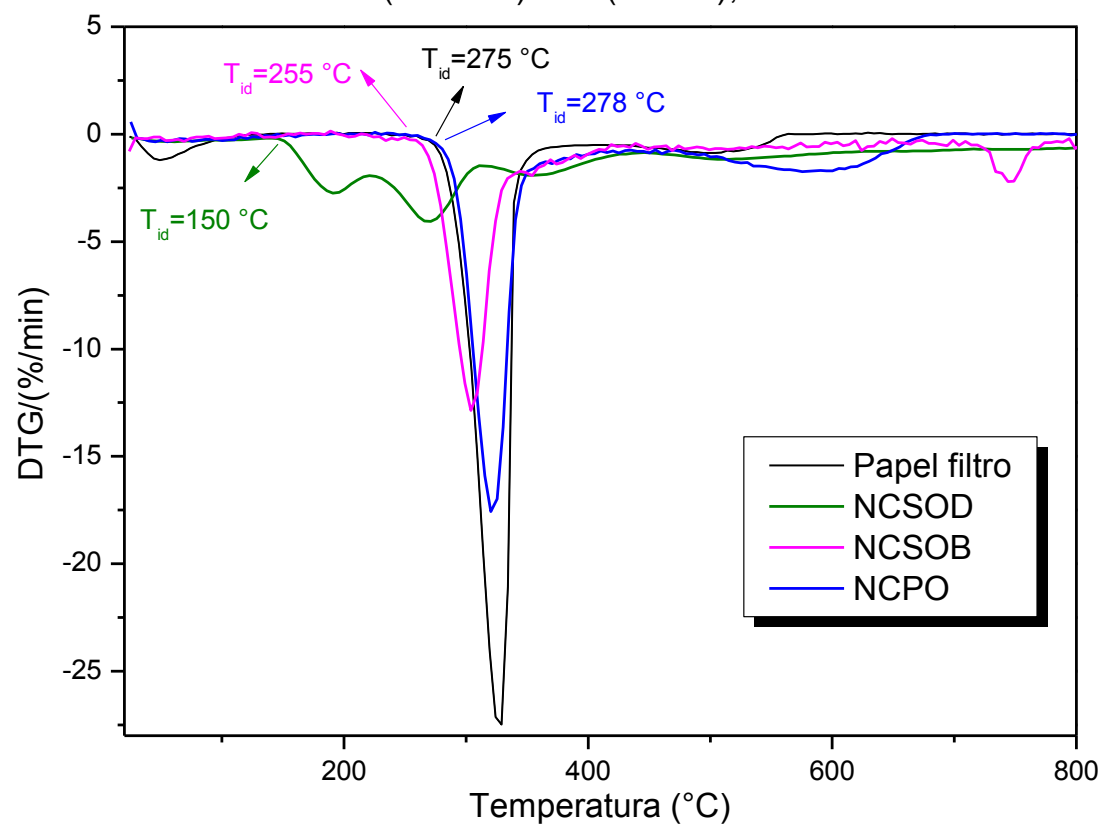

Observa-se na Figura 30 que não houve variação na temperatura de início de degradação ( $\left.T_{i d}\right)$ entre às amostras de NCs preparadas pelo Método III (NCPO) e o papel, apresentando ambas $\mathrm{T}_{\text {id }}$ em torno de $275^{\circ} \mathrm{C}$. Este resultado indica que a reação de hidrólise utilizando-se o ácido fosfórico é capaz de gerar NCs sem perdas de estabilidade térmica. Entretanto, é possível observar uma pequena queda no valor de $\mathrm{T}_{\mathrm{id}}$ das NCs preparadas pelo Método II (NCSOB), apresentando $\mathrm{T}_{\mathrm{id}}=255^{\circ} \mathrm{C}$, em relação ao papel.

Já as NCs preparadas pelo Método I (NCSOD) apresentaram o menor valor de $\mathrm{T}_{\text {id }}\left(150^{\circ} \mathrm{C}\right)$, quando comparadas com o papel e com as NCs preparadas pelos Métodos II e III. Pode-se concluir que a estabilidade térmica das NCs preparadas pelo Método I é significativamente reduzida, quando comparadas com as amostras preparadas pelos outros métodos e com o papel. Este comportamento inviabiliza sua aplicação como carga em compósitos poliméricos preparados por mistura com o polímero no estado fundido. O que provavelmente pode ter ocorrido é que possíveis resíduos do ácido utilizado na reação de hidrólise podem não ter sido neutralizados 
em sua totalidade, e mesmo depois de secas, as NCs, ao serem aquecidas, sofreram novamente ataque ácido, acelerando sua degradação.

Assim, pode-se afirmar que as amostras preparadas pelo Método II e III, apresentam estabilidade térmica de 255 a $278{ }^{\circ} \mathrm{C}$. Este comportamento viabiliza a aplicação destas cargas, em matriz polimérica no estado fundido, desde que submetidas a temperaturas de processo inferiores às acima descritas.

\subsubsection{Fluorescência de raios $X$}

Como as amostras de NCs preparadas pelo Método II contêm sal originado na etapa de neutralização, e sua presença foi evidenciada pela análise de DRX, fezse necessária à realização de uma análise química semi-quantitativa para mensurar, principalmente, a quantidade de sódio presente na amostra, além de se estimar a quantidade de grupos sulfatos e fosfatos que estão presentes na superfície das partículas, que atuam na repulsão entre as partículas e na sua dispersão. A Tabela 7 apresenta a composição química obtida por fluorescência de raios X.

Tabela 7 - Composição química semi-quantitativa das amostras de NCs obtidas pelo Método I, II e III.

\begin{tabular}{cccc}
\hline \multirow{2}{*}{ Elementos } & \multicolumn{3}{c}{ Porcentagem (\%) } \\
& NCSOD & NCSOB & NCPO \\
\hline $\mathrm{Na}$ & 0,065 & 3,81 & $<0,001$ \\
$\mathrm{Mg}$ & 0,135 & $<0,001$ & $<0,001$ \\
$\mathrm{Al}$ & 0,015 & 0,003 & 0,002 \\
$\mathrm{Si}$ & 0,034 & 0,016 & 0,007 \\
$\mathrm{~S}$ & 1,36 & 3,26 & 0,003 \\
$\mathrm{Cl}$ & 0,035 & 0,020 & 0,009 \\
$\mathrm{~K}$ & 0,038 & $<0,001$ & 0,003 \\
$\mathrm{Ca}$ & 0,711 & 0,010 & 0,018 \\
$\mathrm{Fe}$ & 0,003 & 0,003 & 0,002 \\
$\mathrm{Zn}$ & 0,002 & $<0,001$ & $<0,001$ \\
$\mathrm{P}$ & $<0,001$ & $<0,001$ & 0,018 \\
$\mathrm{Sr}$ & $<0,001$ & $<0,001$ & 0,001 \\
$\mathrm{PF}$ & 97,3 & 92,9 & 99,9 \\
\hline
\end{tabular}

$\mathrm{PF}=$ Perda ao fogo 
O resultado da análise apresenta um teor significativo de sódio na amostra de NCs obtidas pelo Método II em comparação com as outras amostras obtidas pelos Métodos I e III. Considerando-se que os 0,065\% de sódio indicados na amostra NCSOD são impurezas geradas no processo, e sendo que a análise de DRX mostrou um pico referente ao sulfato de sódio na amostra NCSOB, pode-se atribuir esta diferença da porcentagem em massa de sódio entre as amostras NCSOD e $\operatorname{NCSOB}(3,75 \%)$ à quantidade de íons de sódio $\left(\mathrm{Na}^{+}\right)$ligados aos íons $\mathrm{SO}_{4}^{-2}$, formando o $\mathrm{Na}_{2} \mathrm{SO}_{4}$ presente na amostra NCSOB. Além disso, outros compostos de sódio podem ter sido formados, como óxidos por exemplo, não sendo possível desta forma quantificar, exatamente, a quantidade do sal gerado.

A porcentagem do enxofre pode indicar a presença dos grupos sulfatos na superfície das NCs obtidas com ácido sulfúrico (NCSOD e NCSOB) e a porcentagem de fósforo na amostra NCPO pode indicar a presença dos grupos fosfatos na superfície das partículas após a hidrólise ácida utilizando-se ácido fosfórico. De acordo com os dados, observa-se que há entre 1,3 a 3,26\% de enxofre para as amostras obtidas com ácido sulfúrico e 0,018\% de fósforo para a amostra obtida com $\circ \mathrm{H}_{3} \mathrm{PO}_{4}$, indicando que a quantidade de grupos sulfato é maior nas superfícies das partículas das amostras NCSOD e NCSOB do que a quantidade de grupos fosfato na amostra de NCPO. Este fato pode interferir na dispersão das partículas, uma vez que tais grupos causam a repulsão entre as mesmas. Sendo que a densidade de grupos ligados às partículas da amostra de NCPO é menor, espera-se que haverá maior aglomeração entre suas partículas em comparação às amostras de NCSOD e NCSOB.

\subsubsection{Birrefringência de fluxo}

A Figura 31 apresenta fotografias de suspensões aquosas contendo as NCs obtidas pelos Métodos I, II e III. As suspensões foram colocadas entre duas lentes polarizadas cruzadas. O objetivo destas imagens é comprovar que as nanopartículas formam uma estrutura organizada em suspensão, as quais apresentam o fenômeno da birrefringência. 
Figura 31- Suspensões aquosas de NCs produzidas pelo Método I (a), II (b) e III (c). As suspensões foram colocadas entre duas lentes polarizadas cruzadas.

(a)

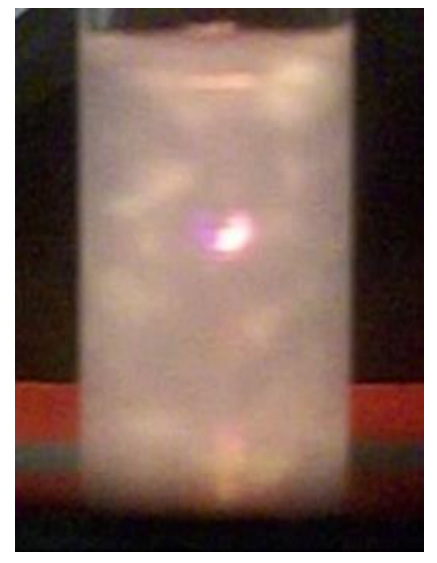

(b)

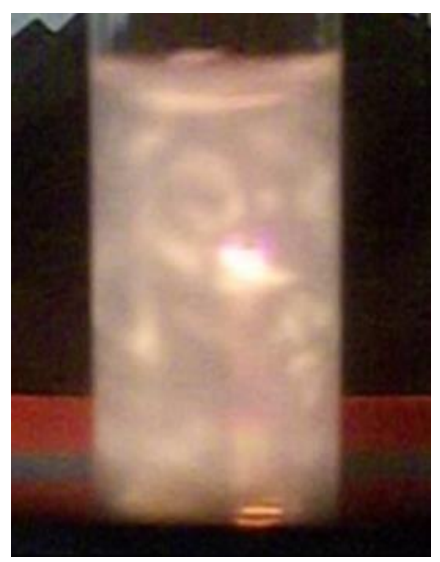

(c)

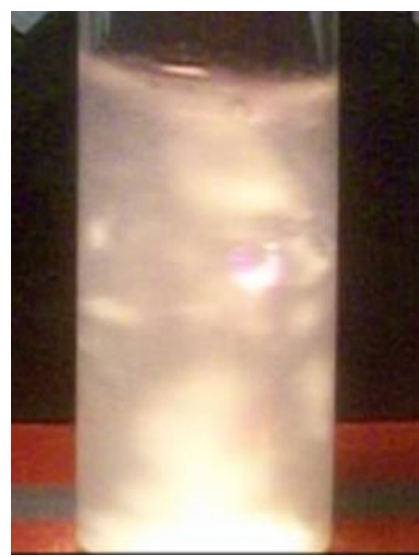

As imagens birrefringentes apresentadas nas suspensões são o primeiro estágio da organização das nanopartículas de celulose em um arranjo anisotrópico líquido-cristalino nemático quiral. $O$ arranjo é formado devido à presença de cargas na superfície das NCs, que criam uma tensão na estrutura gerando um centro quiral responsável pela organização das partículas. ${ }^{[1,5,33]}$

\subsubsection{Análises Morfológicas}

As análises morfológicas foram realizadas apenas nas NCs preparadas pelos Métodos I (NCSOD) e III (NCPO), uma vez que as amostras de NCSOD e NCSOB foram extraídas sob os mesmos parâmetros.

\subsubsection{Microscopia Eletrônica de Transmissão (MET)}

A Figura 32 apresenta imagens obtidas por MET para as NCs obtidas pelos Métodos I (NCSOD) e III (NCPO). 
Figura 32- Micrografias obtidas por MET: (a) e (b) amostras de NCSOD; (c) e (d) NCPO

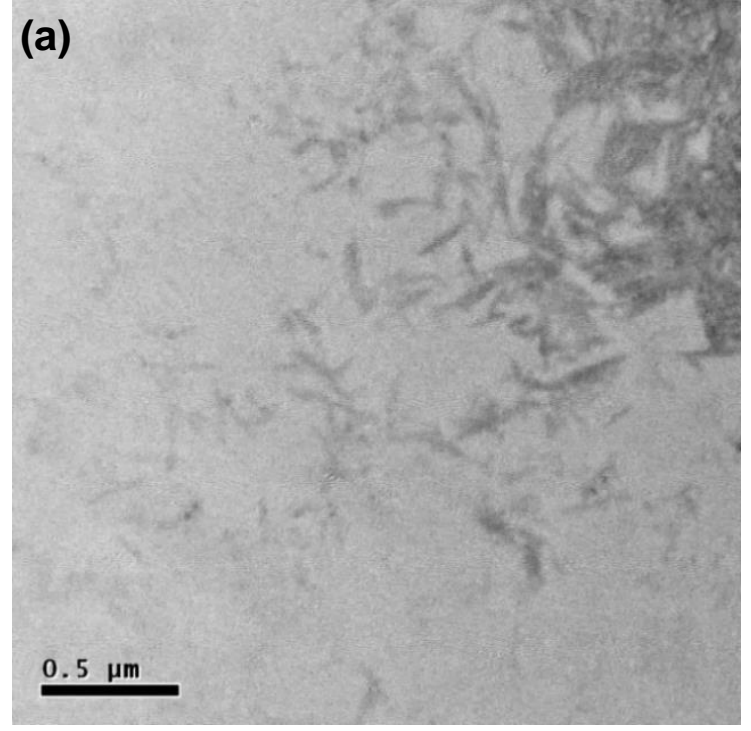

(b)

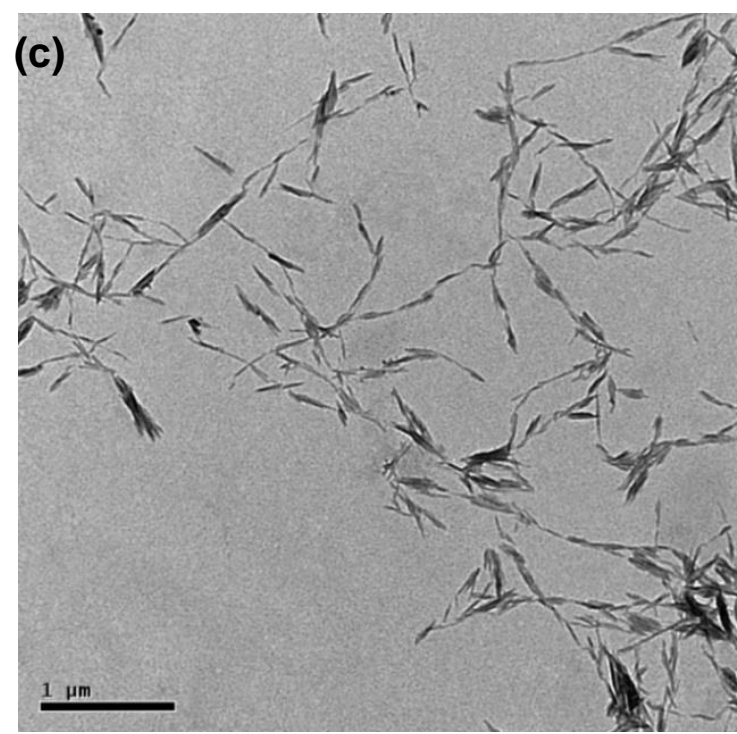

(d)

$\mathrm{Na}$ Figura 32 pode-se observar que as estruturas obtidas encontram-se em escala nanométrica para ambas as amostras e apresentam formato de finas agulhas para as amostras NCSOD (Figuras 32a e 32b), e de agulhas pouco mais espessas para as amostras de NCPO. Além disso, apesar do preparo das amostras ter sido realizado por ultrassonificação das soluções, é possível observar que as partículas da amostra de NCPO estão mais aglomeradas. As partículas da amostra de NCSOD, por sua vez, podem ser encontradas, individualmente, com maior facilidade. Esta diferença pode ser atribuída às diferentes modificações químicas que ocorrem na superfície das partículas durante a hidrólise, em função do uso de ácidos diferentes. Sabe-se que na hidrólise com ácido sulfúrico grupos sulfonados são ligados à superfície das partículas através dos grupos $-\mathrm{OH}$ presentes na 
estrutura celulósica. Tais grupos formam uma camada com carga negativa, que causa repulsão entre as partículas. No caso da hidrólise realizada com ácido fosfórico, grupos fosfato são ligados à superfície, e também podem causar repulsão entre as partículas. ${ }^{[42]}$ Entretanto, a densidade de grupos fosfatos ligados à superfície das NCs, geralmente, é bem menor do que a de grupos sulfatos, como foi também evidenciado na análise de fluorescência de raios $X$. Portanto, a formação de aglomerados é mais favorecida no caso de partículas obtidas por hidrólise com ácido fosfórico do que nas obtidas com ácido sulfúrico. ${ }^{[42]}$

\subsubsection{Microscopia de Força Atômica (MFA)}

A Figura 33 apresenta as imagens topográficas obtidas por MFA das amostras de NCs preparadas pelo Método I (NCSOD).

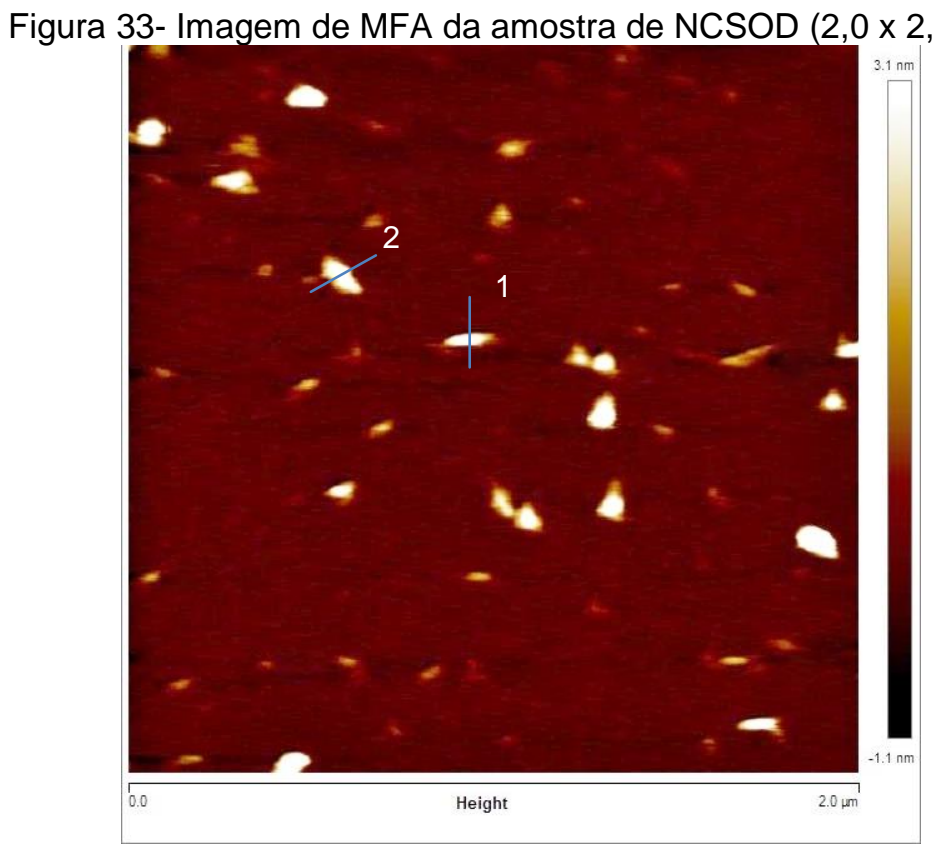

$\mathrm{Na}$ imagem obtida por MFA pode-se observar a presença de partículas individuais, assim como apresentado nas micrografias obtidas por MET. O formato das partículas observadas por MFA não é compatível com o formato das partículas observadas por MET, sendo que as obtidas por MFA possuem aspecto arredondado. Isso se deve ao fato da ponteira utilizada na varredura poder, em alguns casos, arrastar as partículas e distorcer as imagens topográficas. Entretanto, a altura medida, que é exemplificada no gráfico de posição apresentado na 
Figura 34, é precisa e corrobora com os valores de diâmetro de partículas observados nas imagens de MET.

Figura 34- Alturas transversais determinadas ao longo das linhas 1 e 2 apresentadas na Figura 33.

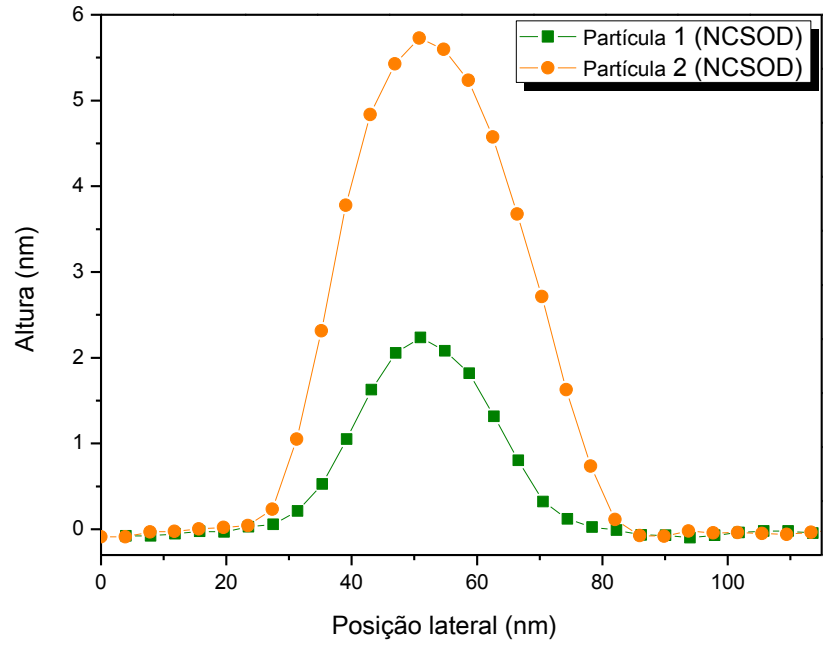

As imagens topográficas obtidas por MFA das amostras de NCs preparadas pelo Método III (NCPO) são apresentadas na Figura 35.

Figura 35- Imagem de MFA da amostra de NCPO $(2,5 \times 2,5 \mu \mathrm{m})$;

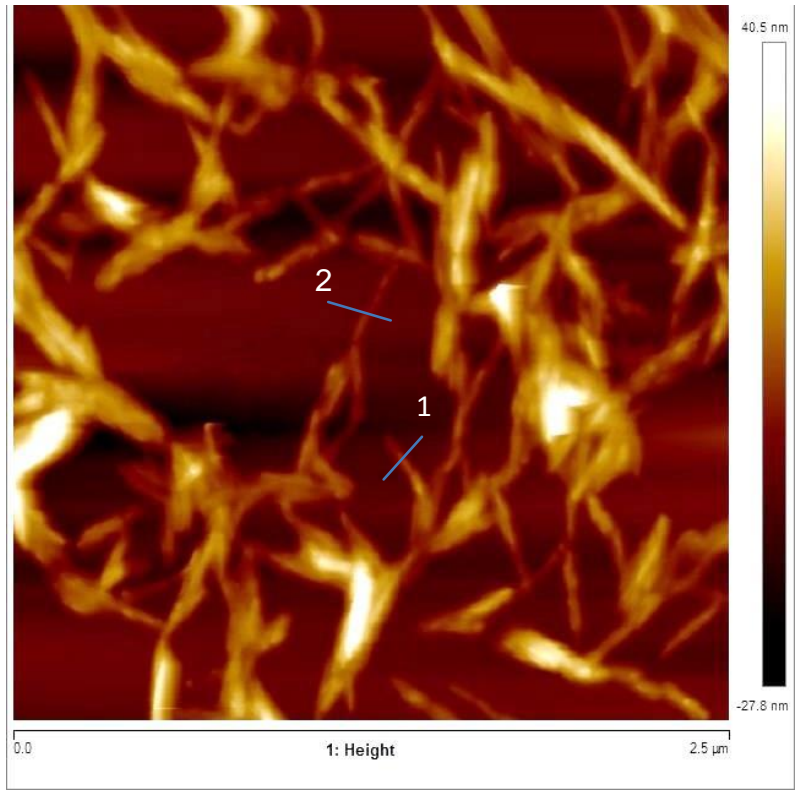

$\mathrm{Na}$ imagem obtida por MFA, apresentada na Figura 35, observa-se que as partículas se encontram aglomeradas e com grande grau de entrelaçamento. Estes resultados estão de acordo com as observações morfológicas obtidas por MET para a amostra NCPO. Entretanto, neste caso, as partículas apresentam formato de agulhas assim como foi observado nas micrografias obtidas por MET. Isto se deve 
ao maior tamanho de partículas, quando comparado ao tamanho de partícula da amostra NCSOD, e à maior ancoragem das amostras no substrato de mica, sendo possível, desta forma, que a ponteira seja capaz de varrer a área sem arrastar as partículas. As alturas medidas são exemplificadas no gráfico de posição na Figura 36, mostrando duas medidas de partículas individuais encontradas na imagem obtida por MFA, indicadas pelas linhas 1 e 2 na Figura 35. As medidas corroboram com os diâmetros de partículas observados nas imagens de MET.

Figura 36- Alturas transversais determinadas ao longo das linhas 1 e 2 apresentadas na Figura 35.

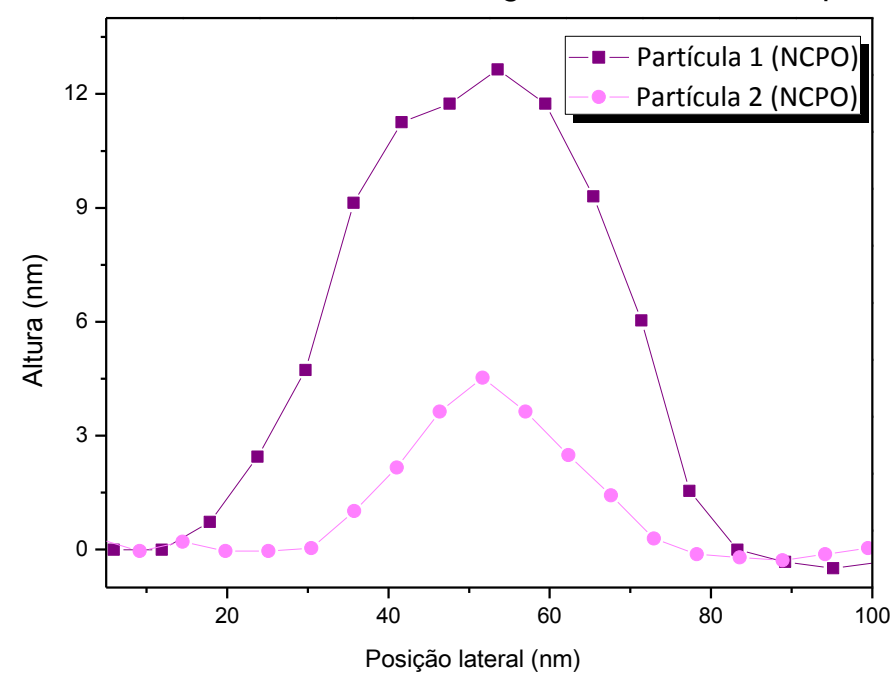

\subsubsection{Determinação das dimensões das NCs através das análises morfológicas}

Os valores do diâmetro (d), comprimento (L) e razão de aspecto (RA) das NCs foram medidos e calculados com base nas medidas realizadas através das imagens de MFA e MET, por meio dos softwares Nanoscope e ImageJ. Foram realizadas até 40 medições para as NCs obtidas pelos Métodos I e III. As médias dos valores e seus respectivos desvios padrão são apresentados na Tabela 8.

Tabela 8- Dimensões das NCs preparadas pelo Método I (NCSOD) e III (NCPO) determinadas por MET e AFM.

\begin{tabular}{ccc} 
& MET e AFM. & \\
\cline { 2 - 3 } & NCSOD & NCPO \\
\hline Comprimento $(\mathrm{nm})$ & $185 \pm 59$ & $301 \pm 46$ \\
Diâmetro $(\mathrm{nm})$ & $6 \pm 4$ & $14 \pm 6$ \\
RA $(\mathrm{L} / \mathrm{d})$ & $38 \pm 18$ & $25 \pm 12$ \\
\hline
\end{tabular}


Pelas médias dos valores apresentadas da Tabela 8 pode-se observar que as NCs obtidas referem-se aos nanocristais de celulose, uma vez que os valores de razão de aspecto (L/d) estão na faixa de 5-50, além dos valores de comprimento e diâmetros estarem em escala nanométrica que caracterizam este tipo de partícula. $A$ distribuição dos valores de razão de aspecto das partículas para cada amostra é apresentada na Figura 37.

Figura 37- Distribuição da razão de aspecto calculados para a amostras de (a) NCSOD e (b) NCPO.

(a)
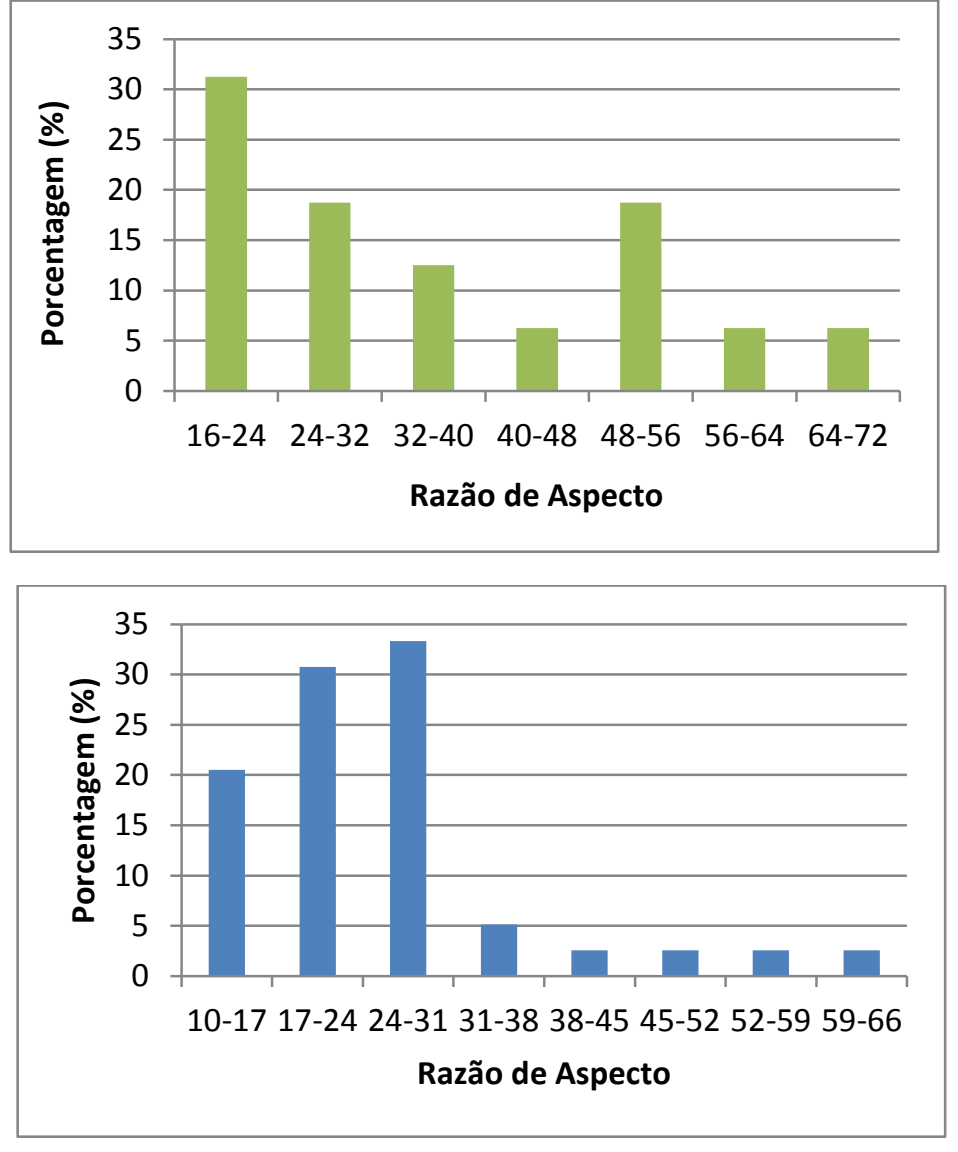

Observa-se que cerca de $88 \%$ dos valores de razão de aspecto encontram-se entre 16-56 para os nanocristais da amostra NCSOD, enquanto que $90 \%$ dos valores de razão de aspecto encontram-se entre 10-38 para os nanocristais da amostra NCPO. Sabe-se que altos valores de RA dos nanocristais de celulose atribuem melhores propriedades aos nanocompósitos quando estes são adicionados à matriz polimérica. ${ }^{[5,92]}$ Neste caso, acredita-se que os NCSO atribuirão melhores propriedades quando adicionado à matriz PLA. Além disso, as medições realizadas mostram que a utilização de ácido sulfúrico na reação de hidrólise é capaz de produzir partículas menores e mais finas do que a utilização do ácido fosfórico. 
Destaca-se que os valores das dimensões das partículas obtidas com ácido fosfórico podem ter sido mascarados pela presença de aglomerados.

\subsection{Obtenção dos compósitos}

Com base nas análises de caracterização das NCs, apenas as obtidas pelos Métodos II e III possuem estabilidade térmica para serem adicionadas à matriz PLA. Assim, descreve-se a seguir resultados obtidos com a adição destas NCs em matriz de PLA.

\subsubsection{Utilização das NCs preparadas pelo Método II (NCSOB)}

As curvas de torque obtidas durante o processamento em câmara de mistura do PLA puro e com 1 e 3 \% em massa de NCSOB são apresentadas na Figura 38.

Figura 38- Curvas de torque obtidas durante o processamento das amostras de PLA puro e com 1 e $3 \%$ de NCs.

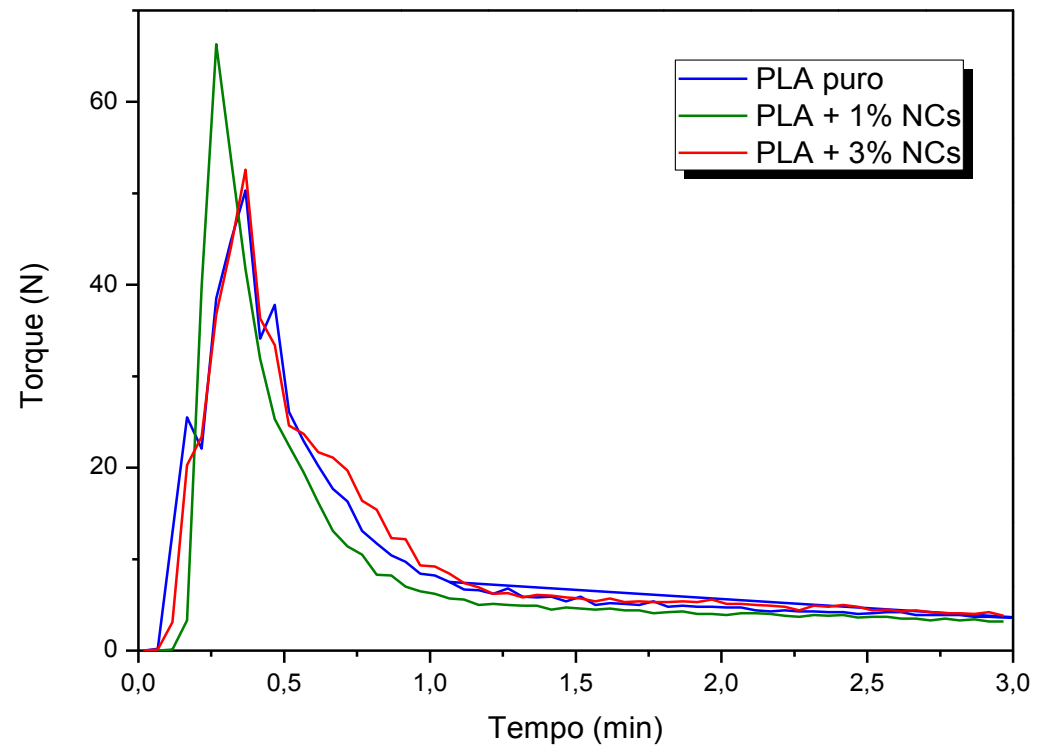

De acordo com as curvas apresentadas, pode-se observar uma estabilidade nos valores de torque após 1,5 minuto de processamento. Este resultado indica que o tempo de processamento de 3 minutos é suficiente para misturar os componentes dos compósitos, uma vez que o material já se encontra fluido na metade do tempo de processamento. Além disso, um maior tempo de processamento poderia ocasionar degradação dos materiais, já que o PLA e as NCs são termicamente sensíveis. O PLA puro e os compósitos obtidos são apresentados na Figura 39. 
Figura 39- Fotografias (a) do PLA puro; e dos compósitos obtidos: b) PLA com 1\% em massa de NCSOB; c) PLA com 3\% em massa de NCSOB. (Discos de 25 mm de diâmetro)

(a)

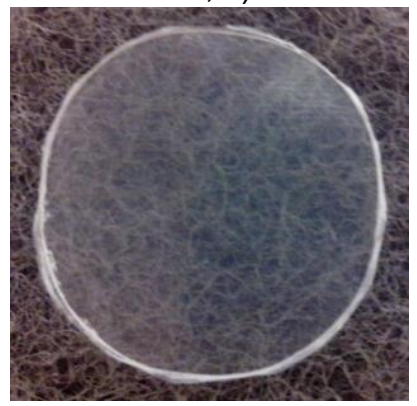

(b)

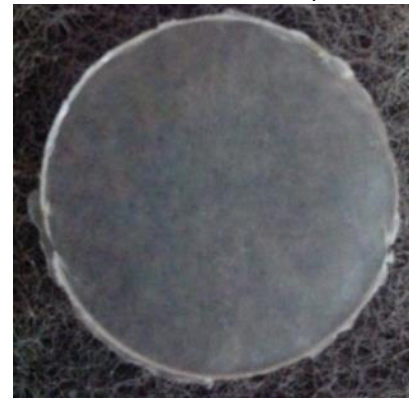

(c)

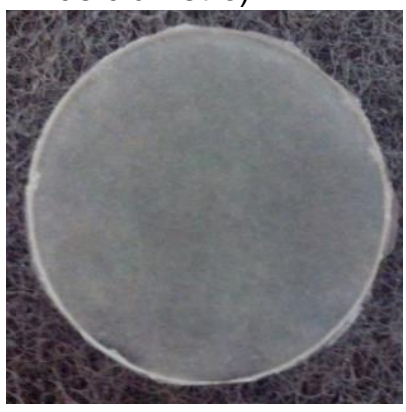

As fotografias apresentadas na Figura 39 indicam que os compósitos apresentam uma dispersão homogênea das cargas na fase matriz, não sendo possível observar a presença de grandes aglomerados.

\subsubsection{Utilização das NCs preparadas pelo Método III (NCPO)}

Seguindo a mesma metodologia, os compósitos de PLA com 1 e $3 \%$ em massa de NCPO foram obtidos em câmara de mistura. Os compósitos obtidos são apresentados na Figura 40.

Figura 40- Fotografias dos compósitos obtidos: a) PLA com 1\% em massa de NCPO; b) PLA com 3\% em massa de NCPO. (Discos de 2,5 mm de diâmetro)

(a)

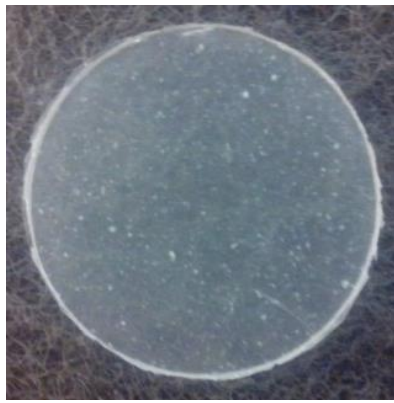

(b)

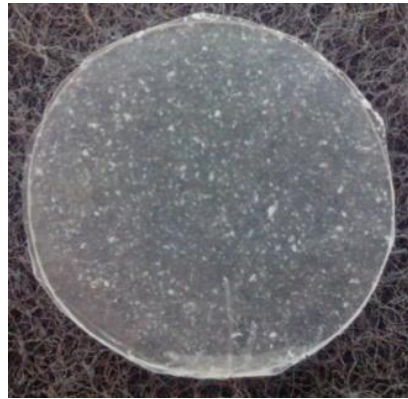

Nas fotografias apresentadas na Figura 40 pode-se observar a presença de grandes aglomerados de carga na fase matriz. Deste modo, pode-se concluir que este compósito não apresenta dispersão predominantemente fina das cargas na fase PLA, quando comparado ao compósito com NCSOB. Este tipo de morfologia pode ser explicada pelo fato das NCs preparadas por ácido fosfórico não apresentarem repulsão entre partículas tão efetiva quanto as apresentadas por NCs preparadas com o ácido sulfúrico. 
Deste modo, para as demais análises de caracterização dos compósitos, apenas os compósitos obtidos a partir das NCs preparadas pelo Método II (NCSOB) serão relatados, visto que não apresentaram aglomerados visíveis.

\subsection{Caracterização dos compósitos de PLA e NCs}

A seguir são apresentados os resultados das análises de caracterização de compósitos de PLA e NCs obtidas pelo Método II.

\subsubsection{Análise Termogravimétrica (TG)}

A Figura 41 apresenta as curvas obtidas por análises termogravimétricas das amostras de PLA puro e com 1 e $3 \%$ em massa de NCs.

Figura 41- (a) Curvas de TG para as amostras de PLA puro e com 1 e $3 \%$ em massa de NCs e (b) detalhe da curva $\mathrm{TG}$ de 250 a $400^{\circ} \mathrm{C}$

(a)

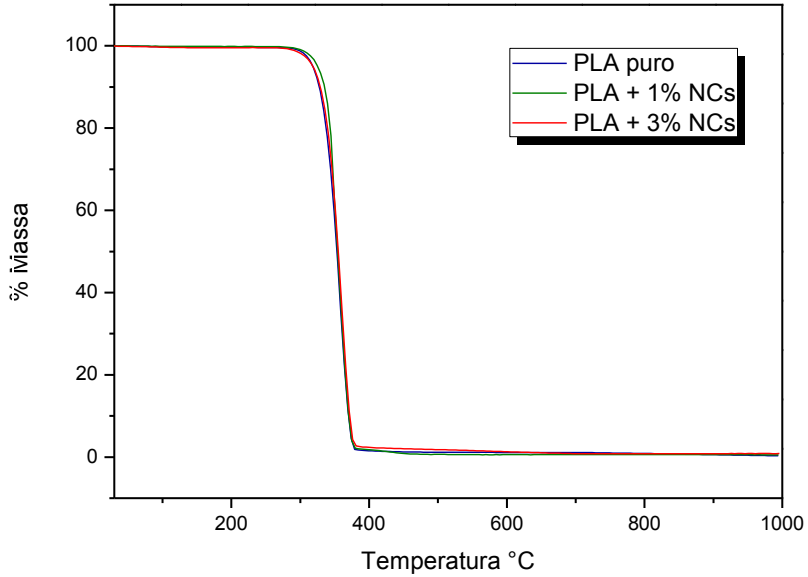

(b)

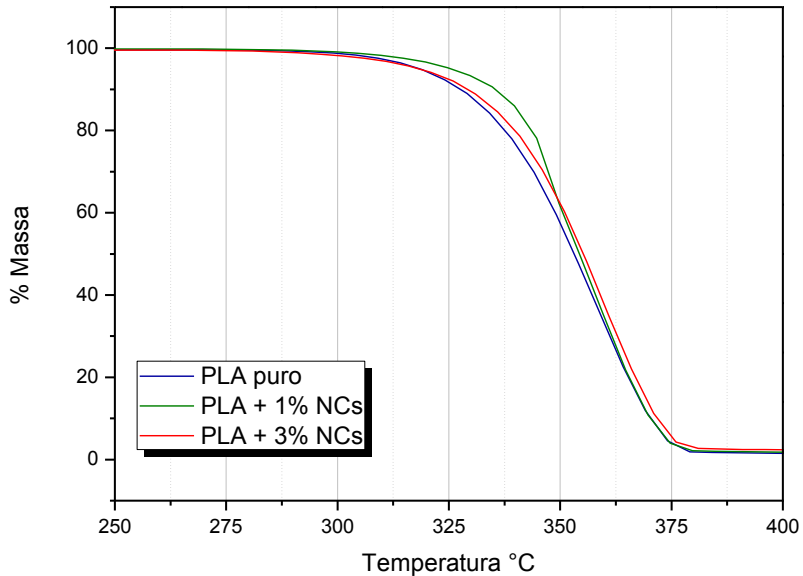

A Figura 42 apresenta a derivada das curvas TG. Juntamente com as curvas TG apresentadas na Figura 41, é possível se determinar as temperaturas de início de degradação $\left(T_{\text {id }}\right)$, a temperatura onde ocorre $50 \%$ de perda de massa $\left(T_{50 \%}\right)$ e porcentagem de massa residual $\left(m_{r}\right)$, apresentadas na Tabela 9. 
Figura 42- Curvas de DTG para as amostras de PLA puro e com 1 e $3 \%$ em massa de NCs, de 200 a $500^{\circ} \mathrm{C}$.

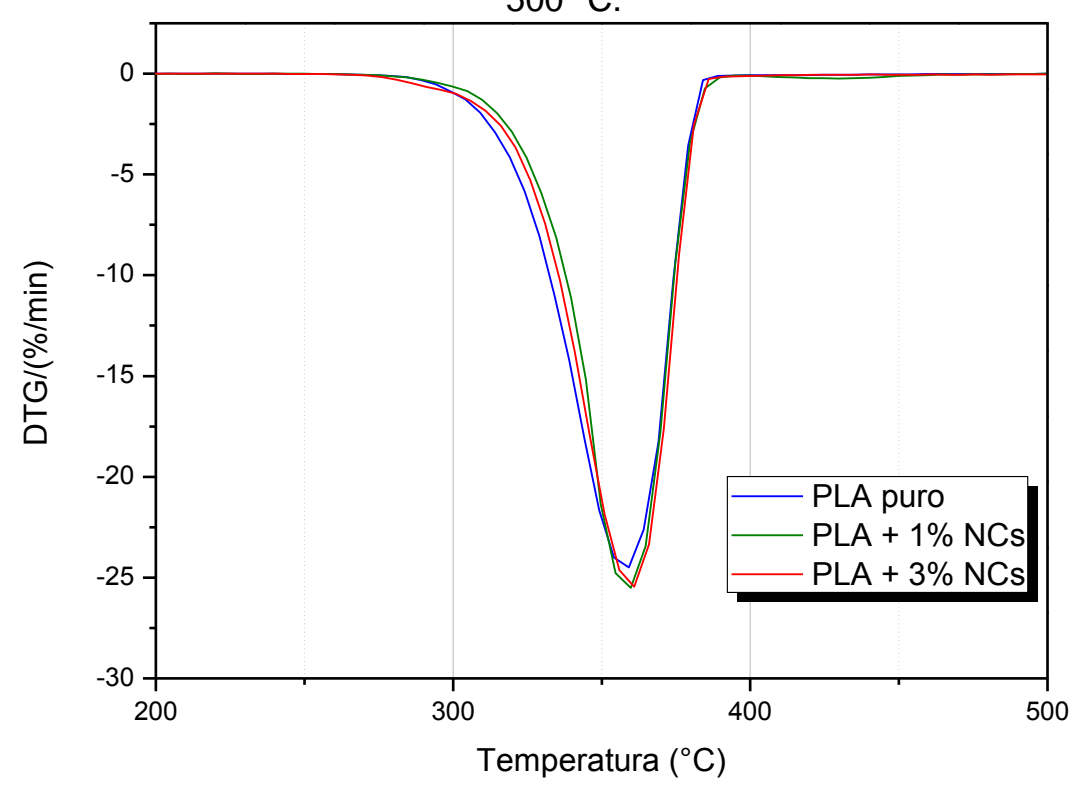

Tabela 9- Temperaturas de início de degradação $\left(T_{i d}\right)$, temperaturas que ocorre perda de $50 \%$ de massa e massa residual das amostras de PLA puro e com 1 e $3 \%$ em massa de NCs.

\begin{tabular}{cccc}
\hline Amostra & $\mathrm{T}_{\text {id }}\left({ }^{\circ} \mathrm{C}\right)$ & $\mathrm{T}_{50 \%}\left({ }^{\circ} \mathrm{C}\right)$ & Massa residual $(\%)$ \\
\hline PLA puro & 300 & 353 & 0,3 \\
PLA + 1\% de NCs & 305 & 354 & 0,5 \\
PLA + 3\% de NCs & 300 & 356 & 0,8 \\
\hline
\end{tabular}

As curvas de DTG apresentadas indicam os mesmos valores de temperatura de início de degradação para as amostras de PLA puro e com 3\% em massa de NCs $\left(300^{\circ} \mathrm{C}\right)$. No entanto, para amostras de PLA com $1 \%$ em massa de NCs, observase que o valores de temperatura de início de degradação é ligeiramente mais alto $\left(305^{\circ} \mathrm{C}\right)$. Observa-se ainda que as temperaturas para $50 \%$ de perda de massa das amostras são próximas, mostrando um pequeno aumento da temperatura com 0 aumento de carga. A porcentagem de massa residual também apresenta valores diretamente proporcionais à adição de carga na fase matriz. Acredita-se que a massa residual é devida à quantidade de $\mathrm{Na}_{2} \mathrm{SO}_{4}$ gerado na neutralização das amostras NCSOB.

De acordo com a literatura ${ }^{[97]}$ a adição de NCs na matriz PLA diminui, proporcionalmente, a temperatura de início de degradação. Entretanto, os resultados obtidos indicam que a interação entre a matriz e $1 \%$ de NCs pode dificultar, 
ligeiramente, a degradação do material resultante, e que com a adição de $3 \%$ em massa de carga este efeito não é observado.

\subsubsection{Calorimetria Exploratória Diferencial (DSC)}

Com as análises de DSC foi possível determinar os valores de temperatura de transição vítrea $\left(T_{g}\right)$, temperatura de cristalização $\left(T_{c}\right)$ e temperatura de fusão $\left(T_{m}\right)$ do PLA puro e do PLA com 1 e $3 \%$ em massa de NCs, conforme apresentado na Figura 43.

Figura 43- Curvas DSC das amostras de PLA puro e com 1 e $3 \%$ em massa de NCs, de $0^{\circ} \mathrm{C}$ a $180^{\circ} \mathrm{C}$.

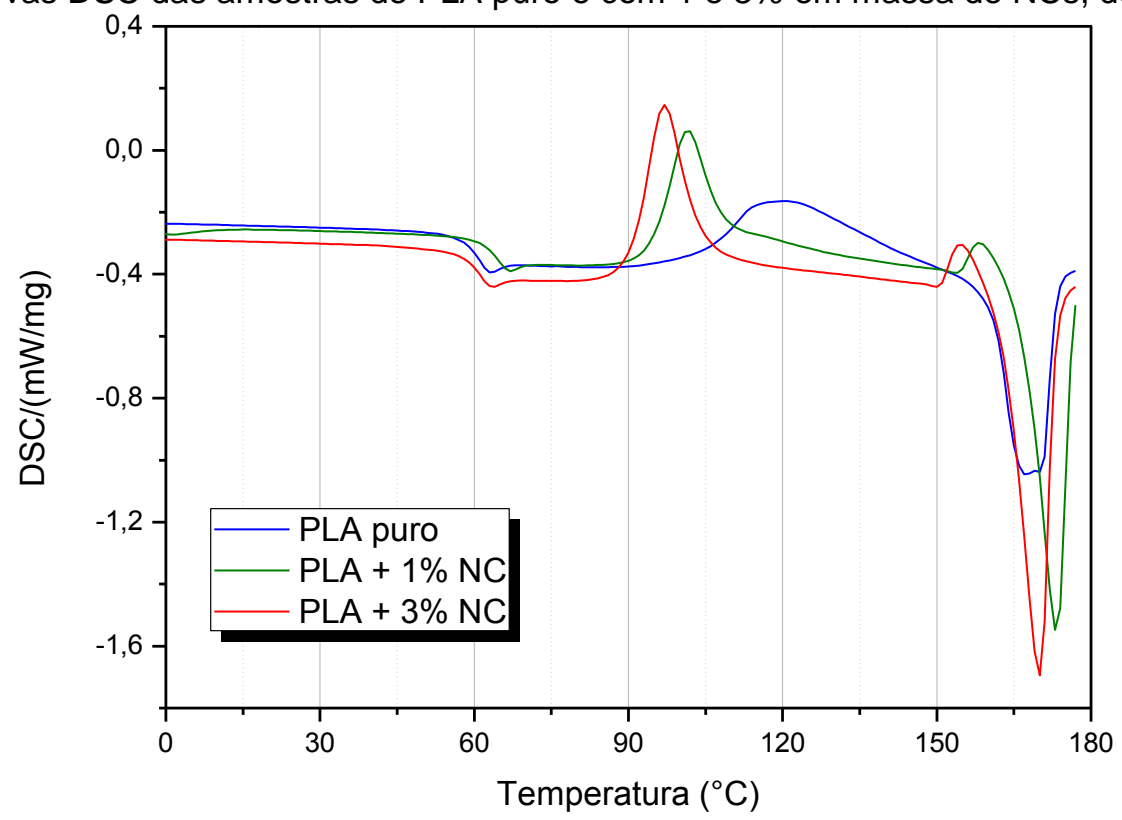

Como reportado em vários estudos ${ }^{[57,87]}$, pode-se observar o pico de cristalização do PLA durante o segundo ciclo de aquecimento. A cristalização deste polímero é relativamente lenta e depende, essencialmente, da taxa de aquecimento e do tempo em que a amostra permanece na respectiva temperatura de cristalização.

Como apresentado na Figura 43, a adição de carga interferiu significativamente na $T_{c}$ da matriz PLA. Enquanto o PLA puro apresenta um pico de cristalização largo em aproximadamente $120^{\circ} \mathrm{C}$, o PLA com $3 \%$ em massa de NCs apresentou um pico mais estreito e de maior intensidade, à temperatura de aproximadamente $97^{\circ} \mathrm{C}$. Já o PLA com $1 \%$ em massa de NCs possui valor de $\mathrm{T}_{\mathrm{c}}$ de 
$102{ }^{\circ} \mathrm{C}$, o qual é ligeiramente próximo ao PLA com 3\% de carga. Os resultados obtidos indicam que a carga tem grande influência na cristalização do PLA.

Através das curvas obtidas por DSC foi possível se obter os valores de entalpias, por cálculo das áreas dos respectivos picos de fusão e cristalização. Com isto, o grau de cristalinidade $(X)$, para cada amostra, pôde ser calculado utilizando a Equação (1) [57], apresentada na revisão da literatura. Os resultados são apresentados na Tabela 10.

Tabela 10 - Valores de entalpia de fusão e cristalização $\left(\Delta \mathrm{H}_{\mathrm{m}}\right.$ e $\left.\Delta \mathrm{H}_{\mathrm{c}}\right)$ e Grau de Cristalinidade $(X)$, para as amostras de PLA puro e com 1 e $3 \%$ em massa de NCs.

\begin{tabular}{cccc}
\hline Amostra & $\Delta \mathbf{H}_{\mathrm{m}}(\mathbf{J} / \mathbf{s})$ & $\Delta \mathbf{H}_{\mathrm{c}}(\mathbf{J} / \mathbf{s})$ & $\boldsymbol{X}(\%)$ \\
\hline PLA puro & 39 & 24 & 16 \\
PLA + 1\% de NCs & 51 & 21 & 32 \\
PLA + 3\% de NCs & 58 & 27 & 33 \\
\hline
\end{tabular}

Conforme observado na Tabela 10, houve um aumento significativo nos valores de grau de cristalinidade do PLA com a adição de NCs. Ao se adicionar $3 \%$ em massa de NCs, o aumento do grau de cristalinidade, comparado com o PLA com $1 \%$ em massa de carga, foi mais atenuado. Vale ressaltar que, conforme encontrado na literatura ${ }^{[4,87]}$, a adição das nanopartículas de celulose, de fato, aumenta o grau de cristalinidade da matriz PLA, e em muitos casos, quanto maior a afinidade do polímero com a carga, maior será o grau de cristalinidade do compósito resultante.

\subsubsection{Micrografia Óptica (MO)}

Na Figura 44 são apresentadas as micrografias ópticas de amostras do PLA puro e do PLA com 3\% em massa de NCs. 
Figura 44- Micrografias ópticas de amostras submetidas às isotermas, nas suas temperaturas de cristalização (Tc): (a) PLA por 1 min na $T_{c 1}$; (b) PLA após 5 min na $T_{c 1}$; (c) PLA + 3\% NCs na $\left(T_{\mathrm{c} 2}-10^{\circ} \mathrm{C}\right) ;(\mathrm{d}) \mathrm{PLA}+3 \% \mathrm{NCs}$ em $\mathrm{T}_{\mathrm{c} 2}$ por 2 min.

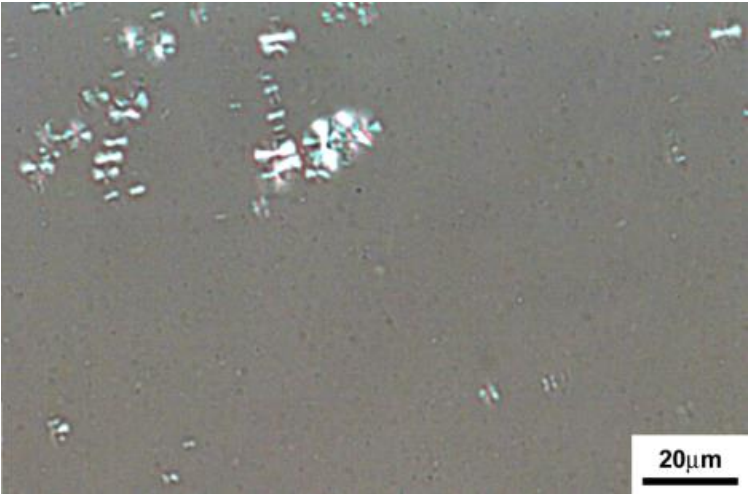

(a)

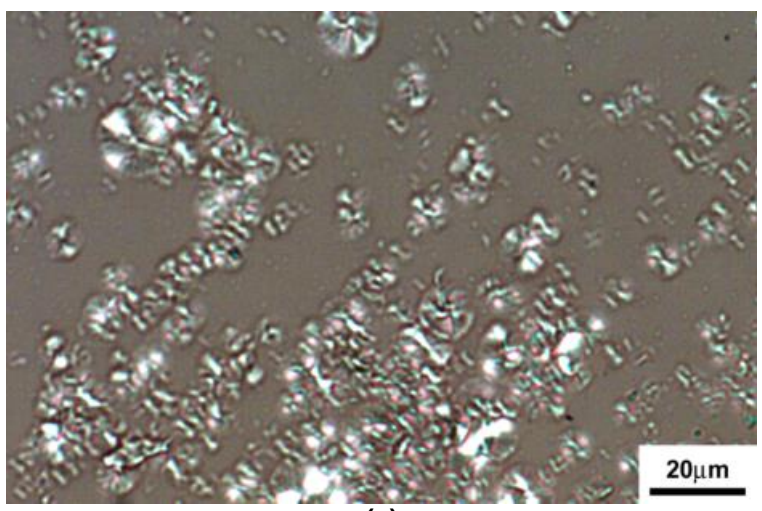

(c)

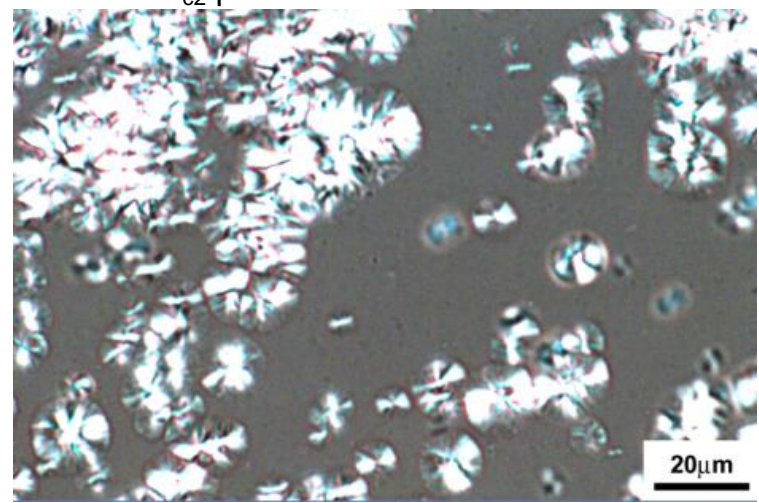

(b)

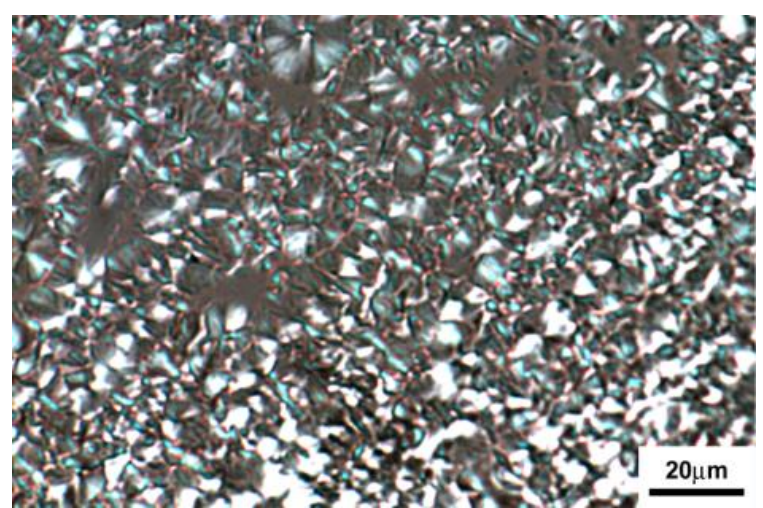

(d)

Pode-se observar nas amostras de PLA puro que as estruturas esferulíticas apareceram depois de cerca de 1 minuto de isoterma, quando a amostra estava na sua temperatura de cristalização $\left(T_{c 1}=120^{\circ} \mathrm{C}\right)$. Após 5 minutos na $T_{c 1}$ observa-se a presença de novos esferulitos e o crescimento dos mesmos. Entretanto, as estruturas cristalinas ainda não ocuparam toda a região de observação. Diferentemente do PLA puro, o PLA com carga apresentou estruturas esferulíticas antes da isoterma. A micrografia apresentada na Figura $44 \mathrm{c}$ foi obtida a $90^{\circ} \mathrm{C}\left(10^{\circ} \mathrm{C}\right.$ abaixo da temperatura de cristalização do compósito, $\left.T_{\mathrm{c} 2}=100^{\circ} \mathrm{C}\right)$. $E$ após permanecer por 2 minutos na $T_{c 2}$, os esferulitos já ocupavam toda a região de observação. As micrografias confirmam os resultados obtidos por análise térmica, na qual se observa que com a presença da carga a cristalização do PLA é antecipada.

\subsubsection{Análises reológicas}

Na Figura 45 são apresentados os resultados dos ensaios de varredura de deformação realizados para as amostra de PLA puro e com 1 e $3 \%$ em massa de 
NCs . As linhas tracejadas indicam a faixa de deformação contida na Região de Viscoelasticidade Linear (RVL).

Figura 45- Curva de G' em função da deformação, de amostras de: (a) PLA puro, (b) PLA com 1\% em

(a)

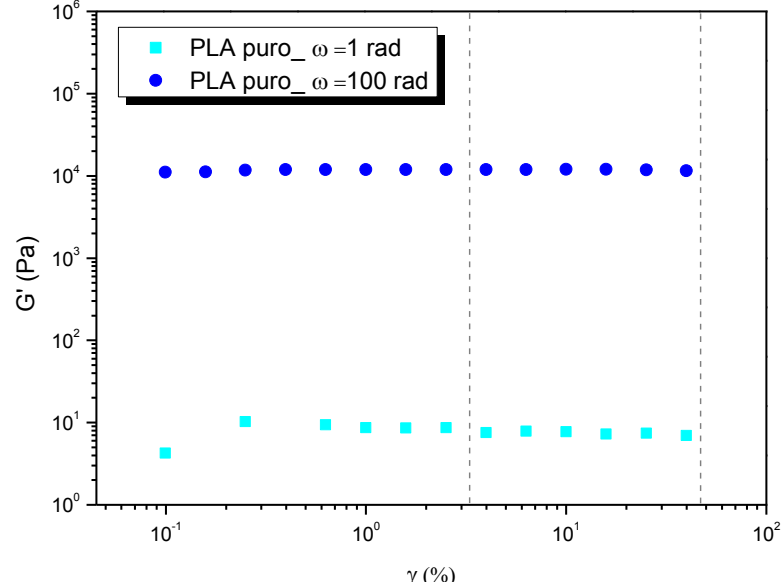

(b)

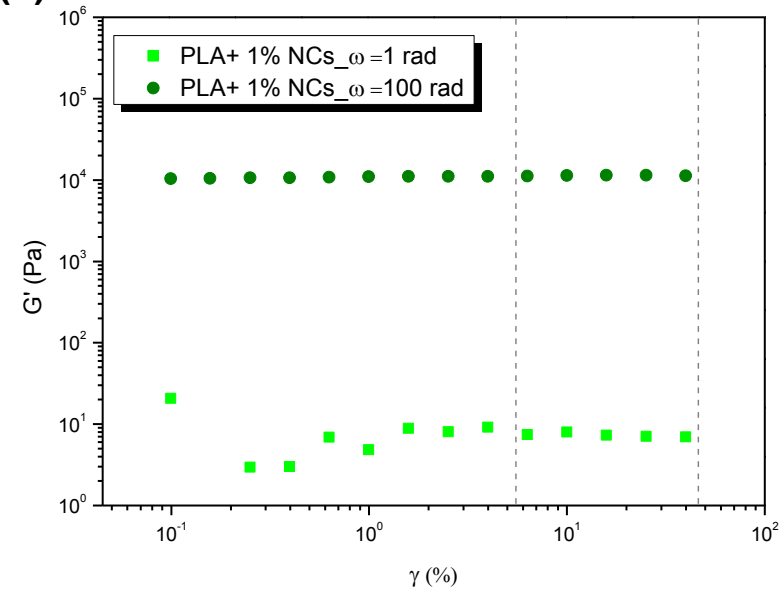

(c)

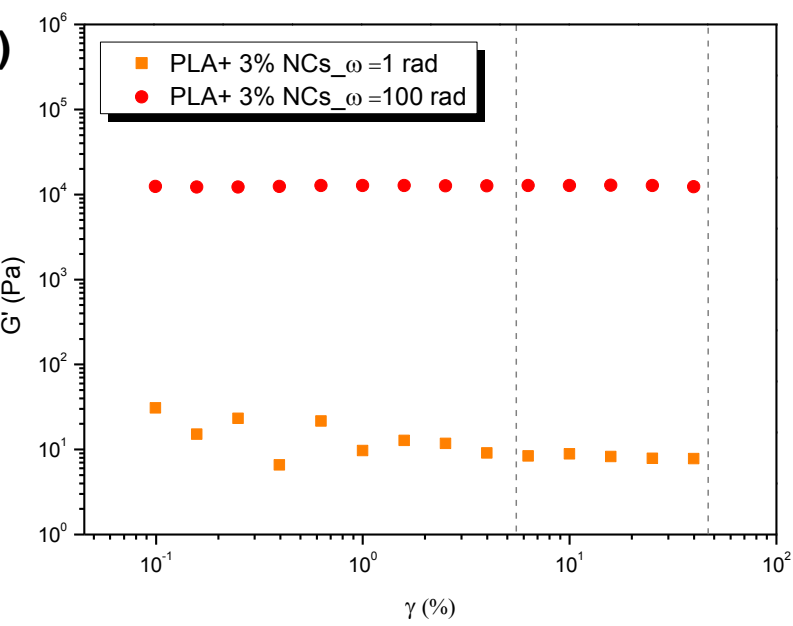

Conforme observado na Figura 45a, a faixa de deformação considerada dentro da RVL está compreendida entre 4 e $40 \%$ para o PLA puro. Para as amostras de PLA com 1 e $3 \%$ em massa de NCs, apresentadas nas Figura 45b e Figura 45c, respectivamente, a faixa de deformação dentro da RVL está compreendida entre 6 e $40 \%$. Adotou-se, então, deformação de $8 \%$ para a realização dos ensaios de COPA de todas as amostras.

Os ensaios de COPA realizados com o PLA puro e PLA com 1\% e 3\% em massa de NCs são apresentados nas Figura 46 e Figura 47. 
Figura 46- Curvas de viscosidade complexa em função da frequência, para amostras de PLA puro e com 1 e $3 \%$ em massa de NCs.

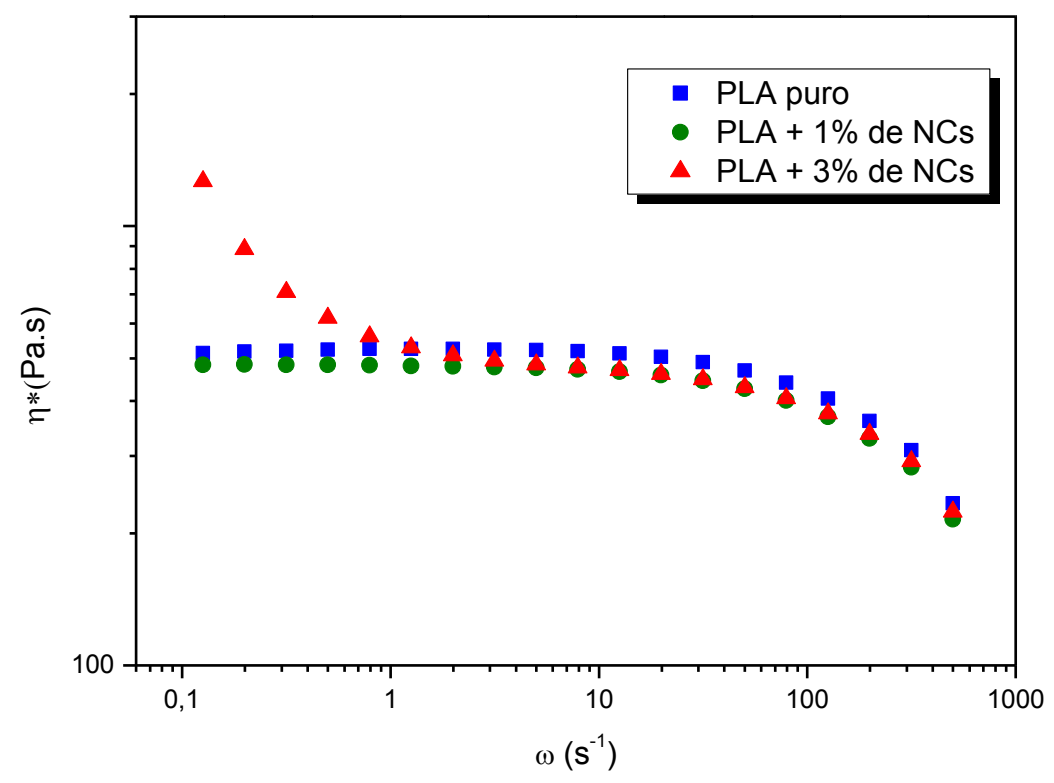

Figura 47- Curva G' e G" em função da frequência, para PLA puro e com 1 e $3 \%$ em massa de NCs.

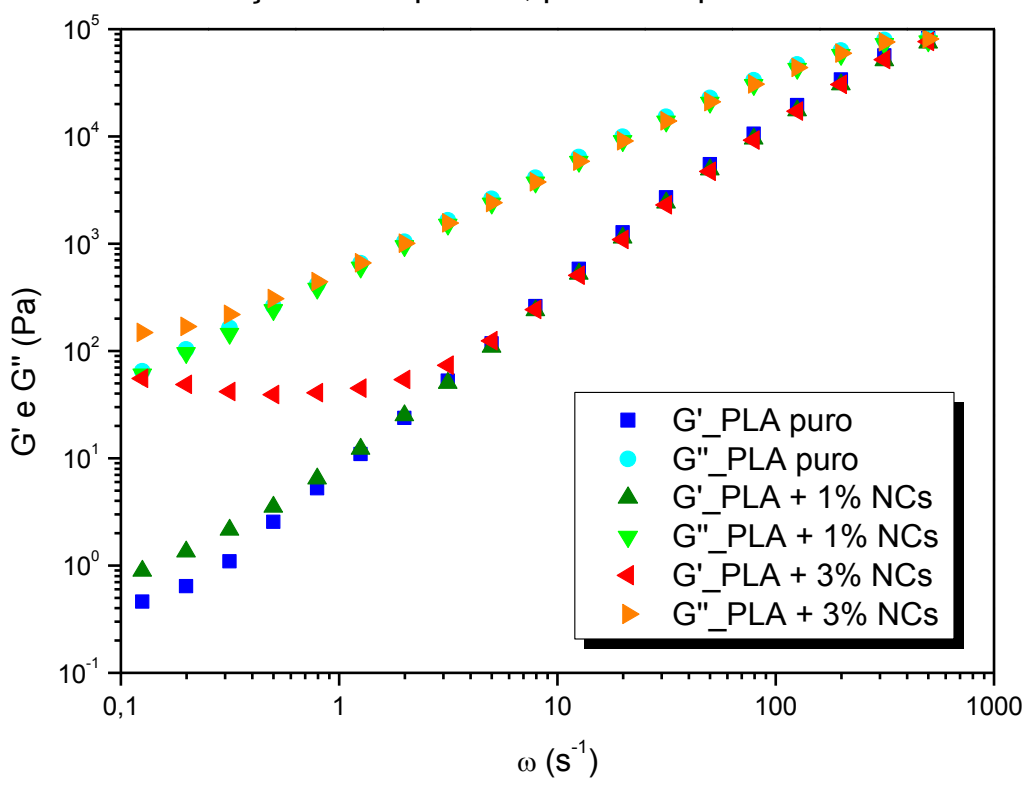

Como pode ser observado na Figura 46, há um significativo aumento nos valores de viscosidade complexa do PLA com 3\% em massa de carga, a baixos valores de frequência, e o patamar da região linear, presente nas amostras de PLA puro, e com $1 \%$ em massa de NCs, não é observado para nenhuma frequência.

Na Figura 47, observa-se que para o PLA puro e o compósito com 1\% em massa de NCs, os valores de G' e de G", nas zonas de baixa frequência, apresentam inclinações terminais características de homopolímeros. Entretanto, com a adição de $3 \%$ em massa de NCs há um desvio deste comportamento e a 
inclinação do módulo diminuiu, formando quase um patamar, no caso da curva de G'. Este comportamento é evidenciado, mais facilmente, na Figura 48.

Figura 48- Curva de G' e G" em função da frequência para o PLA com 3\% em massa de NCs.

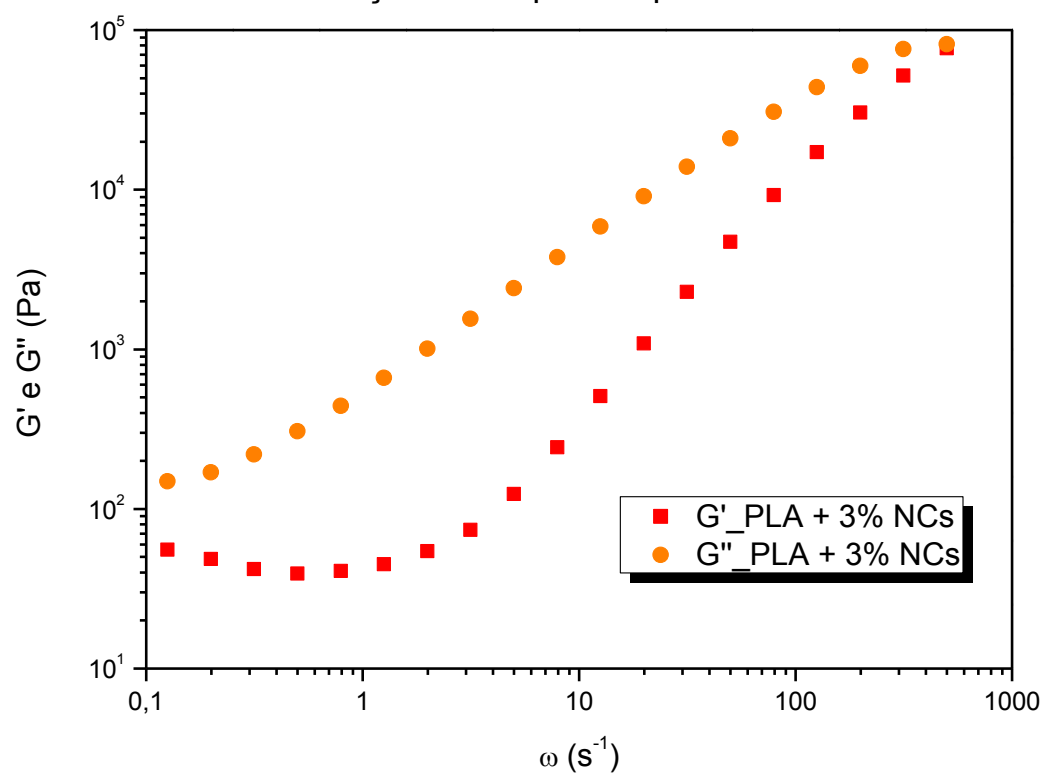

Os resultados obtidos para a amostra de PLA com 3\% em massa de NCs, apresentados na Figura 48, indicam que os valores de G' tendem a ultrapassar os valores de G", a baixas frequências. Este comportamento é típico de nanocompósitos que apresentam uma dispersão homogênea das cargas ao longo da fase matriz, com grande número de partículas dispersas por unidade de volume, que ultrapassaram o limite de percolação, dificultando a relaxação molecular. Como o PLA é um polímero biodegradável, sensível à degradação térmica, não foi possível avaliar seu comportamento a frequências menores do que 0,1 rad/s.

O limite de percolação de nanopartículas de celulose em matriz polimérica pode ser calculado pela equação: ${ }^{[14]}$

$$
\text { Limite de percolação }=\frac{0,7}{L / d}
$$

Onde $\mathrm{L} / \mathrm{d}=$ razão de aspecto, assumindo que as partículas possuem formato cilíndrico.

Para as NCs obtidas com ácido sulfúrico, $\mathrm{L} / \mathrm{d}=38$, logo o limite de percolação $=0,018$, ou seja, precisa-se de 1,8\% em volume de nanopartículas de celulose para se atingir o limite de percolação. Assumindo que a densidade das NCs 
seja de $1,5 \mathrm{~g} / \mathrm{cm}^{3}$ e que a do PLA, na temperatura de fusão, seja de $1,12 \mathrm{~g} / \mathrm{cm}^{3}$, a fração mássica de $3 \%$ corresponde a uma fração volumétrica de $2,3 \%$ de NCs. Já a de $1 \%$ em massa corresponde a uma fração em volume de $0,75 \%$ de NCs. Portanto, os compósitos com 1\% em massa de NCs não possuem a fração volumétrica de carga necessária à percolação. Os compósitos com 3\% em massa de NCs possuem a fração volumétrica de carga necessária para percolação e, segundo indicam os resultados reológicos, grande parte destas NCs realmente percolaram.

\subsubsection{Microscopia Eletrônica de Varredura (MEV)}

As micrografias obtidas por MEV para a amostra de PLA com $3 \%$ de NCs é apresentada na Figura 49.

Figura 49- Micrografias obtida por MEV da amostra de PLA com $3 \%$ em massa de NCs (a) com aumento de 16210 vezes (b) com aumento de 35355 vezes (c) com aumento de 40000 vezes.
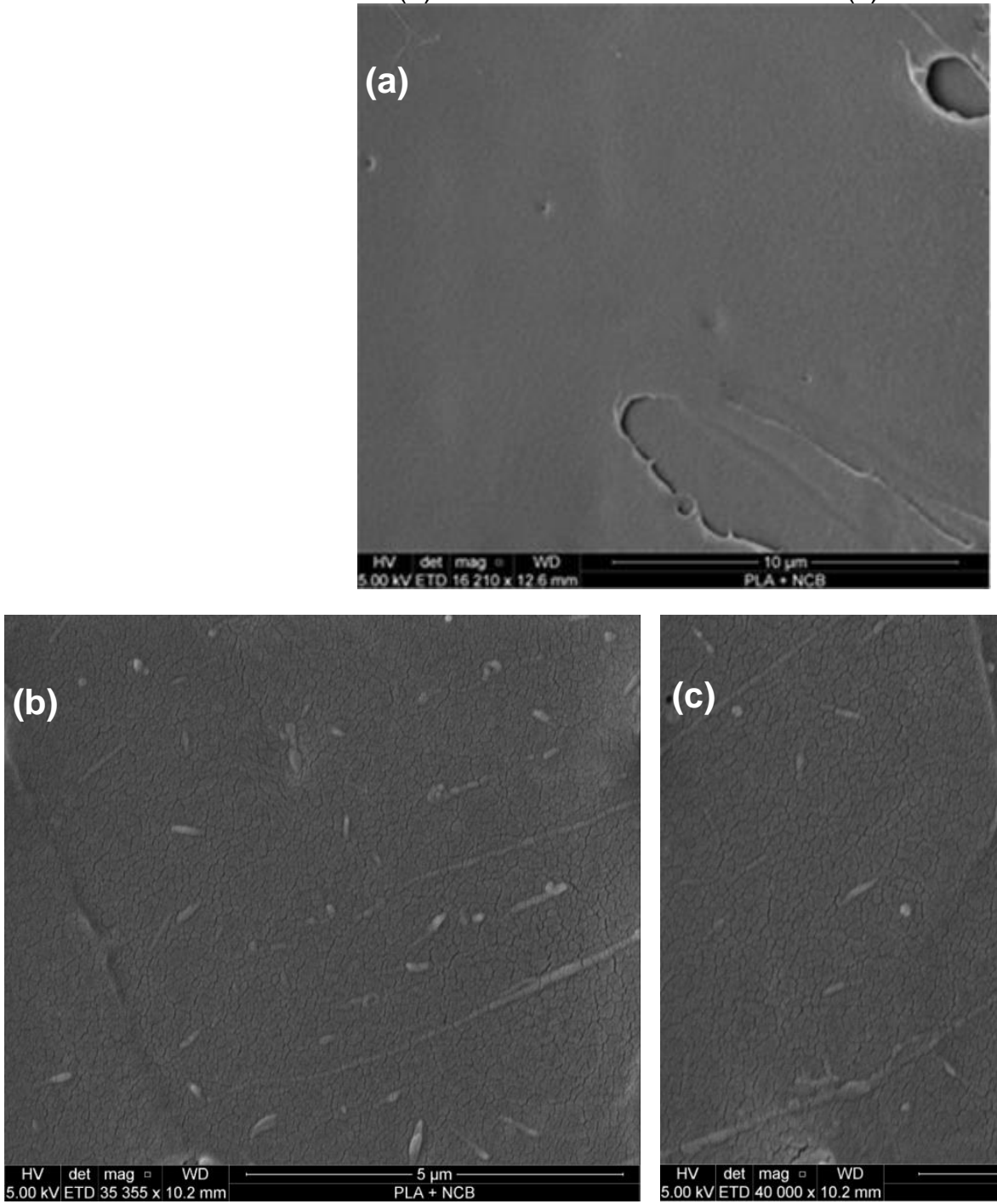
As micrografias obtidas por MEV podem confirmar o comportamento reológico descrito anteriormente para a amostra de PLA com $3 \%$ em massa de NCs. É possível observar pelas micrografias (b) e (c) que a carga NCSOB está dispersa ao longo de toda a extensão da matriz de PLA, ao passo que para o aumento menor (de 16210 vezes) já não é possível encontrá-la, indicando a ausência de grandes aglomerados. As imagens obtidas por MEV corroboram com as imagens obtidas por MET, para as NCs obtidas com $\mathrm{H}_{2} \mathrm{SO}_{4}$, pois as NCs apresentadas na Figura 49 possuem mesmo formato e dimensões compatíveis com as NCs apresentadas anteriormente na Figura 32. Além disso, pode-se notar que grande parte das NCs ocorrem isoladas e estão embebidas na matriz PLA. Algumas regiões possuem pontos que podem indicar NCs na posição transversal à imagem. Entretanto, alguns aglomerados de NCs podem ser vistos na estrutura do compósito. Deste modo, pode-se observar que o compósito obtido possui dispersão predominantemente homogênea da carga na fase matriz, com a presença de pequenos aglomerados. Não foi possível, ademais, realizar a análise de MEV com maiores aumentos devido à forte interação entre o feixe de elétrons e a superfície do polímero, o que ocasionaria a queima do material. Vale ressaltar ainda que a estrutura craquelada observada ao longo das micrografias refere-se à platina utilizada no recobrimento, a qual começa a apresentar rachaduras, devido sua interação com o feixe de elétrons. 


\section{CONCLUSÕES}

De acordo com os resultados obtidos, pode-se considerar que os métodos utilizados para obtenção das nanopartículas de celulose foram eficientes, uma vez que os resultados das técnicas de caracterização corroboram com os apresentados pela literatura. Pode-se afirmar que todos os métodos geraram nanocristais de celulose. Entretanto, os dois procedimentos utilizando-se $\mathrm{H}_{2} \mathrm{SO}_{4}$ na hidrólise e diferente neutralização das suspensões geraram NCs com propriedades distintas.

As NCs neutralizadas por meio da diálise (Método I) resultaram em materiais com menor estabilidade térmica, quando comparados aos neutralizados com bicarbonato de sódio (Método II). Assim, as NCs obtidas pelo Método II, apesar de possuírem pequena quantidade de $\mathrm{Na}_{2} \mathrm{SO}_{4}$ como subproduto, foram utilizadas para a produção dos compósitos, uma vez que os mesmos são preparados por adição da carga no polímero em estado fundido. Além disso, pode-se afirmar que com o Método III, que utiliza $\mathrm{H}_{3} \mathrm{PO}_{4}$ na reação de hidrólise, há obtenção de nanocristais maiores e com razão de aspecto menor. Estas NCs possuem, também, alta estabilidade térmica, quando comparadas às NCs obtidas pelos outros métodos, podendo ser misturadas com o PLA fundido. A maior distinção entre as partículas geradas com $\mathrm{H}_{2} \mathrm{SO}_{4}$ e $\mathrm{H}_{3} \mathrm{PO}_{4}$ está no grau de entrelaçamento entre as nanopartículas. Enquanto as preparadas com ácido fosfórico apresentaram maior aglomeração entre partículas, observadas em micrografias obtidas por MET e MFA, as preparadas com ácido sulfúrico apresentaram maior repulsão entre os nanocristais, visto que são encontradas individualmente nas micrografias.

Tais propriedades dos nanocristais foram também evidenciadas quando estes foram misturados à matriz PLA. No caso das NCs preparadas com ácido fosfórico, os compósitos obtidos apresentaram grandes aglomerados de carga. Já para NCs preparadas com ácido sulfúrico, os compósitos obtidos não apresentaram aglomerados de grandes dimensões, o que pode evidenciar a obtenção de um nanocompósito.

Por este motivo, os compósitos caracterizados foram aqueles que continham 1 e $3 \%$ em massa de $\mathrm{NCs}$, preparadas com $\mathrm{H}_{2} \mathrm{SO}_{4}$ (Método II). Com base nos resultados obtidos, pode-se dizer que a adição das NCs alterou o processo de cristalização do PLA, como observado nos ensaios de DSC e microscopia óptica. Houve redução nos valores da temperatura de cristalização, e significativo aumento 
nos valores de grau de cristalinidade do PLA, em função do aumento do teor de NCs na fase matriz.

Os ensaios de COPA mostraram que $3 \%$ em massa de NCs no PLA foi o suficiente para alterar o comportamento reológico do polímero. Os resultados reológicos indicaram que o compósito apresenta morfologia predominantemente fina, com dispersão homogênea da carga na fase matriz, o que pôde ser evidenciado por imagens obtidas por MEV. As imagens de MEV mostraram que apesar de apresentar pequenos aglomerados, o compósito possui grande parte das NCs finamente dispersas no PLA. 


\section{TRABALHOS FUTUROS}

Com base nos resultados e conclusões do presente trabalho, algumas sugestões para trabalhos futuros, afim da continuação do projeto de pesquisa, são resumidas a seguir:

- Visto que as NCPO apresentaram alta temperatura de início de degradação, a sua utilização como reforço em matriz polimérica é desejada. Desta forma, uma modificação da superfície das NCs obtidas com $\mathrm{H}_{3} \mathrm{PO}_{4}$, utilizando-se silanos, por exemplo, é necessária a fim de melhorar a interação carga-matriz e possibilitando sua utilização em compósitos poliméricos.

- Utilização de processamentos dos nanocompósitos mais semelhantes aos utilizados nas indústrias, como a extrusão e injeção.

- Realização de caracterização das propriedades mecânicas dos compósitos obtidos. 


\section{REFERÊNCIAS BIBLIOGRÁFICAS}

[1] SIQUEIRA, G.; BRAS, J. e DUFRESNE, A. Cellulosic Bionanocomposites: A Review of Preparation, Properties and Applications. Polymers, v. 2, n. 4, p. 728765, doi:10.3390/polym2040728, 2010.

[2] BRITO, G. F. et al. Biopolímeros, Polímeros Biodegradáveis e Polímeros Verdes. Revista Eletrônica de Materiais e Processos, v. 6, n. 2, p. 127-139, 2011.

[3] PEREGO, G. e CELLA, G. D. Mechanical properties. In: AURAS, R. et al. (Eds.). . Poly(Lactic Acid). Hoboken, NJ, USA: John Wiley \& Sons, Inc., 2010. p. 141-153.

[4] ESPINO-PÉREZ, E. et al. Influence of chemical surface modification of cellulose nanowhiskers on thermal, mechanical, and barrier properties of poly(lactide) based bionanocomposites. European Polymer Journal, v. 49, n. 10, p. 3144-3154, doi:10.1016/j.eurpolymj.2013.07.017, 2013.

[5] HABIBI, Y.; LUCIA, L. a e ROJAS, O. J. Cellulose nanocrystals: chemistry, selfassembly, and applications. Chemical reviews, v. 110, n. 6, p. 3479-500, doi:10.1021/cr900339w, 2010.

[6] MOON, R. J. et al. Cellulose nanomaterials review: structure, properties and nanocomposites. Chemical Society reviews, v. 40, n. 7, p. 3941-94, doi:10.1039/c0cs00108b, 2011.

[7] KLEMM, D. et al. Cellulose: fascinating biopolymer and sustainable raw material. Angewandte Chemie (International ed. in English), v. 44, n. 22, p. 3358-93, doi:10.1002/anie.200460587, 2005.

[8] SILVA, D. . J. e ALMEIDA, M. L. O. Cellulose whiskers. IPT Peer-Reviewed Article, 2009.

[9] DUFRESNE, A.; VIGNON, M. R. e CAVAILLE, J. Mechanical Behavior of Sheets Prepared from Sugar Beet Cellulose Microfibrils. p. 1185-1194, 1996.

[10] BRITO, B. S. L. et al. Preparation, morphology and structure of cellulose nanocrystals from bamboo fibers. Cellulose, v. 19, n. 5, p. 1527-1536, doi:10.1007/s10570-012-9738-9, 2012.

[11] SACUI, I. A. et al. Comparison of the Properties of Cellulose Nanocrystals and Cellulose Nano fi brils Isolated from Bacteria, Tunicate, and Wood Processed Using Acid, Enzymatic, Mechanical, and Oxidative Methods. ACS applied materials \& interfaces, n. 6, p. 6127-6138, 2014.

[12] ISHIKAWA, A.; OKANO, T. e SUGIYAMA, J. Fine $s \mathrm{t} r \mathrm{u} c \mathrm{t} u \mathrm{r}$ e and tensile properties of ramie fibres in the crystalline $f \circ \mathrm{r} m$ of cellulose I, II, IIII and IVi. Polymer, v. 38, n. 2, p. 463-468, 1997. 
[13] SULLIVAN, A. C. O. Cellulose: the structure slowly unravels. Cellulose, v. 4, p. 173-207, 1997.

[14] DUFRESNE, A. Nanocellulose. [S.I.]: De Gruyter, 2012.

[15] HORIKAWA, Y. e SUGIYAMA, J. Localization of crystalline allomorphs in cellulose microfibril. Biomacromolecules, v. 10, n. 8, p. 2235-9, doi:10.1021/bm900413k, 2009.

[16] YAMAMOTO, H. e HORII, F. CP/MAS 13C NMR Analysis of the Crystal Transformation Induced for Valonia Cellulose by Annealing at High Temperatures. Macromolecules, v. 26, p. 1313-1317, 1993.

[17] Technical Association of the Pulp \& Paper Industry. WI 3021: Standart Terms and Their Definition for Cellulose Nanomaterial., 2014.

[18] SAITO, T. et al. Cellulose nanofibers prepared by TEMPO-mediated oxidation of native cellulose. Biomacromolecules, v. $8, \quad$ n. 8, p. 2485-91, doi:10.1021/bm0703970, 2007.

[19] BLEDZKI, A. K. e GASSAN, J. Composites reinforced with cellulose based fibres. Progress in Polymer Science, v. 24, p. 221-274, 1999.

[20] JOHN, M. e THOMAS, S. Biofibres and biocomposites. Carbohydrate Polymers, v. 71, n. 3, p. 343-364, doi:10.1016/j.carbpol.2007.05.040, 2008.

[21] LEVIS, S. R. e DEASY, P. B. Production and evaluation of size reduced grades of microcrystalline cellulose. International journal of pharmaceutics, v. 213, n. 1-2, p. 13-24, 2001.

[22] TURBAK, A. F.; SNYDER, F. W. e SANDBERG, K. R. Microfibrillated cellulose, a new cellulose product: properties, uses, and commercial potential. Journal of Applied Polymer Science: Applied Polymer Symposium, v. 37, p. 815-27, 1983.

[23] SAITO, T. et al. Individualization of nano-sized plant cellulose fibrils by direct surface carboxylation using TEMPO catalyst under neutral conditions. Biomacromolecules, v. 10, n. 7, p. 1992-6, doi:10.1021/bm900414t, 2009.

[24] GARCIA DE RODRIGUEZ, N. L.; THIELEMANS, W. e DUFRESNE, A. Sisal cellulose whiskers reinforced polyvinyl acetate nanocomposites. Cellulose, v. 13, n. 3, p. 261-270, doi:10.1007/s10570-005-9039-7, 2006.

[25] ELAZZOUZI-HAFRAOUI, S. et al. The shape and size distribution of crystalline nanoparticles prepared by acid hydrolysis of native cellulose. Biomacromolecules, v. 9, n. 1, p. 57-65, doi:10.1021/bm700769p, 2008.

[26] KASYAPI, N.; CHAUDHARY, V. e BHOWMICK, A. K. Bionanowhiskers from jute: preparation and characterization. Carbohydrate polymers, v. 92, n. 2, p. 111623, doi:10.1016/j.carbpol.2012.10.021, 2013. 
[27] BONDESON, D.; MATHEW, A. e OKSMAN, K. Optimization of the isolation of nanocrystals from microcrystalline cellulose by acid hydrolysis. Cellulose, v. 13, n. 2, p. 171-180, doi:10.1007/s10570-006-9061-4, 2006.

[28] DONG, X. M.; REVOL, J.-F. e GRAY, D. G. Effect of microcrystallite preparation conditions on the formation of colloid crystals of cellulose. Cellulose, v. 5, p. 19-32, 1998.

[29] STELTE, W. e SANADI, A. R. Preparation and Characterization of Cellulose Nanofibers from Two Commercial Hardwood and Softwood Pulps. Industrial \& Engineering Chemistry Research, v. 48, n. 24, p. 11211-11219, doi:10.1021/ie9011672, 2009.

[30] IWAMOTO, S.; NAKAGAITO, a. N. e YANO, H. Nano-fibrillation of pulp fibers for the processing of transparent nanocomposites. Applied Physics A, v. 89, n. 2, p. 461-466, doi:10.1007/s00339-007-4175-6, 2007.

[31] JOHNSON, R. K. et al. A new bio-based nanocomposite: fibrillated TEMPOoxidized celluloses in hydroxypropylcellulose matrix. Cellulose, v. 16, n. 2, p. 227238, doi:10.1007/s10570-008-9269-6, 2008.

[32] TIBOLLA, H.; MARIA, F. e CECILIA, F. LWT - Food Science and Technology Cellulose nano fi bers produced from banana peel by chemical and enzymatic treatment. LWT Food Science and Technology, p. 1-8, 2014.

[33] SAMIR, M. A. S. A.; ALLOIN, F. e DUFRESNE, A. Review of recent research into cellulosic whiskers, their properties and their application in nanocomposite field. Biomacromolecules, v. 6, n. 2, p. 612-26, doi:10.1021/bm0493685, 2005.

[34] LIMA, M. M. de S. e BORSALI, R. Rodlike Cellulose Microcrystals: Structure, Properties, and Applications. Macromolecular Rapid Communications, v. 25, n. 7, p. 771-787, doi:10.1002/marc.200300268, 2004.

[35] ARAKI, J. et al. Flow properties of microcrystalline cellulose suspension prepared by acid treatment of native cellulose. Colloids and Surfaces A., v. 142, n. 1, p. 75-82, doi:10.1016/S0927-7757(98)00404-X, 1998.

[36] BAJPAI, S. K. et al. Cellulose Nano Whiskers (CNWs) Loaded-Poly(sodium acrylate) Hydrogels. Part-I. Effect of Low Concentration of CNWs on Water Uptake. Journal of Macromolecular Science, Part A, v. 50, n. 5, p. 466-477, doi:10.1080/10601325.2013.780946, 2013.

[37] LABCONCO. A Guide to Freeze Drying for the Laboratory. Disponível em: <http://chiron.no/pdf/Labconco_guide_to_freeze_drying.pdf>. Acesso em: 17 jul. 2014.

[38] LAHIJI, R. R. et al. Atomic force microscopy characterization of cellulose nanocrystals. Langmuir: the ACS journal of surfaces and colloids, v. 26, n. 6, p. 4480-8, doi:10.1021/la903111j, 2010. 
[39] DIDDENS, I. et al. Anisotropic Elastic Properties of Cellulose Measured Using Inelastic X-ray Scattering. Macromolecules, v. 41, n. 24, p. 9755-9759, doi:10.1021/ma801796u, 2008.

[40] NISHINO, T.; MATSUDA, I. e HIRAO, K. All-Cellulose Composite. Macromolecules, v. 37, n. 20, p. 7683-7687, doi:10.1021/ma049300h, 2004.

[41] PETERSSON, L.; KVIEN, I. e OKSMAN, K. Structure and thermal properties of poly(lactic acid)/cellulose whiskers nanocomposite materials. Composites Science and Technology, v. 67, n. 11-12, p. 2535-2544, doi:10.1016/j.compscitech.2006.12.012, 2007.

[42] ESPINOSA, S. C. et al. Isolation of thermally stable cellulose nanocrystals by phosphoric acid hydrolysis. Biomacromolecules, v. 14, n. 4, p. 1223-30, doi:10.1021/bm400219u, 2013.

[43] YANO, H. et al. Optically Transparent Composites Reinforced with Networks of Bacterial Nanofibers. Advanced Materials, v. 17, n. 2, p. 153-155, doi:10.1002/adma.200400597, 2005.

[44] MESQUITA, J. P. Nanocristais de Celulose para Preparação de Bionanocompósitos com Quitosana e Carbonos Nanoestruturados para Aplicações Tecnológicas e Ambientais. Universidade Federal de Minas Gerais (UFMG) - [S.I.]. 2012.

[45] DONG, X. M.; KIMURA, T. e GRAY, D. G. Effects of Ionic Strength on the Isotropic - Chiral Nematic Phase Transition of Suspensions of Cellulose Crystallites. Langmuir, v. 12, n. 8, p. 2076-2082, doi:0743-7463/96/2412-2076\$12.00, 1996.

[46] NORMA ASTM D6400-04. Standard Specification for Compostable Plastics, [S.d.].

[47] MOHANTY, A. K. et al. Natural Fibers, Biopolymers, and Biocomposites: An Introduction. Natural Fibers, Biopolymers, and Biocomposites. [S.I.]: Boca Raton: Taylor \& Francis, 2005. .

[48] Norma ABNT NBR 15448-1. Embalagens plásticas degradáveis e/ou de fontes renováveis Parte 1: Terminologia., [S.d.].

[49] FECHINE, G. J. M. Era dos Polímeros Biodegradáveis. [S.I.]: Plástico Moderno., [S.d.]. p. 2010

[50] AL-ITRY, R.; LAMNAWAR, K. e MAAZOUZ, A. Improvement of thermal stability, rheological and mechanical properties of PLA, PBAT and their blends by reactive extrusion with functionalized epoxy. Polymer Degradation and Stability, v. 97, n. 10, p. 1898-1914, doi:10.1016/j.polymdegradstab.2012.06.028, 2012.

[51] GRAUPNER, N. Application of lignin as natural adhesion promoter in cotton fibre-reinforced poly(lactic acid) (PLA) composites. Journal of Materials Science, v. 43, n. 15, p. 5222-5229, doi:10.1007/s10853-008-2762-3, 2008. 
[52] LIN, P.-L. et al. Effects of hydroxyapatite dosage on mechanical and biological behaviors of polylactic acid composite materials. Materials Letters, v. 61, n. 14-15, p. 3009-3013, doi:10.1016/j.matlet.2006.10.064, 2007.

[53] DENG, C. et al. Choice of dispersants for the nano-apatite filler of polylactidematrix composite biomaterial. Current Applied Physics, v. 7, n. 6, p. 679-682, doi:10.1016/j.cap.2007.03.005, 2007.

[54] HONG, J. e KIM, D. S. Preparation and Physical Properties of Polylactide / Cellulose Nanowhisker / Nanoclay Composites. Polymers Composites, p. 293-298, doi:10.1002/pc, 2013.

[55] CASARANO, R. Copolímeros biodegradáveis com potencial uso como biomaterial. Universidade de São Paulo - [S.I.]. 2009.

[56] RUDNIK, E. Compostable polymer materials - definitions, structures and methods of preparation. Compostable polymer materials. [S.I.]: Oxford: Elsevier, 2008. p. 10-36.

[57] FAMBRI, L. e MIGLIARESI, C. Crystallization and Thermal Properties. In: AURAS, R. et al. (Eds.). . Poly(Lactic Acid). Hoboken, NJ, USA: John Wiley \& Sons, Inc., 2010. p. 113-124.

[58] PEREGO, G.; CELLA, G. D. e BASTIOLI, C. Effect of molecular weight and crystallinity on poly(lactic acid) mechanical properties. Journal of Applied Polymer Science, v. 59 , n. 1 , p. 37-43, doi:10.1002/(SICI)10974628(19960103)59:1<37::AID-APP6>3.0.CO;2-N, 1996.

[59] GRIJPMA, D. W. et al. Improvement of the mechanical properties of poly(D,Llactide) by orientation. Polymer International, v. 51, n. 10, p. 845-851, doi:10.1002/pi.988, 2002.

[60] ENGELBERG, I. e KOHN, J. Physico-mechanical properties of degradable polymers used in medical applications: a comparative study. Biomaterials, v. 12, n. 3, p. 292-304, 1991.

[61] BARROWS, T. H. Degradable implant materials: a review of synthetic absorbable polymers and their applications. Clinical Materials, v. 1, p. 233-257, 1986.

[62] KALB, B. e PENNINGS, A. J. General crystallization behaviour of poly ( L- lactic acid ). Polymer, v. 21, p. 607-612, 1980.

[63] MIGLIARESI, C. et al. The Effect of Thermal History on the Crystallinity of Different Molecular Weight PLLA Biodegradable Polymers. Clinical Materials, v. 8, p. 111-118, 1991.

[64] FISCHER, E. W.; STERZEL, H. J. e WEGNER, G. Investigation of the structure of solution grown crystals of lactide copolymers by means of chemical reactions.

Kolloid-Z. u. Z. Polymere, v. 251, p. 980-990, 1973. 
[65] MIGLIARESI, C. et al. Dynamic mechanical and calorimetric analysis of compression-molded PLLA of different molecular weights: Effect of thermal treatments. Journal of Applied Polymer Science, v. 43, n. 1, p. 83-95, doi:10.1002/app.1991.070430109, 1991.

[66] LIM, L.-T.; CINK, K. e VANYO, T. Processing of Poly(lactic acid). In: AURAS, R. et al. (Eds.). . Poly(Lactic Acid). Hoboken, NJ, USA: John Wiley \& Sons, Inc., 2010. p. 191-215.

[67] LIM, L.-T.; AURAS, R. e RUBINO, M. Processing technologies for poly(lactic acid). Progress in Polymer Science, v. 33, n. 8, p. 820-852, doi:10.1016/j.progpolymsci.2008.05.004, 2008.

[68] SUZUKI, S. et al. Part V- Applications. In: AURAS, R. et al. (Eds.). . Poly(Lactic Acid). Hoboken, NJ, USA: John Wiley \& Sons, Inc., 2010. p. 443-486.

[69] PADEE, S. et al. Preparation of Poly(Lactic Acid) and Poly(Trimethylene Terephthalate) Blend Fibers for Textile Application. Energy Procedia, v. 34, p. 534541, doi:10.1016/j.egypro.2013.06.782, 2013.

[70] BAIG, G. A. Reduction clearing of simulated disperse dyed PLA fabrics and their tensile properties. Indian Journal of Fibre \& Textile Research, v. 38, p. 22-28, 2013.

[71] RODRIGUES, A. L. et al. Use of biopolymers as solid substrates for denitrification. Water Science \& Technology, v. 65.1, p. 105-111, doi:10.2166/wst.2011.83S, 2012.

[72] FAN, Z.; HU, J. e WANG, J. Biological nitrate removal using wheat straw and PLA as substrate. Environmental Technology, v. 33, n. 21, p. 2369-2374, doi:10.1080/09593330.2012.669411, 2012.

[73] PERTICI, V. et al. Repair of the injured spinal cord by implantation of a synthetic degradable block copolymer in rat. Biomaterials, v. 35, n. 24, p. 6248-58, doi:10.1016/j.biomaterials.2014.04.020, 2014.

[74] JOUKAINEN, a et al. Strength retention of self-reinforced drawn poly-L/DLlactide 70/30 (SR-PLA70) rods and fixation properties of distal femoral osteotomies with these rods. An experimental study on rats. Journal of biomaterials science. Polymer edition, v. 11, n. 12, p. 1411-28, 2000.

[75] JOUKAINEN, A. et al. Bioabsorbable screw fixation for the treatment of ankle fractures. Journal of orthopaedic science, $v .12, n$. 1, p. 28-34, doi:10.1007/s00776-006-1077-y, 2007.

[76] MIAO, C. e HAMAD, W. Y. Cellulose reinforced polymer composites and nanocomposites: a critical review. Cellulose, v. 20, n. 5, p. 2221-2262, doi:10.1007/s10570-013-0007-3, 2013. 
[77] KRISHNAMOORTI, RAMANAN; VAIA, R. A. Polymer Nanocomposites. Washington: American Chemical Society, 2002.

[78] CHAWLA, K. K. Composite Materials. 3rd. ed. [S.I.]: Springer, 2012.

[79] BRETAS, R. E. S. e D'AVILA, M. Reologia de Polímeros Fundidos. São Carlos: [s.n.], 2000.

[80] GARCIA, P. L. OBTENÇÃO E CARACTERIZAÇÃO DE NANOCOMPÓSITOS DE PS/ARGILA ESMECTÍTICA. Universidade de São Paulo - [S.I.]. 2010.

[81] BARNES, H. A.; HUTTON, J. F. e WALTERS, K. An Introduction to Rheology. [S.I.]: Elselvier B. V., 1989.

[82] DEALY, J. M. e WISSBRUN, K. F. Melt Rheology and Its Role In Plastics Processing-Theory and Appications. New York: Van Nostram Reynhold, 1990.

[83] CASSAGNAU, P. Melt rheology of organoclay and fumed silica nanocomposites. Polymer, v. 49, n. 9, p. 2183-2196, doi:10.1016/j.polymer.2007.12.035, 2008.

[84] ZHAO, J.; MORGAN, A. B. e HARRIS, J. D. Rheological characterization of polystyrene-clay nanocomposites to compare the degree of exfoliation and dispersion. Polymer, v. 46, n. 20, p. 8641-8660, doi:10.1016/j.polymer.2005.04.038, 2005.

[85] FAVIER, V.; CHANZY, H. e CAVAILLE, J. Y. Polymer Nanocomposites Reinforced by Cellulose Whiskers. Macromolecules, v. 28, p. 6365-6367, doi:00249297/95/2228-6365\$09.00/0, 1995.

[86] RAQUEZ, J.-M. et al. Polylactide (PLA)-based nanocomposites. Progress in Polymer Science, v. 38, n. 10-11, p. 1504-1542, doi:10.1016/j.progpolymsci.2013.05.014, 2013.

[87] FRONE, A. N. et al. Morphology and thermal properties of PLA-cellulose nanofibers composites. Carbohydrate polymers, v. 91, n. 1, p. 377-84, doi:10.1016/j.carbpol.2012.08.054, 2013.

[88] RAQUEZ, J.-M. et al. Surface-modification of cellulose nanowhiskers and their use as nanoreinforcers into polylactide: A sustainably-integrated approach. Composites Science and Technology, v. 72, n. 5, p. 544-549, doi:10.1016/j.compscitech.2011.11.017, 2012.

[89] BITINIS, N. et al. Poly(lactic acid)/natural rubber/cellulose nanocrystal bionanocomposites part I. Processing and morphology. Carbohydrate polymers, v. 96, n. 2, p. 611-20, doi:10.1016/j.carbpol.2013.02.068, 2013.

[90] EICHHORN, S. J. Cellulose nanowhiskers: promising materials for advanced applications. Soft Matter, v. 7, n. 2, p. 303, doi:10.1039/c0sm00142b, 2011. 
[91] PETERSSON, L. e OKSMAN, K. Biopolymer based nanocomposites: Comparing layered silicates and microcrystalline cellulose as nanoreinforcement. Composites Science and Technology, v. 66, n. 13, p. 2187-2196, doi:10.1016/j.compscitech.2005.12.010, 2006.

[92] FORTUNATI, E. et al. Microstructure and nonisothermal cold crystallization of PLA composites based on silver nanoparticles and nanocrystalline cellulose. Polymer Degradation and Stability, v. 97, n. 10, p. 2027-2036, doi:10.1016/j.polymdegradstab.2012.03.027, 2012.

[93] SANCHEZ-GARCIA, M. D.; GIMENEZ, E. e LAGARON, J. M. Morphology and barrier properties of solvent cast composites of thermoplastic biopolymers and purified cellulose fibers. Carbohydrate Polymers, v. 71, n. 2, p. 235-244, doi:10.1016/j.carbpol.2007.05.041, 2008.

[94] LEE, J. H.; PARK, S. H. e KIM, S. H. Surface modification of cellulose nanowhiskers and their reinforcing effect in polylactide. Macromolecular Research, v. 22, n. 4, p. 424-430, doi:10.1007/s13233-014-2064-3, 2014.

[95] SARASUA, J. et al. Crystallization and Melting Behavior of Polylactides. Macromolecules, v. 31, n. 12, p. 3895-3905, 1998.

[96] GOFFIN, A.-L. et al. From interfacial ring-opening polymerization to melt processing of cellulose nanowhisker-filled polylactide-based nanocomposites. Biomacromolecules, v. 12, n. 7, p. 2456-65, doi:10.1021/bm200581h, 2011.

[97] LEE, J. H.; PARK, S. H. e KIM, S. H. Preparation of cellulose nanowhiskers and their reinforcing effect in polylactide. Macromolecular Research, v. 21, n. 11, p. 1218-1225, doi:10.1007/s13233-013-1160-0, 2013.

[98] RAY, S. S. Nanocomposites. In: AURAS, R. et al. (Eds.). . Poly(Lactic Acid). Hoboken, NJ, USA: John Wiley \& Sons, Inc., 2010. p. 311-322.

[99] KAMAL, M. R. e KHOSHKAVA, V. Effect of cellulose nanocrystals (CNC) on rheological and mechanical properties and crystallization behavior of PLA/CNC nanocomposites. Carbohydrate Polymers, v. 123, p. 105-114, doi:10.1016/j.carbpol.2015.01.012, 2015.

[100] CHO, S. Y. et al. Influence of cellulose nanofibers on the morphology and physical properties of poly(lactic acid) foaming by supercritical carbon dioxide. Macromolecular Research, v. 21, n. 5, p. 529-533, doi:10.1007/s13233-013-1057y, 2012.

[101] DLOUHÁ, J.; SURYANEGARA, L. e YANO, H. The role of cellulose nanofibres in supercritical foaming of polylactic acid and their effect on the foam morphology. Soft Matter, v. 8, n. 33, p. 8704, doi:10.1039/c2sm25909e, 2012.

[102] KIM, J. Y.; KIM, D. K. e KIM, S. H. Effect of modified carbon nanotube on physical properties of thermotropic liquid crystal polyester nanocomposites. 
European Polymer Journal, v. 45, n. 2, p. 316-324, doi:10.1016/j.eurpolymj.2008.10.043, 2009.

[103] KIM, J. Y. et al. Influence of modified carbon nanotube on physical properties and crystallization behavior of poly(ethylene terephthalate) nanocomposite. Polymer Composites, v. 31, n. 5, p. 858-869, doi:10.1002/pc.20868, 2010.

[104] RULAND, W. X-ray determination of crystallinity and diffuse disorder scattering. Acta Crystallographica, v. 14, n. 11, p. 1180-1185, doi:10.1107/S0365110X61003429, 1961.

[105] PARK, S. et al. Cellulose crystallinity index: measurement techniques and their impact on interpreting cellulase performance. Biotechnology for biofuels, v. 3, p. 10, doi:10.1186/1754-6834-3-10, 2010.

[106] $\mathrm{OH}, \mathrm{S}$. Y. et al. Crystalline structure analysis of cellulose treated with sodium hydroxide and carbon dioxide by means of X-ray diffraction and FTIR spectroscopy. Carbohydrate research, v. $340, \quad$ n. 15, p. 2376-91, doi:10.1016/j.carres.2005.08.007, 2005. 
APÊNDICE A- Dados para cálculo do Índice de Cristalinidade das nanopartículas através das curvas de DRX pelo método de subtração do alo amorfo.

\section{1) Papel Filtro}

Tabela 11- Área total da curva de DRX da amostra de papel filtro sem correção de linha base.

\begin{tabular}{cccc}
\hline Área total & $\mathbf{2}_{\boldsymbol{i}}$ & $\mathbf{2}_{\boldsymbol{f}}$ & Centro do pico \\
\hline 19044,6 & 11,0 & 39,9 & 22,9 \\
\hline
\end{tabular}

Figura 50- Correção de linha base da curva de DRX da amostra de papel filtro utilizada para cálculo da área da região cristalina.

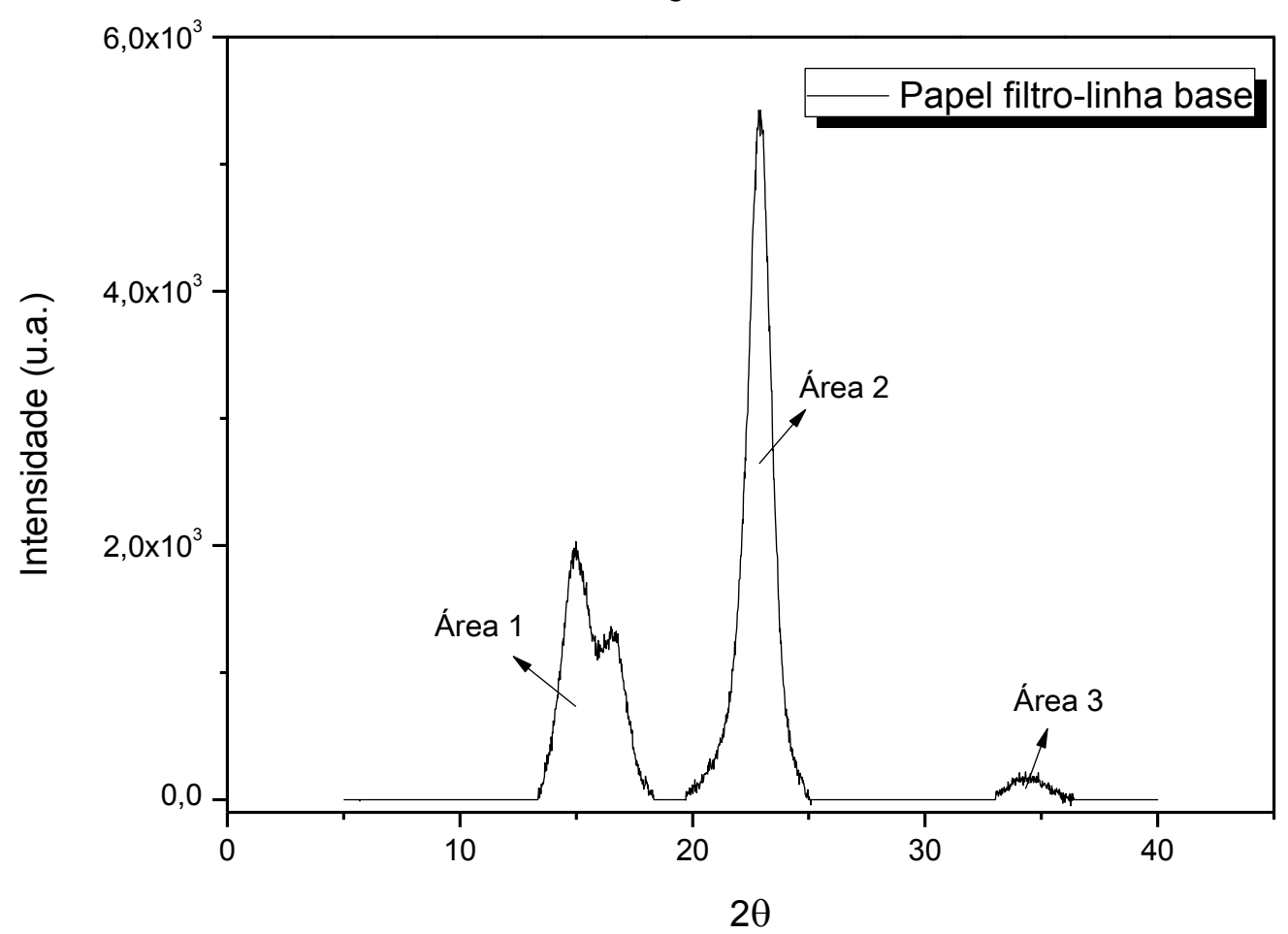

Tabela 12- Áreas dos picos da curva de DRX da amostra de papel filtro após correção de linha base.

\begin{tabular}{ccccc}
\hline Pico & Área & $\mathbf{2 \theta}_{\mathbf{i}}$ & $\mathbf{2 \theta}_{\mathbf{f}}$ & Centro do pico \\
\hline 1 & 4685,0 & 13,3 & 18,4 & 15,0 \\
2 & 7800,2 & 19,7 & 25,2 & 22,9 \\
3 & 329,6 & 33,1 & 36,5 & 34,3 \\
\hline
\end{tabular}




\section{2) NCs preparadas pelo Método I (NCSOD)}

Tabela 13- Área total da curva de DRX da amostra NCSOD sem correção de linha base.

\begin{tabular}{cccccc}
\hline $\begin{array}{c}\text { Área da } \\
\text { curva }\end{array}$ & $\begin{array}{c}\text { Área dos picos } \\
\text { remanescentes }\end{array}$ & Área total & $\mathbf{2}_{\mathbf{i}}$ & $\mathbf{2}_{\mathbf{f}}$ & $\begin{array}{c}\text { Centro do } \\
\text { pico }\end{array}$ \\
\hline 13518,3 & 98,4 & 13419,9 & 12,8 & 40,0 & 22,7 \\
\hline
\end{tabular}

Figura 51- Correção de linha base da curva de DRX da amostra NCSOD utilizada para cálculo da área da região cristalina

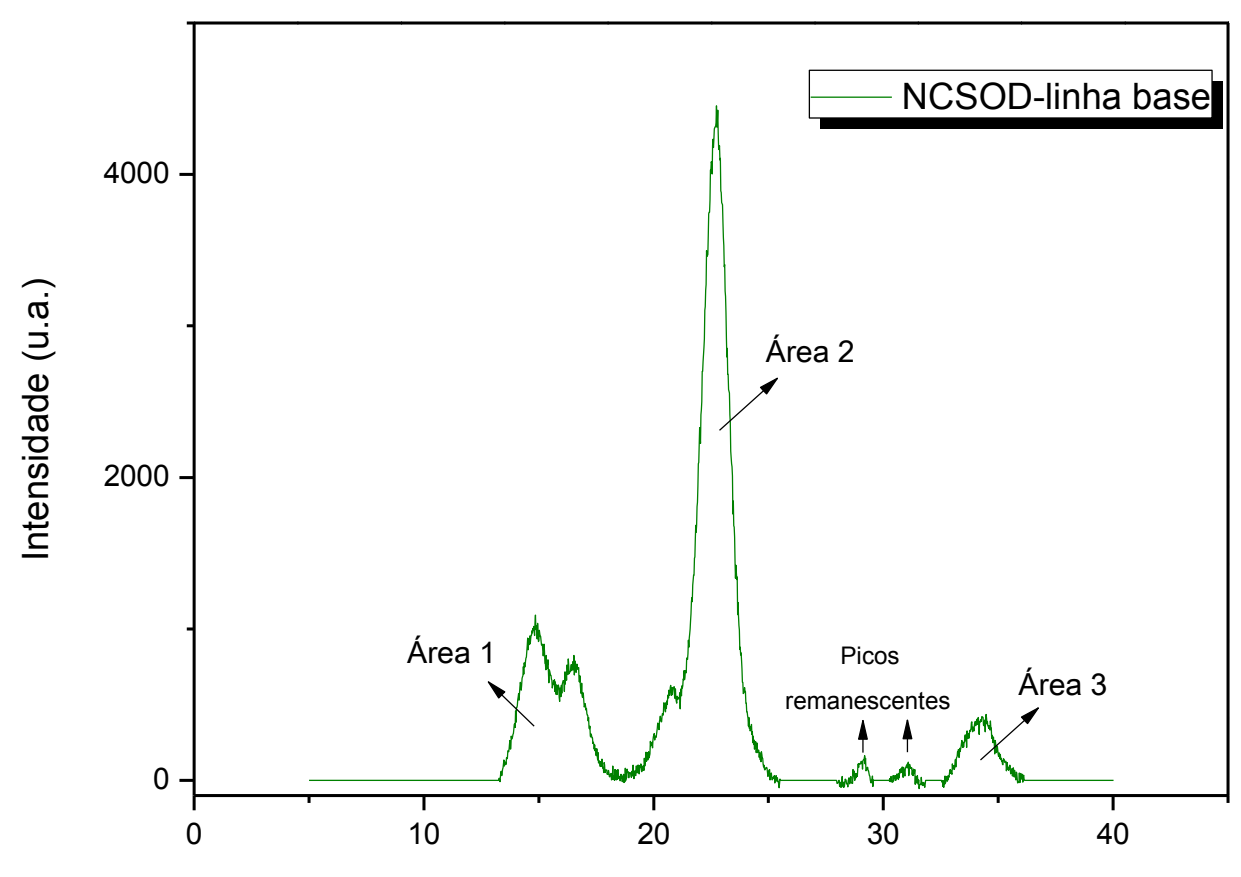

$2 \theta$

Tabela 14- Áreas dos picos da curva de DRX da amostra NCSOD após correção de linha base.

\begin{tabular}{ccccc}
\hline Pico & Área & $\mathbf{2 \theta}_{\mathrm{i}}$ & $\mathbf{2 \theta}_{\mathrm{f}}$ & Centro do pico \\
\hline 1 & 2587,9 & 13,3 & 18,7 & 14,9 \\
2 & 7357,2 & 18,7 & 25,6 & 22,7 \\
3 & 668,2 & 32,8 & 36,2 & 34,5 \\
\hline
\end{tabular}


3) NCs preparadas pelo Método II (NCSOB)

Tabela 15- Área total da curva de DRX da amostra NCSOB sem correção de linha base.

\begin{tabular}{cccccc}
\hline $\begin{array}{c}\text { Área da } \\
\text { curva }\end{array}$ & $\begin{array}{c}\text { Área dos picos } \\
\text { remanescentes }\end{array}$ & Área total & $\mathbf{2}_{\mathbf{i}}$ & $\mathbf{2}_{\mathbf{f}}$ & $\begin{array}{c}\text { Centro do } \\
\text { pico }\end{array}$ \\
\hline 11657,0 & 479,9 & 11177,1 & 13,2 & 40,0 & 22,7 \\
\hline
\end{tabular}

Figura 52- Correção de linha base da curva de DRX da amostra NCSOB utilizada para cálculo da área da região cristalina

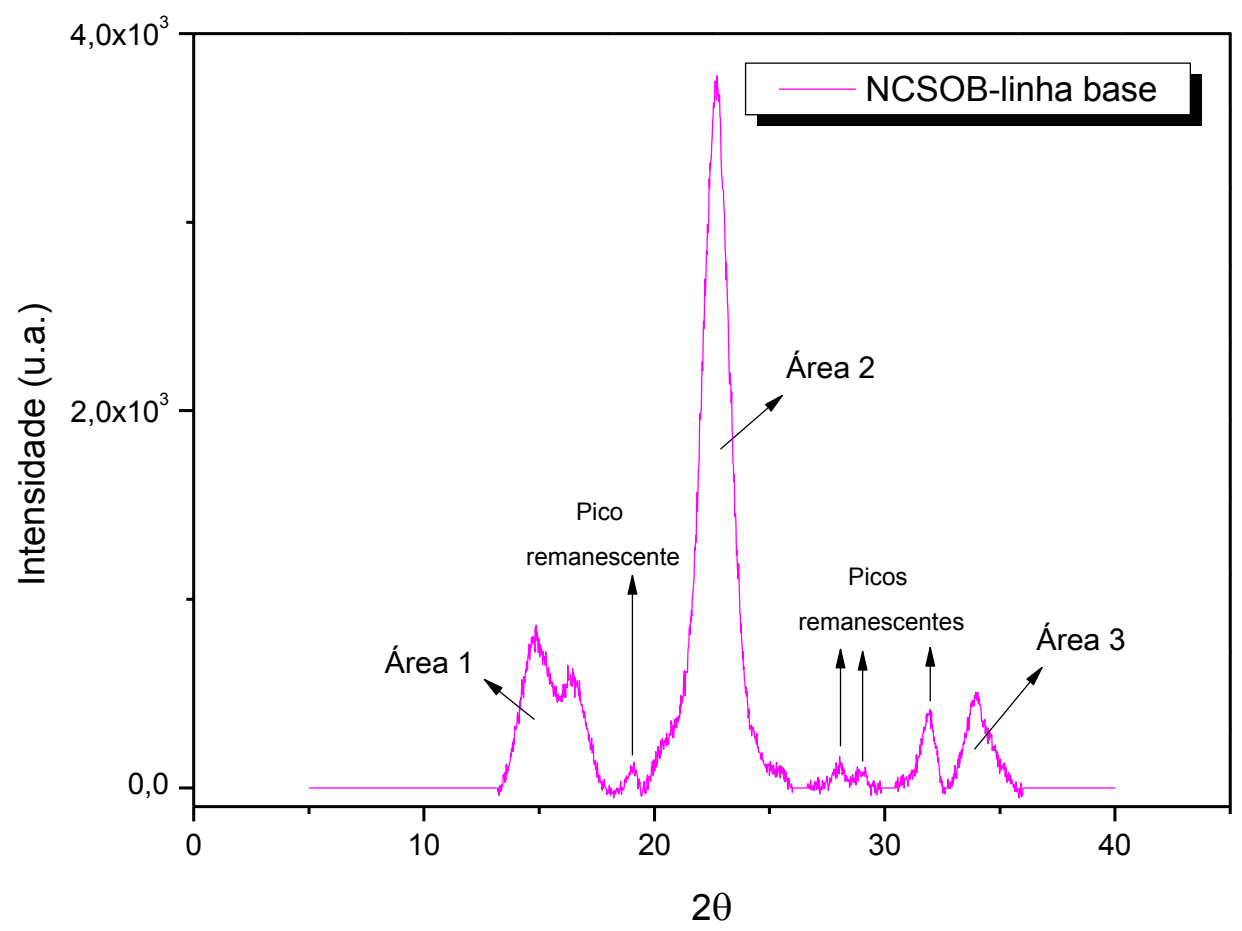

Tabela 16- Áreas dos picos da curva de DRX da amostra NCSOB após correção de linha base.

\begin{tabular}{ccccc}
\hline Pico & Área & $\mathbf{2}_{\mathbf{i}}$ & $\mathbf{2}_{\mathbf{f}}$ & Centro do pico \\
\hline 1 & 1939,2 & 13,3 & 18,2 & 14,9 \\
2 & 6229,5 & 19,7 & 26,1 & 22,7 \\
3 & 615,4 & 32,7 & 36,0 & 34,0 \\
\hline
\end{tabular}


4) NCs preparadas pelo Método III (NCPO)

Tabela 17- Área total da curva de DRX da amostra NCPO sem correção de linha base.

\begin{tabular}{cccc}
\hline Área total & $\mathbf{2}_{\mathbf{i}}$ & $\mathbf{2}_{\boldsymbol{f}}$ & Centro do pico \\
\hline 17837,0 & 13,1 & 39,9 & 22,7 \\
\hline
\end{tabular}

Figura 53- - Correção de linha base da curva de DRX da amostra NCPO utilizada para cálculo da área da região cristalina

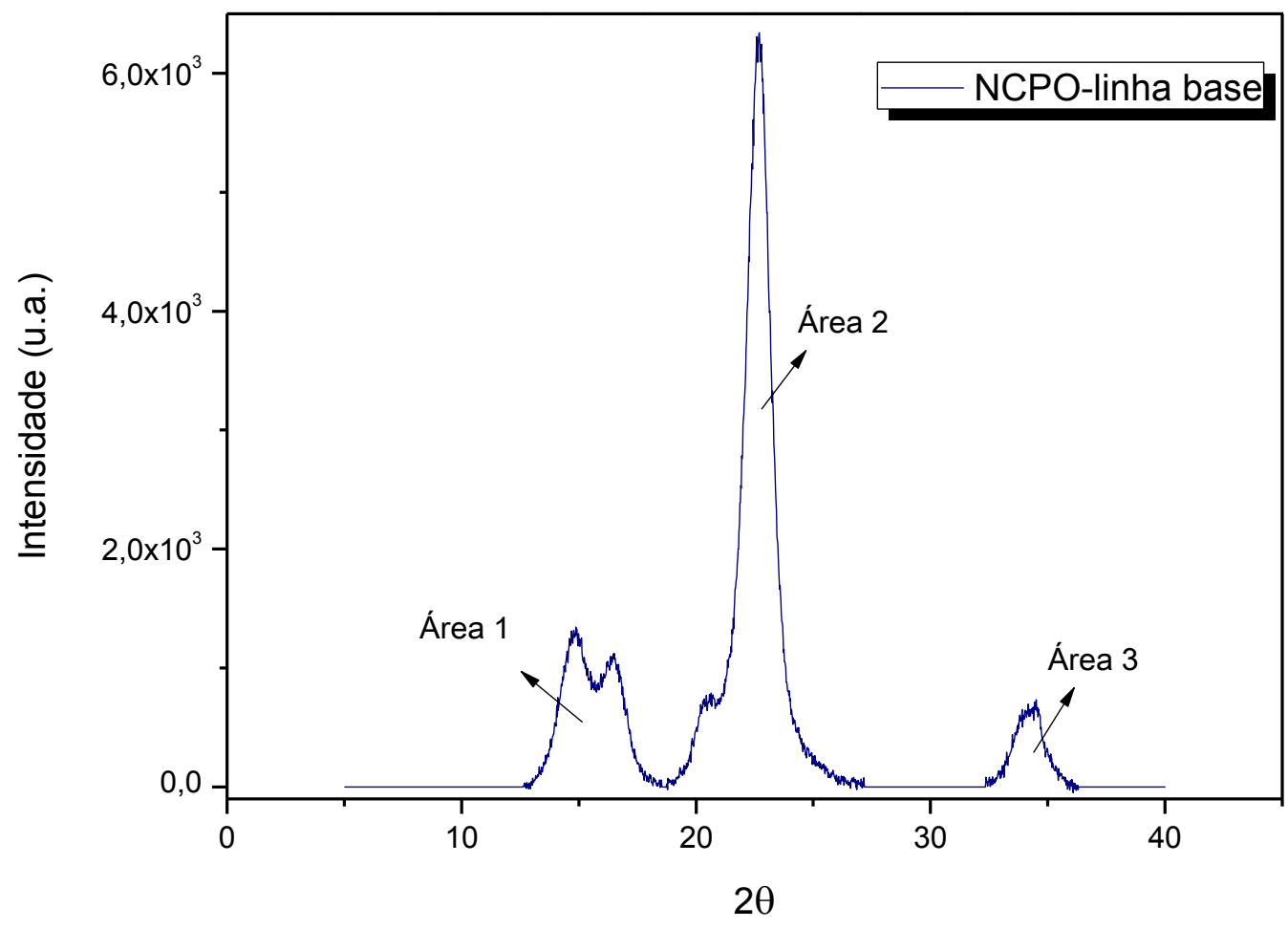

Tabela 18- Áreas dos picos da curva de DRX da amostra NCPO após correção de linha base.

\begin{tabular}{ccccc}
\hline Pico & Área & $\mathbf{2 \theta}_{\mathbf{i}}$ & $\mathbf{2}_{\mathbf{f}}$ & Centro do pico \\
\hline 1 & 3446,1 & 12,6 & 18,7 & 14,9 \\
2 & 10338,5 & 18,7 & 27,1 & 22,7 \\
3 & 1073,8 & 32,4 & 36,3 & 34,5 \\
\hline
\end{tabular}

